Portland State University

PDXScholar

\title{
Alternating current studies and kinetic analysis of valinomycin mediated charge-transport through lipid bilayer membranes
}

Kenneth Lee Cox

Portland State University

Follow this and additional works at: https://pdxscholar.library.pdx.edu/open_access_etds

Part of the Biological and Chemical Physics Commons

Let us know how access to this document benefits you.

\section{Recommended Citation}

Cox, Kenneth Lee, "Alternating current studies and kinetic analysis of valinomycin mediated chargetransport through lipid bilayer membranes" (1984). Dissertations and Theses. Paper 3380.

https://doi.org/10.15760/etd.5253

This Thesis is brought to you for free and open access. It has been accepted for inclusion in Dissertations and Theses by an authorized administrator of PDXScholar. Please contact us if we can make this document more accessible: pdxscholar@pdx.edu. 
AN ABSTRACT OF THE THESIS OF Kenneth Lee Cox for the Master of Science in Physics presented June 5, 1984.

Title: Alternating Current Studies and Kinetic Analysis of Valinomycin Nediated Charge-Transport through Lipid Bilayer Membranes.

APPROVED BY IEMBERS OF THE THESIS COMMITTEE:

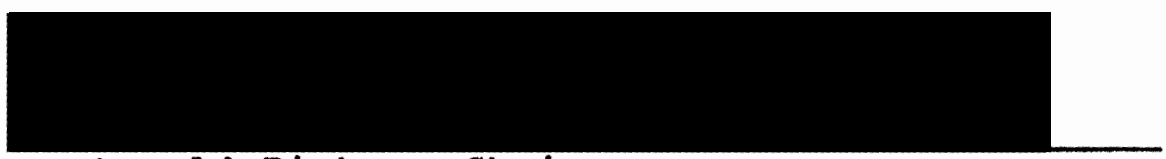

Arnold Pickar, Chairman

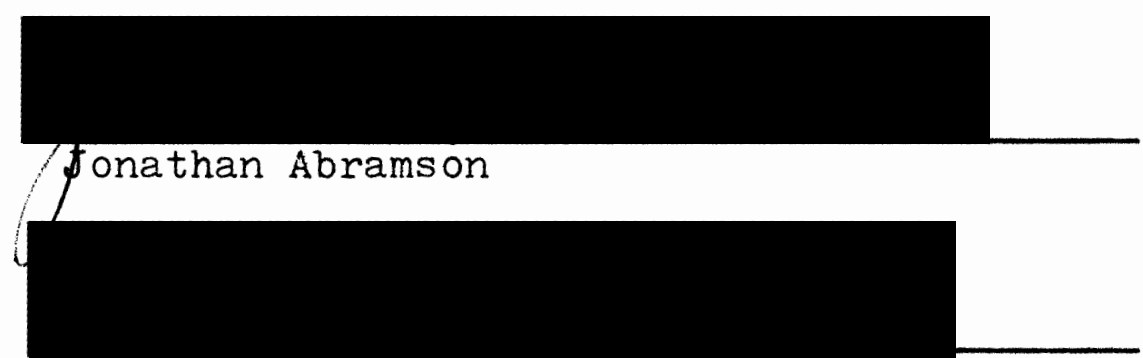

Pavel Smejtek"

In this study we have investigated the frequency dependence of bilayer lipid membranes for a series of glycerylmonoolein/n-decane bilayers in various aqueous ionic solutions containing the ionophore valinomycin. Reliable values of membrane capacitance and conductance were obtained over the frequency range $0.2-200 \mathrm{KHz}$ using an automatic balancing bridge under the control of a microprocessor unit. The admittance data was then normalized and curve-fitted to produce relaxation times and amplitudes from which the kinetic 
rate parameters, as deduced from a single slab dielectric membrane model, were calcuated. These ac experimental rate constants were then compared with those obtained from chargepulse relaxation methods.

It is shown that the values of the rate constants derived from alternating current measurements differ significantly $(t>.05)$ with those obtained from the charge-pulse experiments. However, the rate constants do exhibit similar trends with changes in the experimental conditions. The discrepancies are most serious for the lowest metal ion concentration $(0.01 \mathrm{M} \mathrm{RbCl})$ and particularly for the loaded carrier translocation rate constant.

In view of these discrepancies and the prototypical nature of this study various possible sources of experimental error are discussed as well as the additional refinement of the kinetic model to reflect a three slab dielectric membrane. Such considerations still do not fully reconcile the ac results with those from charge-pulse studies. Therefore, these differences may imply that the membrane kinetic model requires forther modification. Several such model changes and experimental modifications are briefly discussed. 
ALTERNAT ING CURRENT STUDIES AND KINETIC ANALYSIS OF VAL I NOMYCIN MED I ATED CHARGE -TRANSPORT THROUGH LIPID BILAYER MEMBRANES

by

KENNETH L. COX

A thesis submitted in partial fulfillment of the requirements for the degree of

MASTER OF SCIENCE

in

PHYSICS

Portland State University

1984 
TO THE OFFICE OF GRADUATE STUDIES AND RESEARCH:

The members of the Committee approve the thesis of Kenneth Lee Cox presented June 5, 1984.

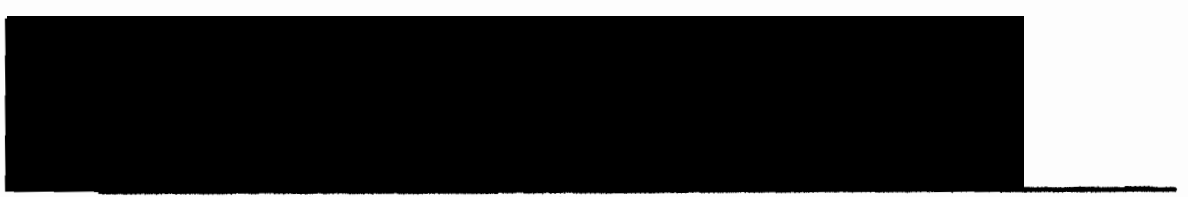

Arnold Pickar, Chairman

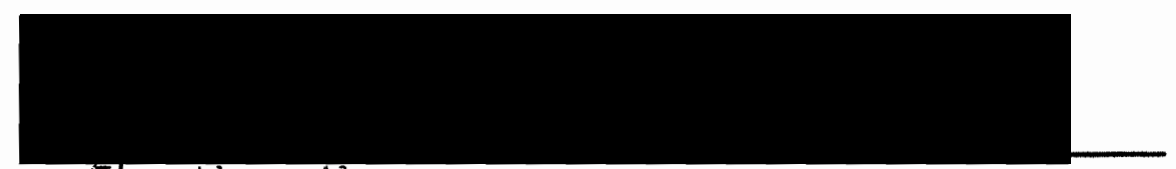

Jonathan Abrams on

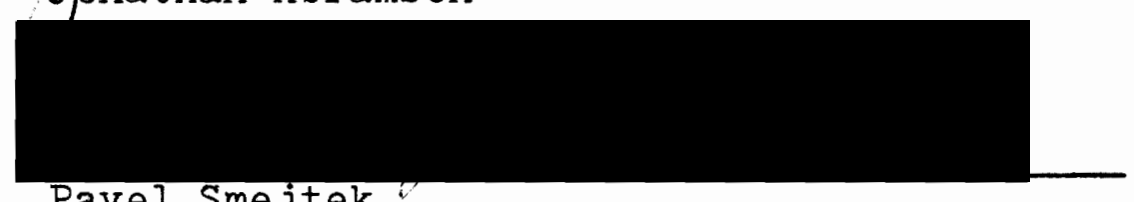

Pavel Smejtek

APPROVED :

Raymond. Sommerfeldt, Director, Physics

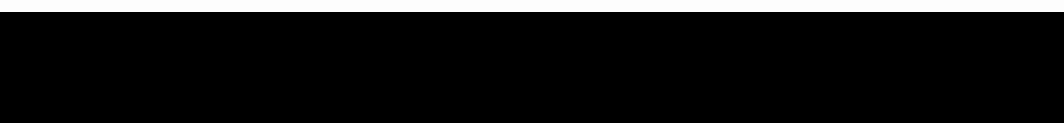

Stanley E. Rauch, Dean of Graduate Studies and Research 


\section{ACKNOWLEDGEMENTS}

I would like to extend my thanks to:

Dr. Arnold Pickar for guidance, advice, information and most of all, patience.

Dr. Donald Howard, Dr. Pavel Smejtek, and Julian Hobbs for the development of certain data reduction programs and lucid instruction in the operation of the computer.

Lee Thanum and $\mathrm{Br}$ ian McLaughlin

for construction, programing and maintenance of the microprocessor unit and the associated electronic equipment. 
APPROVAL PAGE

\section{NTRODUCT ION}

Membranes . . . . . . . . . . . . 1

Electrical Properties of Membranes....... 10

Membrane Modifiers . . . . . . . . . . 13

Valinomycin and Other Ion Carriers....... 13

Carrier-Ion Complexes . . . . . . . . . 16

Experimental Approaches . . . . . . . . . 17

THEORY

Carrier Model . . . . . . . . . . . 20

Ionic Charge Transport . . . . . . . . . 22

Steady-State and Voltage-Jump Theory . . . . . 28

Charge-Pulse Theory . . . . . . . . . . 33

A.C. Theory . . . . . . . . . . . . 36

EXPERIMENTAL METHODS AND MATERIALS

Introduction . . . . . . . . . . . . . 41

Materials . . . . . . . . . . . 4 42

Cell Preparation .............. . . . 44

Membrane Formation . . . . . . . . . . 45

Electrical Measurements . . . . . . . . 45 
$\underline{\text { Page }}$

Alternating Current System . . . . . . . . . 45

Microcomputer . . . . . . . . . . . . . 49

A.C. Operations . . . . . . . . . . . . . . 50

Bridge Settings . . . . . . . . . . . . 51

D.C. Circuit . . . . . . . . . . . . . . 53

D.C. Operations . . . . . . . . . . . . . 53

Data Reduction . . . . . . . . . . . . . 55

REDU 1 . . . . . . . . . . . . . . . . 56

Determination of Cell Resistance . . . . . 58

REDU 2, TOTAL, TOECAP . . . . . . . . . . 62

PDA 1. . . . . . . . . . . . . . . 67

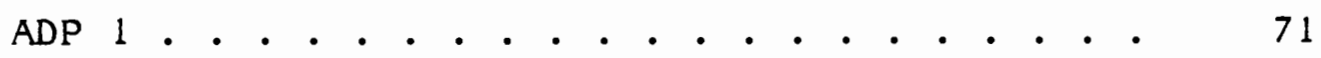

ADP 2 . . . . . . . . . . . . . . . . 71

RESULTS AND DISCUSSION

Control Membrane Data . . . . . . . . . . . 72

Type I Conductance Controls . . . . . . . . . 72

Type II Conductance Controls . . . . . . . . . . 73

Capacitance Controls. . . . . . . . . . . . . 73

Kinetic Parameters. . . . . . . . . . . . . . . 76

Loss Tangent Results and Discussion . . . . . . 83

Three Capacitor Model . . . . . . . . . . . 88

CONCLUSIONS • • • • • • • • • • • • • • • • • • • 96

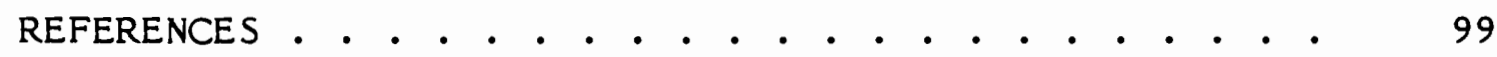

Appendix A - Computer Printouts . . . . . . . . . 103

Appendix B - Three Capacitor Model . . . . . . . 108 


\section{LIST OF TABLES}

Table:

Page

1

Hewlett-Packard Bridge Settings ......

2

Computer Program Summary . . . . . . . .

55

3

Typical Cell Resistance Calculation.... .

61

4 Comparison of Experimental and Regenerated Values of Conductance and Capacitance . . .

An Example of the Effect on Rate Constants

Due to Variations in or

Low Frequency Conductance in the Absence of Valinomycin . . . . . . . .

Conductance of $\mathrm{GMO} / \mathrm{n}$-decane BLM's in the Presence of 10 Valinomycin ........

8 Capacitance of $\mathrm{GMO} / \mathrm{n}$-decane BLM's with Various Aqueous Ionic Solutions... . . . 74

A.C. Relaxation Times and Amplitudes . . . 78

Kinetic Parameters Corresponding to Table 9

11 Variation of Solution Resistance with Ionic Concentration . . . . . . . . . . . .

12 Variation of Rate Parameters Due to Uncertainty in $\mathrm{R}_{\mathrm{S}} \cdot$. . . . . . . . . . . . . .

Percent Variation in Rate Parameters Due to Uncertainty in $\mathrm{R}_{\mathrm{S}}$............ 


\section{LIST OF FIGURES}

Figure

$\underline{\text { Page }}$

1 Structures of Phospholipid, Cholesterol, Sphingomye $\mathrm{l}$ in and GMO .......... . 3

2 Structure of a Bilayer Lipid Membrane....

3 Distribution of Lipids and Proteins in a

Human Red Blood Cell Membrane.......

4 Possible Locations of Peripheral and Integral Membrane Proteins . . . . . . . 7

5 Fluid-Mosaic Model of Membrane Structure. .

6 Diffusion of Membrane Proteins in a

Fused Hybrid Cell. . . . . . . . . . . 9

7 Structure of Valinomycin . . . . . . . . 15

8 Basic Experimental Set-up . . . . . . . . 19

9 Carrier Model . . . . . . . . . . . . 21

10 Eyring Mechanism Potential Barrier . . . . 23

11 Parameter Determination through Variations

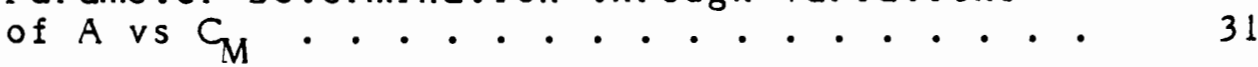

12 Membrane in Place Across Aperture in Teflon

13 A.C. Instrumentation . . . . . . . . . 47

14 Graphical Determination of Cel1 Resistance 59

15 Least-Squares Curve-Fitting of Capacitance and Conductance Data . . . . . . . . . .

16 Reconstructed Capacitance and Conductance

Curves . . . . . . . . . . . . . . . 
17 Loss Tangent vs Freq, based on Relaxation and A.C. Data, 1.0 M KCl .. . . . . . 84

18 Loss Tangent vs Freq, based on Relaxation, 3 Capacitor and A.C. Data, 1.0 M RbCl.... 85

19 Loss Tangent vs Freq, based on Relaxation, 3 Capacitor and A.C. Data, $0.1 \mathrm{M} \mathrm{RbCl}$. . . 86

20 Loss Tangent vs Freq, based on Relaxation, 3 Capacitor and A.C. Data, $0.01 \mathrm{M} \mathrm{RbCl}$. . 87

21 Loss Tangent Perturbations due to Variations in the Rate Constant, $k_{R}$.........

22 Loss Tangent Perturbations due to Variations in the Rate Constant, $k_{D}$......... . 90

23 Loss Tangent Perturbations due to Variations in the Rate Constant, kMS . . . . . . .

24 Loss Tangent Perturbations due to Variations in the Rate Constant, $\mathrm{k}_{\mathrm{S}}$......... . 


\section{INTRODUCTION}

\section{Membranes}

Biological membranes have become a major research focus for many biologists, chemists, physicists and psysiologists. Entire journals are devoted to this subject due to the vital importance of membranes in life processes. Membranes function as both a biochemical and a physical barrier, separating cells from the surrounding environment or partitioning the cell into smaller specialized sections (such as the endoplasmic reticulum, Golgi apparatus, lysosomes, etc.). Most cellular activities occur on or near membranes, including protein assembly, enzymatic reactions, photosynthesis, selective transfer of molecules, etc. General references $[1,13,28,29,35,40]$ may be helpful supplements to the following brief discussion of membrane structure and associated electrical properties.

Most membranes consist of approximately equal ratios of proteins and lipids. The ratio varies with each membrane and its associated function, although the mass of protein component usually meets or exceeds the quantity of lipid. A notable exception is the specialized myel in sheath produced by Schwann or oligodendroglia cells of the mamalian nervous system. These membranes contain significantly less protein than lipid, which allows the myelin to function better as an insulator for the enclosed neuron, thereby facilitating the transport of electrical impulses [21]. 
Membrane lipids are predominantly polar, consisting mainly of phospholipids (e.g. phosphatidylcholine, phosphatidylethanolamine), cholesterol and smaller amounts of sphingomyelin. See Figure 1 for representative structures. The ratio of the different polar lipids varies with the type of membrane system, the organ and the species. For example, cholesterol is a common constituent of the external (plasma) membranes of cells, but the endoplasmic reticulum and organelle membranes contain much less. Cholesterol is completely lacking in plant and bacterial membranes [41].

Certain membrane proteins and lipids are further modified by the attachment of oligosaccharide chains. These chains contain predominantly mannose, galactose, N-acetylglucosamine, N-acetyl-

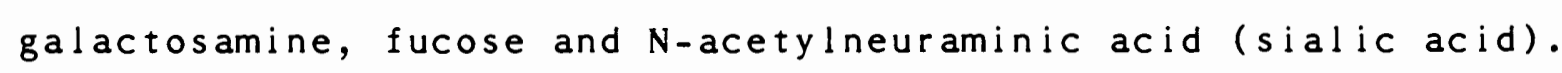
The latter two sugars are found only in the terminal position of a chain. The sugar units are added individually, by specific enzymes, within the rough endoplasmic reticulum and/or the Golgi complex. These oligosaccharide side chains may play an important role in directing newly formed glycoproteins to be included in specific membranes. For instance, in inclusion cell disease, there is a failure of the system which phosphorylates the newlyforming lysosomal enzymes. These enzymes are then secreted outside of the cell rather than being sequestered within the cell lysosomes, which leads to an impairment of intracellular digestion [31]. 


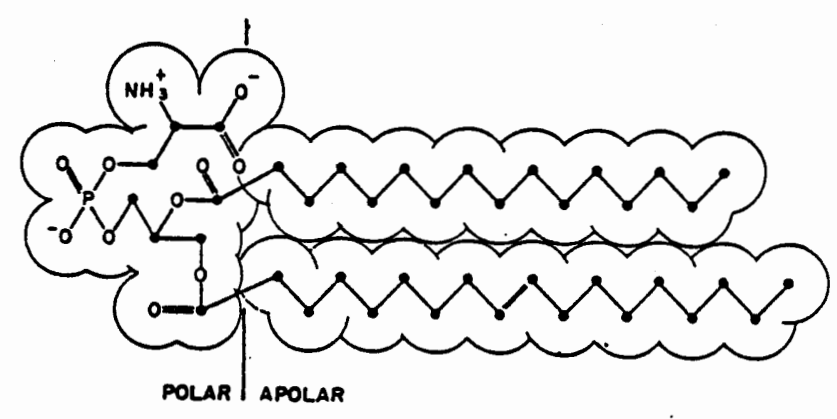

A. Phosphatidy I Serine
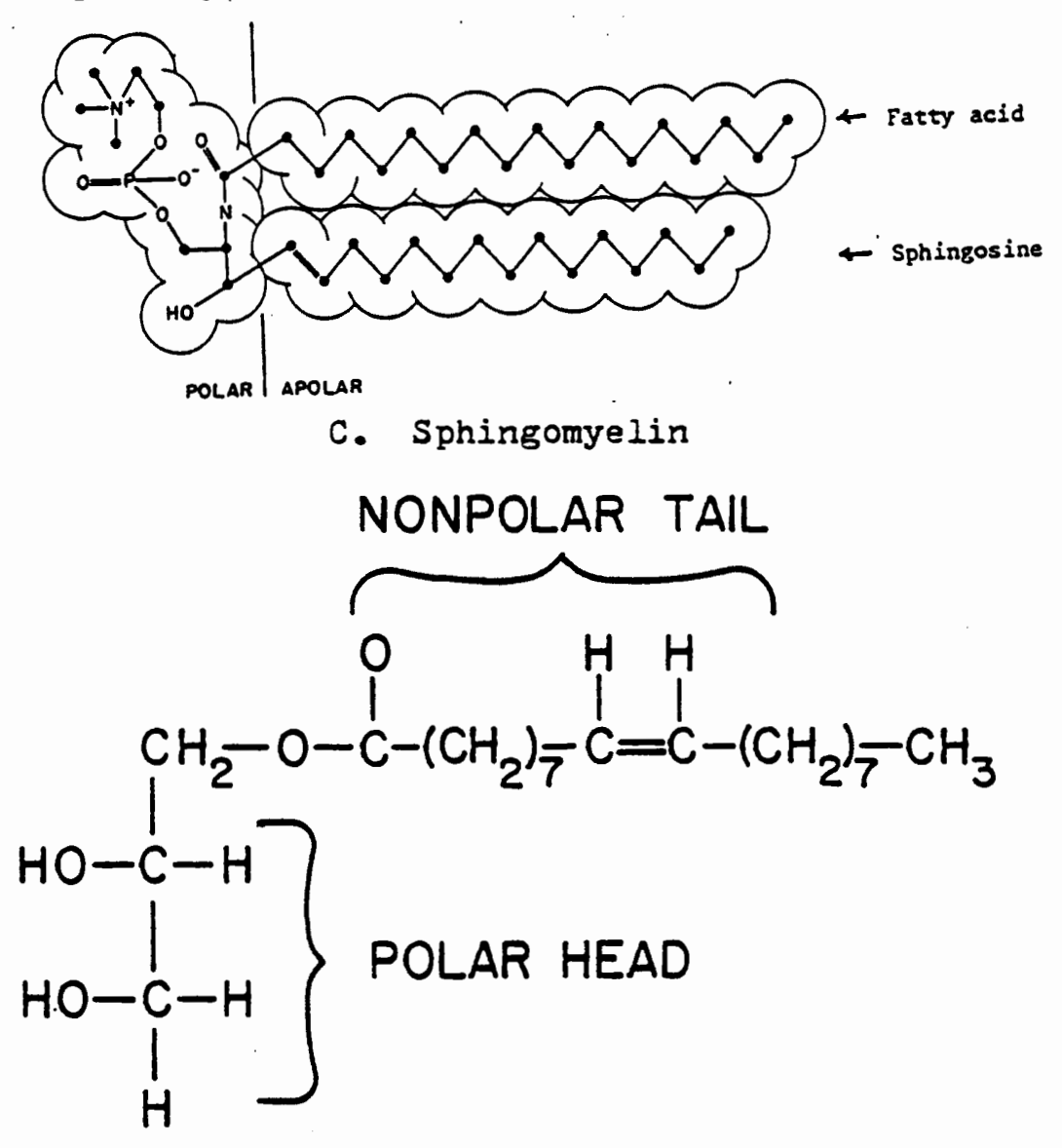

D. Glycerylmonooleate (GMO)

Fig. 1 Representative Chemical Structures 
Various methods have been used to determine the physical configuration of the lipid and protein molecules in the membrane structure. Electron microscopy has revealed that membranes have a trilaminar structure (see Figure 2). Spin labeling techniques have also been employed where an appropriate label, e.g a nitroxyl group, has been incorporated into the membrane lipids [30]. The label contains an unpaired electron whose spin has a specific direction in relation to the long axis of the fatty acid. The motion and directional orientation of the spin-labeled fatty acid or lipid can then be determined by electron paramagneticresonance spectroscopy which is sensitive to the magnetism of the unpaired electron's spin. These spin label experiments have confirmed that the membrane lipid molecules are arranged in a bi layer configuration, where the non-polar (hydrophobic) tails are adjacent to one another and directed toward the center of the membrane while the polar heads form the exterior surfaces in contact with an aqueous environment (see Figure 2). This configuration is often referred to as a lipid bilayer or bilayer lipid membrane (BLM).

With a bilayer configuration there is the possibility that the membrane components may be distributed asymetrically between the two layers. This was found to be true; for instance, in the human red blood cell plasma membrane glycolipids and glycoproteins are found only on the outer surface, phosphatidylcholine and sphingomyelin predominate in the outer monolayer while 


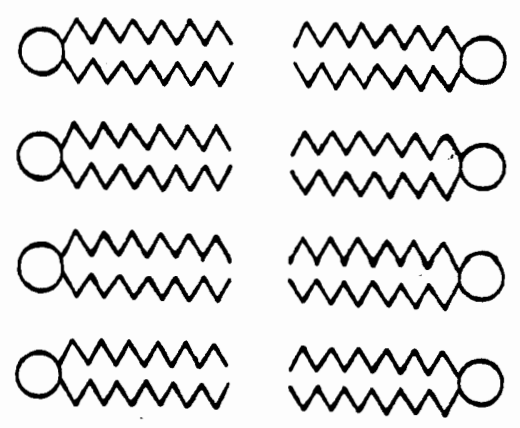

Fig. 2 Structure of a Bimolecular Lipid Membrane

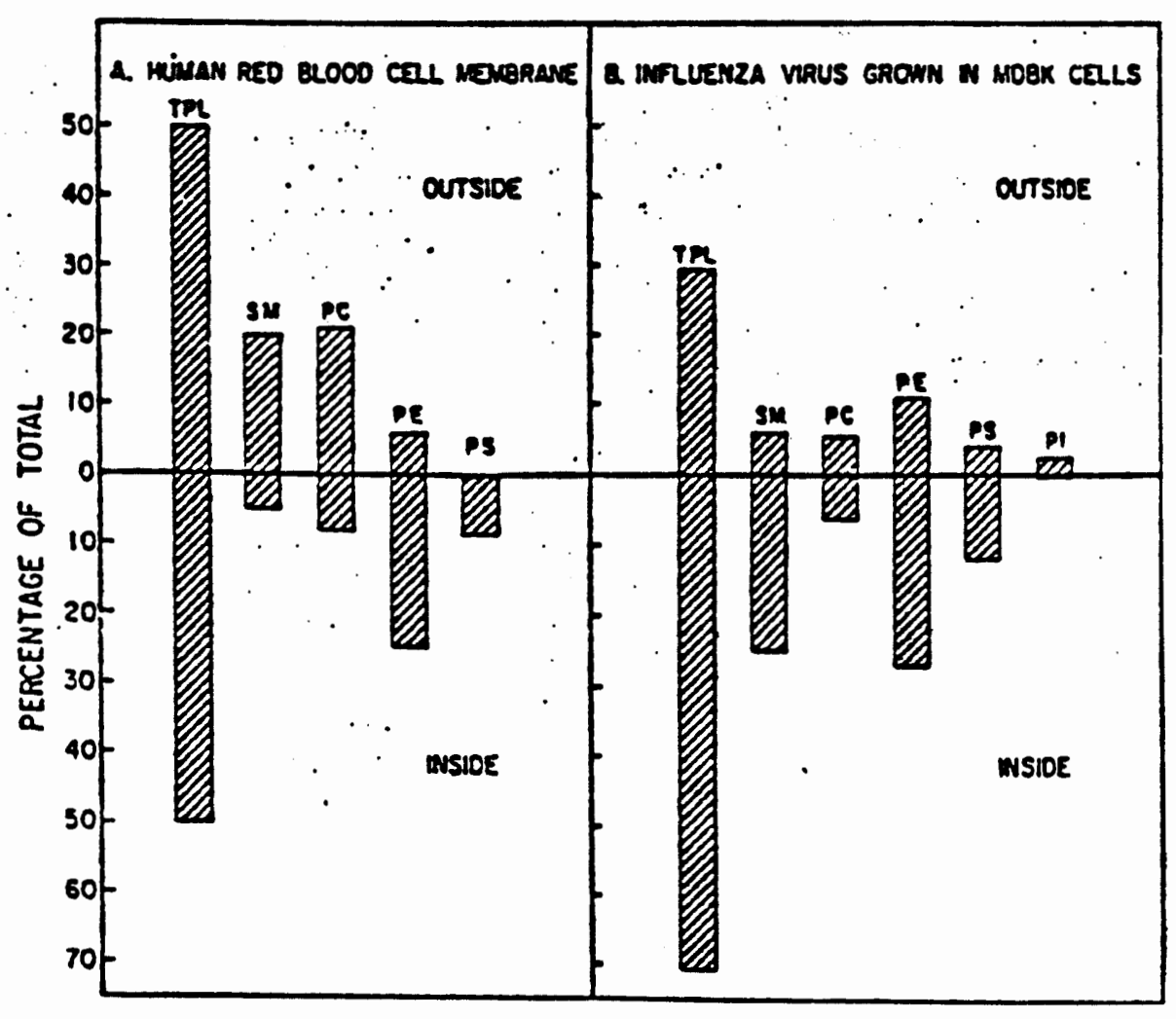

Fig. 3 Asymmetrical Distribution of Fhospholipids in Membranes of human red blood cells (35) and influenza virus grown in MDBK cells, expressed as mole percent. Abbreviations: TPL, total phospholipid; PC, phosphatidylcholine; SM, sphingomyelin; $\bar{F}$, phospatidylethanolamine; PS, phosphatidylserine; and PI, phosphatidylinositol. (Adaoted from OHSU, Con 410 syllabus, 1980-81) 
phosphatidylethanolamine and phosphatidylserine predominate in the inner monolayer (see Figure 3 ). Cholesterol is symetrically distributed between the inner and outer monolayers and is believed to moderate membrane rigidity in the face of environmental stresses, especially in those regions where Van der Waals forces are the predominant forces maintaining the membrane structural integrity. Membrane proteins are asymetrically distributed and consist of two general types: integral proteins which are tightly bound to the nonpolar portion of the membrane, and peripheral proteins which bind only to the external hydrophilic regions (see Figure 4). The integral proteins constitute approximately seventy percent or more of the total membrane protein and can be removed only by drastically disrupting the membrane with detergents. Some integral proteins extend completely across the membrane and may contain pores allowing the transport of appropriately sized particles. Peripheral proteins are only loosely attached to the membrane surface and can be easily removed by mild extraction processes, such as high salt concentrations. Cellular membranes generally contain many more proteins on the inside (cytoplasmic side) than on the outside (external side); the evidence for this will be discussed below.

The fluid-mosaic model, first proposed in 1972 [43], is the most satisfactory model of membrane structure to date. This model postulates that the phospholipids are arranged in a bilayer, as previously discussed, with protein inclusions (see 


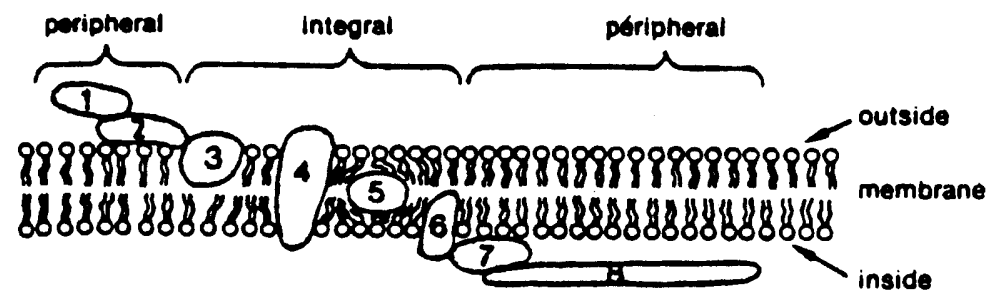

Fig. 4 Possible locations of peripheral and integral membrane proteins.

(Adapted from OHSU, Con 410 Syllabus, 1980-81)

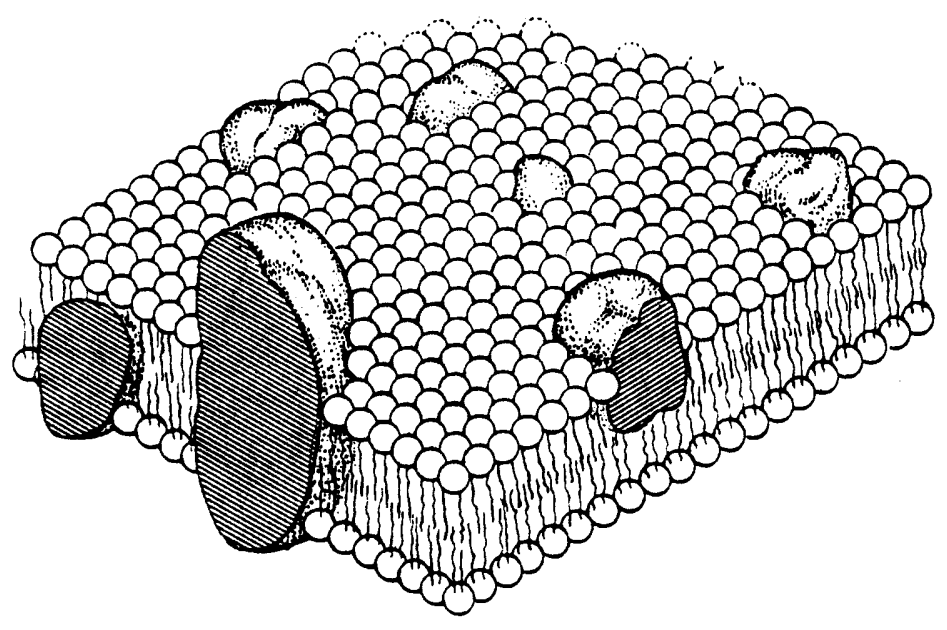

Fig. 5 Fluid-Mosaic Model of Vembrane Structure (Adapted from S.J. Singer. Science, 175:720) 
Figure 5). The hydrophobic tails form a fluid core, allowing the individual lipid molecules to move laterally. The continuous hydrocarbon phase also endows the membrane with a high electrical resistance and renders it relatively impermeable to polar molecules. The membrane proteins are also free to diffuse laterally. This fluidity is important since it allows transient associations between various membrane proteins and permits the transfer of electrons between proteins, as in the oxidative-phosphorylation process mediated by cytochrome oxidase which is associated with the inner mitochondrial membrane.

Evidence which supports this fluid-mosaic model includes hybrid cell fusion and freeze-fracture microscopy, which will be discussed in greater detail. The hybrid cell fusion consists of a mouse and human cell which are fused together under the influence of the sendai virus. By labeling specific human and mouse proteins it is found that the proteins become completely intermixed with time (see Figure 6). Furthermore, this intermixing is not observed if the fusion is performed at temperatures below $15^{\circ} \mathrm{C}$ which is the freezing temperature of the plasma membrane phospholipids [20], which supports the fluid core hypothesis of the model.

In freeze-fracture electron microscopy cells are frozen so that the aqueous regions become stiff. If these frozen specimens are then fractured the cleavage line will pass through the area of least resistance, usually near the center of the bilayer. 


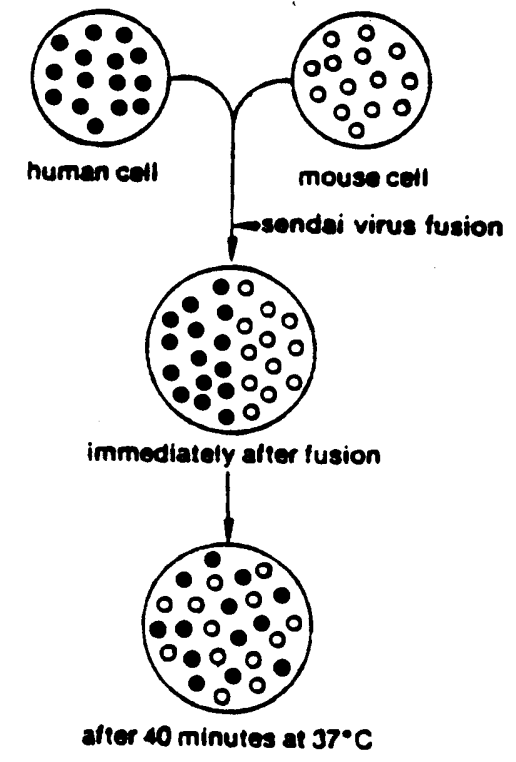

Fig. 6 A diagram showing the fusion of a mouse cell and a human cell followed by diffusion of membrane proteins in the plane of the plasma membrane. The human and mouse proteins are completely intermingled after forty minutes. (Adapted from $L$. Frye and $M$. Edidin, J. Cell Sci, 7, 319, 1970) 
Each protein will remain with the lipid layer to which it was most firmly bound. Such freeze-fractured membranes, when observed with a scanning electron microscope, would seem to support the fluid-mosaic model and have shown that the cytoplasmic face of the membrane has a much larger concentration of internal proteins than does the external face.

Since natural membranes are fragile and difficult to obtain for in-vitro studies, research has been confined to various forms of artificial membranes, which allows the exclusion of numerous complicating variables associated with biological membranes. Thus, individual chemical effects and mechanisms can be directly investigated. Artificial membranes may be formed from both natural and/or artificial materials, including various monoglycerides or lecithins. Glycerylmonooleate (GMO) was the only lipid employed in this study, solely for ease of comparison with various literature values obtained from experiments which also ut il ized GMO membranes.

\section{Electrical Properties of Membranes}

Among the electrical properties of biological membranes which have been investigated over the years are: capacitance, conductance, resting potential, breakdown voltage, and refractive index. Researchers [35] have shown that artificial bilayer lipid membranes are suitable models of natural membranes since they reasonably mimic these electrical properties of natural membranes. 
Two of the most straightforward properties of a BLM to measure are conductance and capacitance. An unmodified bilayer 1 ipid membrane has a very small conductance, a property which can be understood by considering the self energies of the free ions in the surrounding aqueous solution. The stored energy of a distribution of charge at potential $V$ is:

$$
\mathbf{W}=\frac{1}{2} \mathrm{QV}
$$

where $Q$ is the total charge. If an ion is considered as a sphere with total charge $Q$, then the potential is:

$$
V=\frac{1}{4 \pi \epsilon_{0} \epsilon} \frac{Q}{r}
$$

where $\epsilon_{0}$ is the permittivity of free space, $\epsilon$ represents the relative permittivity of the medium (substance which contains $Q$ ), and $r$ is equivalent to the ionic radius. Substituting Eq-2 for $V$ in Eq-1 yields:

$$
W=\frac{1}{8 \pi \epsilon_{0} r} \frac{Q^{2}}{\epsilon}
$$

The extra energy necessary for the ion to transfer from a high dielectric medium (water, $\epsilon_{W} \approx 80$ ) to the lower dielectric membrane $\left(\epsilon_{M}\right)$ is :

$$
W=\frac{Q^{2}}{8 \pi \epsilon_{0} r}\left[\frac{1}{\epsilon_{M}}-\frac{1}{\epsilon_{W}}\right]
$$

It is apparent that the additional energy needed is inversely proportional to the radius and $\Delta \epsilon$ so that the smaller ions common 
to aqueous salt solutions (such as $\mathrm{H}^{+}, \mathrm{OH}^{-}, \mathrm{K}^{+}, \mathrm{Cl}^{-}$) will be unlikely to penetrate a membrane which can be thought of as having an $\varepsilon$ in hydrocarbon of approximately 2 . Using $\varepsilon_{M}=2.1$ [6], $\varepsilon_{\mathrm{W}}=80.1, \mathrm{r}=1.33 \AA[51], \mathrm{Q}=$ electronic charge in Eq-4 yields a $\Delta W$ of $2.5 \mathrm{ev}$ for the potassium ion. This is one hundred times larger than the available room temperature thermal energy of $k T=0.025 \mathrm{ev}$. The conductance is not actually zero due to the statistical variation of self energies in a population of ions (so that some ions will possess sufficient energy to allow thermal penetration of the membrane) and the fact that the free energy (amount of energy available to perform work) is also affected by membrane structural fluctuations and surface electrical potential. This electrical potential may result from either the presence of a net surface charge (i.e., the charged lipid head groups, such as phosphate or choline, or adsorbed charged molecules) or from a net dipole moment resulting from the orientation of polar groups (e.g. the ester linkages of cholesterol) or amphoteric groups (as in phosphatidyl choline) at the membrane surface. This surface potential contributes to the free energy of the ionic species depending on the sign and magnitude of the potential, e.g. a positive surface potential would be expected to reduce the penetrability of positive ions while enhancing the penetration of negative ionic species, etc. However, most biological membranes are negatively charged at physiological pH's and yet permit anion exchange, thereby implying that other transport mechanisms are involved. Those effects due to a surface charge layer may be differentiated from those due to 
a layer of oriented dipoles since only the former would be expected to change in magnitude with variations of the aqueous salt concentration.

\section{Membrane Modifiers}

A variety of substances exist which, when added to the membrane or aqueous environment, will cause order of magnitude changes in the membrane conductance. Certain of these substances (e.g. nonactin, valinomycin) function as ionic carriers and directly affect the membrane conductance (see below for details) while others function indirectly as modifiers which may cause changes in membrane thickness, diffusion constants (see the Carrier Model in Theory section), surface dipole moments, etc., but do not form ion complexes. In this experiment valinomycin was employed so that convenient comparisons might be made with various literature values.

\section{Valinomycin and Other I on Carriers}

While searching for specific ion carriers to explain the ability of some membranes to selectively transport a particular substance against its concentration gradient (so called active transport or "pump" action), it was discovered that valinomycin and certain other antibiotics enhanced cation transport across mitochondrial membranes [39]. These antibiotics were termed ionophores because of their selective enhancement of cations in general, e.g. $\mathrm{K}^{+}, \mathrm{Rb}^{+}, \mathrm{Cs}^{+}$. The mitochondrial membrane normally doesn't transport $K^{+}$but will in the presence of an ionophore. 
This destroys any existing $\mathrm{K}^{+}$gradient and leads to a new ionic equilibrium distribution. The membrane potential due to this ionic distribution may be obtained from the Nernst Equation [26]:

$$
E_{K}=\frac{R T}{F} \ln \frac{\left[K^{+}\right]}{\left[K^{+}\right]} \text {outside } \quad \text { Eq }-5
$$

where $R$ is the universal gas constant, $T$ the temperature $\left({ }^{\circ} \mathrm{K}\right)$ and $F$ is the Faraday constant. Mitchell and others, using methods based on this, have reported values for the mitochondrial membrane of -150 to $-200 \mathrm{mV}$, "inside" (cytoplasm) negative [33]. Valinomycin has also been examined as a potential antibiotic. Although bactericidal, it exhibits little selectivity and is consequently not useful in medical therapy. However, it has continued to be an important research tool for investigating ion transport functions in artificial membranes $[9,28,45,46,47$, $48,50]$.

The ability of valinomycin to transport cations can be explained by its hydrophobic exterior and hydrophilic interior (see Figure 7). This allows the carriers to insert themselves into a membrane while providing carbonyl groups to coordinate with the inorganic cation, thereby providing a clathrate haven permitting safe transport through the membrane [18]. 


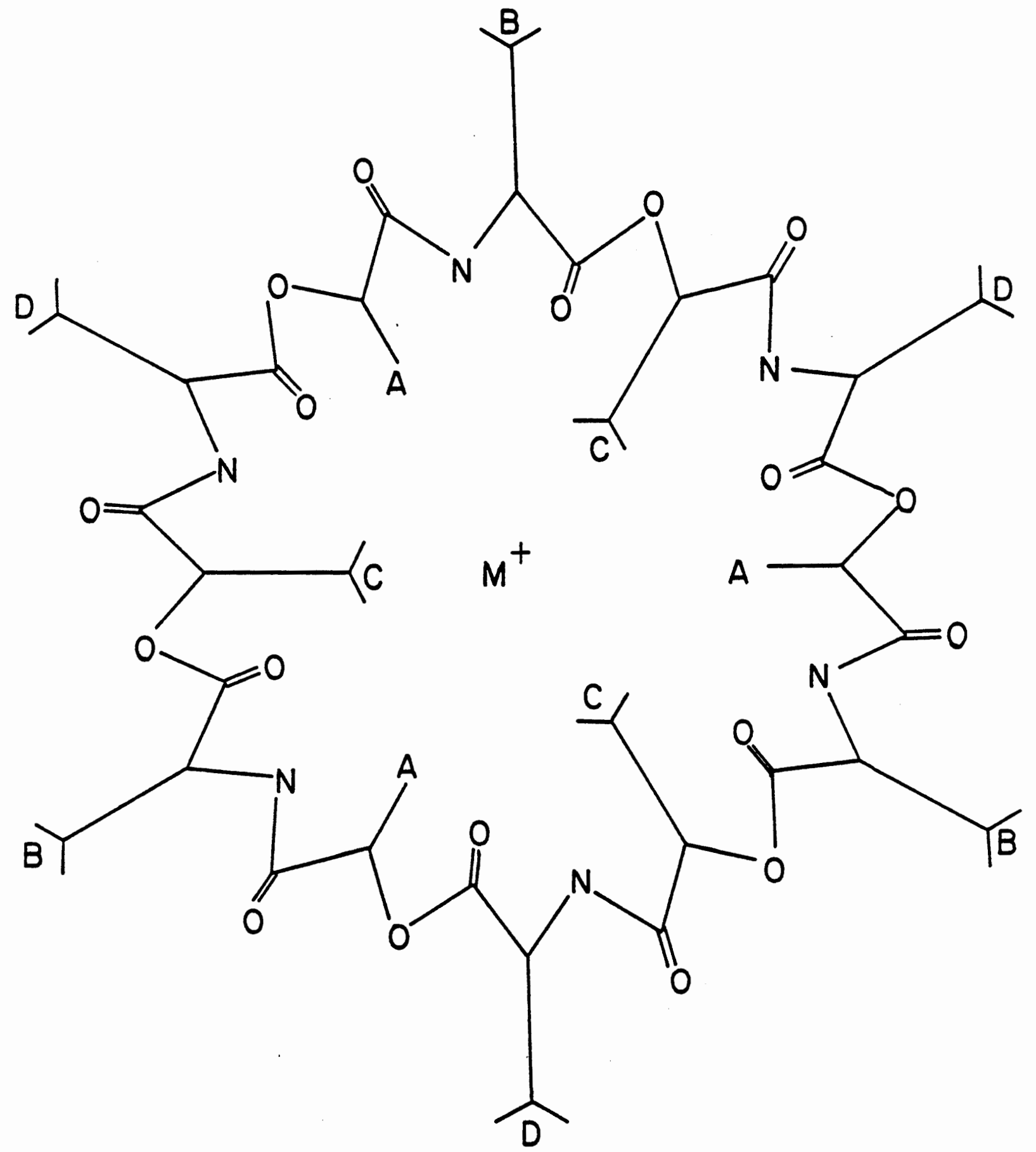

Fig. 7 Structure of Valinomycin

$$
\begin{aligned}
& M=\text { Metal lon } \\
& A=L-\text { lactate } \\
& B=L-\text { valine } \\
& C=D-\text { hydroxyisovalerate } \\
& D=D-\text { valine }
\end{aligned}
$$


Carrier-Ion Complexes

Although valinomycin is primarily known as a carrier of potassium, it will also transport other cations of the same chemical family (but not lithium, presumably because lithium's larger sphere of hydration prevents adequate complexing with the carrier). In order to make comparisons among the various experimental methods, this study has been restricted to the widely employed ions $\mathrm{K}^{+}$and $\mathrm{Rb}^{+}$. There are several factors which indicate that rubidium may be the ion of choice.

First, consider the general reaction of a metal cation $\left(\mathrm{M}^{+}\right)$ with a carrier

$$
\text { Valinomycin }+\mathrm{M}^{+} \leftrightharpoons \text { Valinomycin }-\mathrm{M}^{+} \text {complex }
$$

where the equilibrium constant, in water, is defined by:

$$
K=\frac{c_{M S}}{c_{S} C_{M}}
$$

$G_{M S}, C_{S}, C_{M}$ signify the equilibrium concentrations, in bulk aqueous solution, of the carrier-ion complex, carrier and cation respectively. Rubidium has a smaller $K$ than does potassium $(0.1$ vs. $\left.1.0 \mathrm{M}^{-1}[9]\right)$. This implies that there is little complexing between valinomycin and rubidium in water (i.e. GMS is smal1). Therefore, the total concentration of valinomycin in the aqueous solution $\left(C_{0} \equiv C_{S}+C_{M S}\right)$ may be approximated by $C_{S}$ if rubidium is the cation. This approximation holds for ionic concentrations 
less than or equal to $1.0 \mathrm{M}\left(\mathrm{T} \approx 25^{\circ} \mathrm{C}\right)$; at higher concentrations the aqueous complexing is no longer negligible $[9,42]$. Our own study examined concentrations ranging between $10^{-3}$ and $1.0 \mathrm{M}$ so that this approximation could be used in the calculation of the number of carrier molecules which might be expected to enter a membrane in contact with aqueous solutions containing the ions. The calculated value can be given in terms of the partition coefficient, $\gamma_{S}$, which is the ratio of the carrier concentration averaged over the volume of the membrane to the carrier concentration in the aqueous solution. The partition coefficient, $\gamma_{S}$, is a dimensionless parameter which may be written [27]:

$$
\gamma_{\mathrm{S}}=\frac{2 \mathrm{~N}_{\mathrm{S}}}{\mathrm{dC}_{\mathrm{S}}}
$$

where $\mathrm{N}_{S}$ is the number of carrier molecules per membrane unit area, $d$ is the membrane thickness, and $C_{S}$ is the concentration of the carrier in the aqueous phase. Researchers have found a variety of ways to employ the ion carriers and the above relationship to investigate membrane charge transport.

\section{Experimental Approaches}

Various methods have been employed to investigate the electrical properties of bilayer membranes and the variations which occur with the addition of modifying substances, such as valinomycin. Of particular value in uncovering information on the kinetics of complex formation and transport are the relaxation 
methods. These include voltage-jump techniques, where a membrane is subjected to a sudden displacement of the voltage and the resulting membrane current is followed over time [8,9,47]; and the charge-pulse technique, where a short current pulse is used to charge the membrane capacitance to an initial voltage and the subsequent decay of voltage is monitored after the termination of the pulse [7]. Other studies have utilized temperature jump experiments [24] and current noise analysis [25] to investigate membrane electrical properties without the application of membrane biasing external voltages. Another approach to obtain kinetic information, suggested long ago but little used to date, involves the application of an external voltage which varies periodically with time (alternating current studies) and observing the resultant variations of membrane current.

Alternating current studies have the additional advantage of remaining sensitive to membrane capacitive changes as well as variations in membrane conductance. Such dynamic measurements were explored in this experiment. In particular a GM bilayer membrane separating two identical aqueous salt solutions (see Figure 8 ) of $\mathrm{K}^{+}$or $\mathrm{Rb}^{+}$with valinomycin was exposed to an alternating voltage. In the following section the theoretical bas is for Steady-State, Voltage-Jump, Charge-Pulse and Alternating Current experimental approaches will be detailed. 


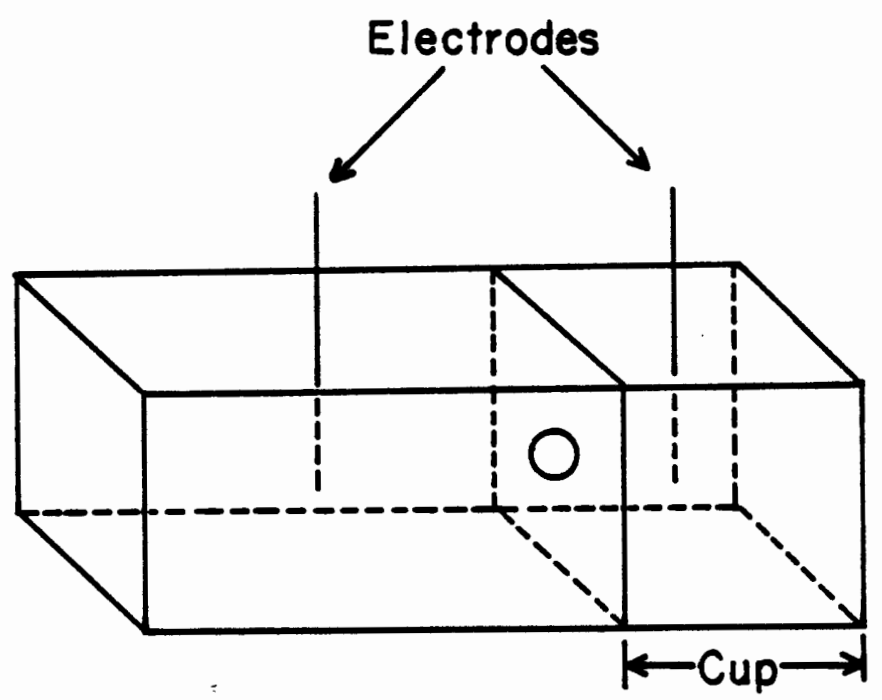

Fig. 8 Teflon Cup and Container Basic Experimental Set-up 


\section{THEORY}

\section{Carrier Model}

A simplified model for ion transport of alkali metal ions in aqueous solution by a carrier, such as valinomycin, may be summarized by three basic steps (Figure 9): formation of the carrier-ion complex within the membrane surface; transportation of the complex to the opposite surface, under the application of a voltage; and release of the ion into the solution. A detailed analysis must take into account a number of physical processes [45]:

(1) adsorption or release of the neutral carrier at the membrane surface (rate constants $k_{S}^{a q-m}$ and $k_{S}^{m-a q}$, where aq-m denotes from aqueous to membrane, etc.);

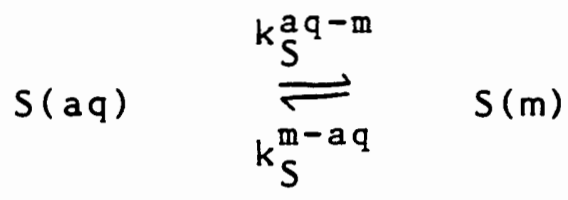
$\mathrm{Eq}-8$

where: $S \equiv$ carrier, aq $\equiv$ aqueous solution and $m \equiv$ membrane;

(2) the formation or dissociation of the carrier-ion complex (rate constants $k_{R}$ and $k_{D}$ respectively);

$$
\mathrm{M}^{+}(\mathrm{aq})+\mathrm{S}(\mathrm{m}) \stackrel{\mathrm{k}_{\mathrm{R}}}{\rightleftharpoons} \mathrm{MS}^{+}(\mathrm{m})
$$

where: $M^{+} \equiv$ metal ion, with aqueous concentration $C_{M}$ and $\mathrm{S} \equiv$ carrier, with aqueous concentration $\mathrm{C}_{\mathrm{S}}$; 

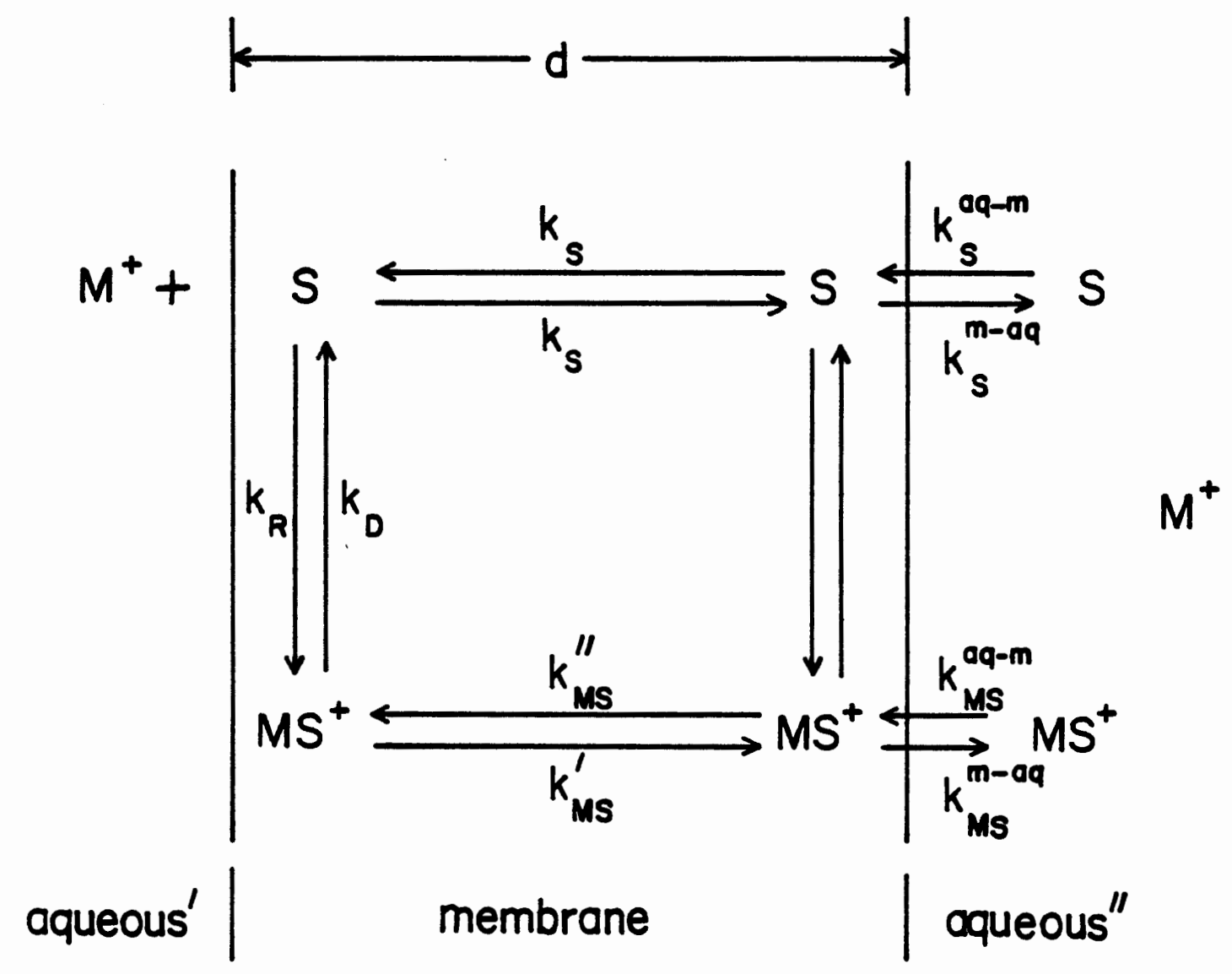

Fig. 9 Carrier Mediated Ion Transport 
(3) the adsorption or release of complexes, formed in the aqueous solution, at the membrane surface (rate constants $\mathrm{k}_{\mathrm{MS}}^{\mathrm{aq}-\mathrm{m}}$ and $\mathrm{k}_{\mathrm{MS}}^{\mathrm{m}-\mathrm{aq}}$ );

$$
\mathrm{MS}+(\mathrm{aq}) \quad \underset{\mathrm{k}_{\mathrm{MS}}^{\mathrm{m}-\mathrm{aq}}}{\stackrel{\mathrm{k}_{\mathrm{MS}}^{\mathrm{aq}-\mathrm{m}}}{\rightleftharpoons}} \mathrm{MS}+(\mathrm{m})
$$$$
\text { Eq }-10
$$

(4) the electrodiffusion of the complex through the membrane interior ( $r a t e$ constant $k_{M S}^{\prime}$ for movement in the direc$t$ ion of the applied field $(\vec{E})$ and $k_{M S}^{\prime \prime}$ for transport in the opposite direction);

(5) and the diffusion and back diffusion of the neutral carrier through the membrane due to concentration gradients (rate constant, $k_{S}$ ).

\section{Ionic Charge Transport}

The charge transfer across the membrane interior may be described by an "Eyring" mechanism [27] where one regards the two interfaces (an interface refers to the poorly demarcated regions where water and lipid intermingle on each side of the membrane) as being separated by a symetrical energy barrier (see Figure 10). If an MS+ complex possesses sufficient energy it can "jump" across this barrier and transport the charge in this fashion. Presumably the uncomplexed carrier is also able to traverse its own particular energy barrier.

Although the uncomplexed ion is predominantly excluded from the membrane, $S$ and $M S+$ may be exchanged between the aqueous and membrane phases (equations 8 and 10 ). Besides this, a chemical 
d
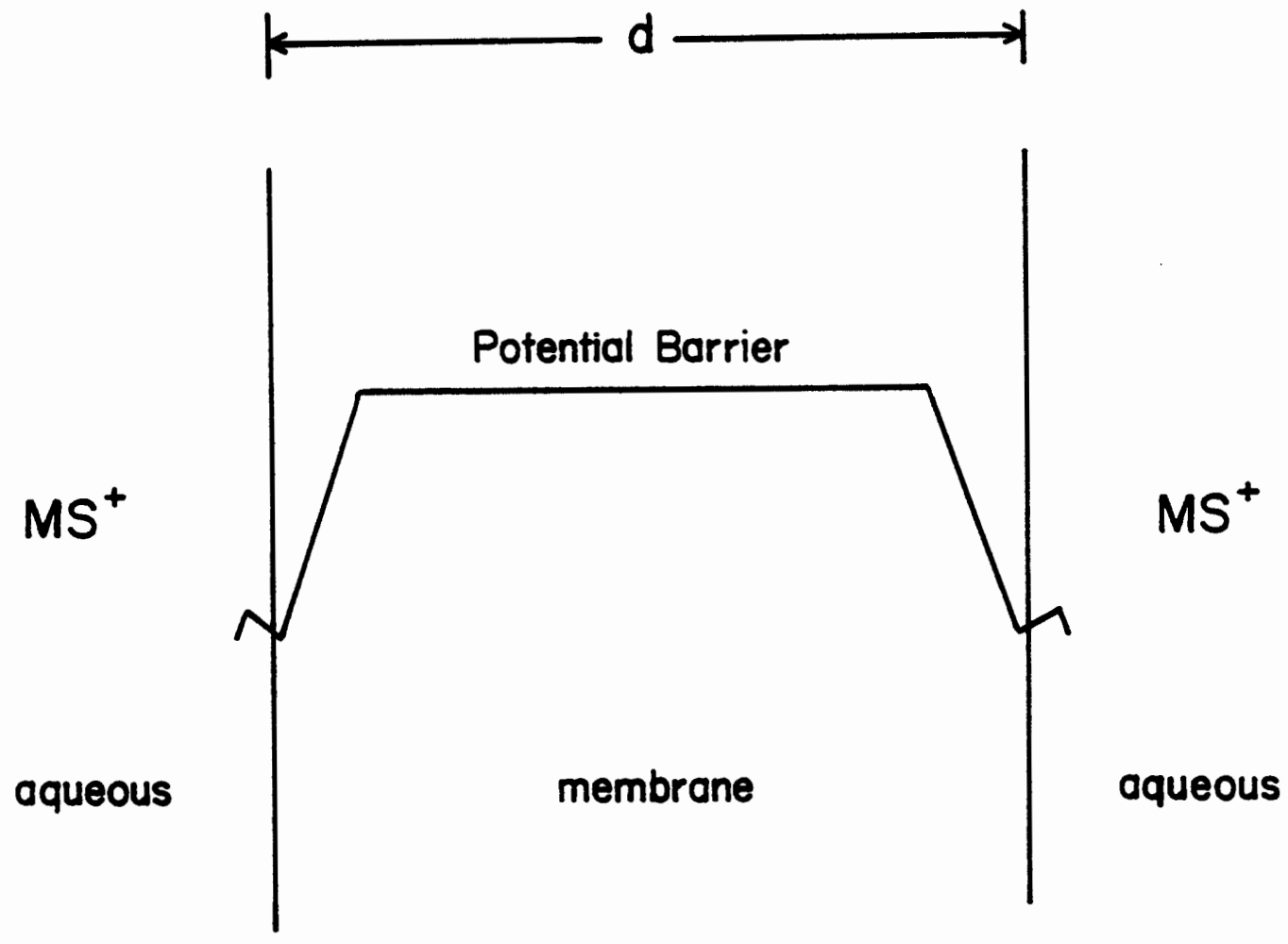

Fig. 10 Erying Mechanism Potential Barrier 
reaction can take place at the interface between a carrier $S$ in the membrane and an ion $\mathrm{M}^{+}$from the aqueous solution (equation 9 ). The rate constants for these reactions may be related to the partition coefficients of the carrier and complex, as outlined by Läuger and Stark [27]. If we denote the concentrations of $S$ and $\mathrm{MS}^{+}$, in the left-hand and $r$ ight-hand interfacial regions, by $N_{S}^{\prime}, N_{S}^{\prime \prime}, N_{M S}^{\prime}$ and $N_{M S}^{\prime \prime}$, respectively, then the fluxes $(\Phi)$ of $S$ and MS+ across the membrane are given by:

$$
\begin{aligned}
\Phi_{S} & =k_{S}\left(N_{S}^{\prime}-N_{S}^{\prime \prime}\right) \\
\Phi_{M S} & =k_{M S}^{\prime} N_{M S}^{\prime}-k_{M S}^{\prime \prime} N_{M S}^{\prime \prime}
\end{aligned}
$$

The current density ( $J$ ) may be related to $\Phi_{M S}$, as the complex is the only charge carrier within the membrane, by ( $F=$ Faraday constant):

$$
\mathrm{J}=\mathrm{F} \Phi_{\mathrm{MS}}
$$

In the presence of an externally applied voltage the rate constant $k_{S}$, for the translocation of the neutral carrier $S$, should be the same regardless of the ionic flow's direction. However, the rate constants $k_{M S}^{\prime}$ and $k_{M S}^{\prime \prime}$, associated with translocation of the charged complex, will vary with the external voltage $V$. For $V=0$ :

$$
k_{M S}^{\prime}=k_{M S}^{\prime \prime}=A e^{-E / R T} \equiv k_{M S}
$$

$E$ is the energy (per mole) for zero voltage at the top of the 
membrane's symetrical energy barrier $(R=$ gas constant, $T=$ absolute temperature, $A=$ constant). For $V \neq 0$, the barrier height will be changed by the electrostatic energy of the charged complex (MS $\left.{ }^{+}\right)$. If one assumes that the electrical potential $\tau(x)$ in the center of the membrane $(x=d / 2, d=$ membrane thickness) is equal to $V / 2$, then the barrier height becomes $E-F V / 2$ for transport from right to left and $E+F V / 2$ for transport from left to right. Therefore,

$$
\begin{aligned}
& k_{M S}^{\prime}=k_{M S} e^{-u / 2} \quad u=\frac{v}{R T / F} \\
& k_{M S}^{\prime \prime}=k_{M S} e^{u / 2}
\end{aligned}
$$

It can be shown [3] that $\tau(d / 2)=V / 2$ is valid for a constant field strength (i.e., a homogenous dielectric) within the membrane, which is a good approximation for lipid bilayer membranes, under most experimental conditions.

For each particle at each interface the sum of the net chemical production (equation 9) and of the fluxes toward the interface must vanish in the stationary state:

$$
\frac{d N_{S}^{\prime}}{d t}=-k_{R} C_{M} N_{S}^{\prime}+k_{D} N_{M S}^{\prime}-\Phi_{S}+k_{S}^{a q-m} C_{S}-k_{S}^{m-a q}{ }_{S}^{\prime}=0
$$

$$
\frac{d N_{S}^{\prime \prime}}{d t}=-k_{R} C_{M} N_{S}^{\prime \prime}+k_{D} N_{M S}^{\prime \prime}+\Phi_{S}+k_{S}^{a q-m} C_{S}-k_{S}^{m-a q_{S}^{\prime \prime}}=0
$$


26

$$
\frac{d N_{M S}^{\prime}}{d t}=k_{R} C_{M} N_{S}^{\prime}-k_{D} N_{M S}^{\prime}-\Phi_{M S}+k_{M S}^{a q-m} C_{M S}-k_{M S}^{m-a q} N_{M S}^{\prime}=0
$$

Eq -19

$$
\frac{d N_{M S}^{\prime \prime}}{d t}=k_{R} G_{M} N_{S}^{\prime \prime}-k_{D} N_{M S}^{\prime \prime}+\Phi_{M S}+k_{M S}^{m-a q} C_{M S}-k_{M S}^{a q-m} N_{M S}^{\prime \prime}=0
$$

Eq -20

For $V=0$, the membrane and aqueous solution chemical processes are in equilibrium, ie., equations 8,9 and 10 are in dynamic balance. Then the relations $N_{S}^{\prime}=N_{S}^{\prime \prime}=N_{S}, N_{M S}^{\prime}=N_{M S}^{\prime \prime}=N_{M S}$, and $k_{M S}^{\prime}=k_{M S}^{\prime \prime}=k_{M S}$ will hold and the following relations may be obtained from equations $17-20$ :

$$
\begin{aligned}
-k_{R} C_{M} N_{S}+k_{D}^{N_{M S}} & =0 \\
k_{S}^{a q-m} C_{S}-k_{S}^{m-a}{ }_{S}^{q} & =0 \\
k_{M S}^{m-a g} C_{M S}-k_{M S}^{a q-m} N_{M S} & =0
\end{aligned}
$$

Eq -21

Eq-22

Eq -23

From equations 22,23 and 7 , the equilibrium state may be chiracterized by the partition coefficients of the free carrier and complex, $\gamma_{S}$ and $\gamma_{M S}$ respectively.

$$
\gamma_{S}=\frac{2 N_{S} / d}{C_{S}}=\frac{2 k_{S}^{a q-m}}{d k_{S}}
$$

Eq -24

$$
\gamma_{M S}=\frac{2 N_{M S} / d}{C_{M S}}=\frac{2 k_{M S}^{a q-m}}{d_{M S}^{m-a q}}
$$

Eq -25 
In addition, the equilibrium constant of the chemical reaction $\left(K_{h}\right)$ may be expressed in terms of $\gamma_{S}$ and $\gamma_{M S}$ by using equations 21,24 and 25 .

$$
K_{h}=\frac{k_{R}}{k_{D}}=\frac{N_{M S}}{C_{M} N_{S}}=\frac{\gamma_{M S}}{\gamma_{S}} K, \quad K=\frac{C_{M S}}{C_{M S} C_{S}}
$$

In principle, both reactions (equations 9 and 10 ) could be the controlling or rate limiting processes for the charge transport through the membrane interface in the presence of an external voltage. However, due to the hydrophobic exterior of the carrier, $C_{M S}$ and $C_{S}$ in the aqueous solution will be quite small. The ratio of $\mathrm{C}_{S}$ lipid to $\mathrm{C}_{S}$ aqueous has been determined to be about $5 \times 10^{3}$ [48] for monactin, a carrier similar to valinomycin. Since $C_{M S}$ and $C_{S}$ are small, the carrier is predominantly available as a substrate only within the membrane. Therefore, the rate of the chemical reaction (equation 9) should be high when compared to the rates of the exchange reactions (equations 8 and 10 ), and the bulk of the charge transport through the interface will occur via the chemical reaction [27,45].

In order to investigate the validity of this model, attempts have been made to determine the values of the various rate constants. Experimental approaches in the past have included voltage-jump, charge-pulse, current noise analysis, and steady-state methods. This paper employs alternating current methods, which will be developed following a brief discussion of voltage-jump, charge-pulse, and steady-state theory. 
28

Steady-State and Voltage-Jump Theory

Stark, et al. [45,47] proposed that all the rate constants for the valinomycin-M+ $M^{+}$system can be evaluated from a combination of steady-state conductance measurements and voltage-jump data as follows :

Conductance is defined as:

$$
G \equiv \frac{1}{R}=1 / v
$$

Eq -27

with $R=$ resistance, $V=$ the electrical potential difference across the membrane, and $I$ = the current. The zero-voltage conductance $\left(G_{0}\right)$ is defined as:

$$
G_{0} \equiv I / v, \quad \lim \frac{I}{V} \text { as } v \rightarrow 0
$$

Eq -28

The following relationship for the electrical current (I) has been obtained by Läuger and Stark [27]:

$$
I=\frac{F d k_{M S} k C_{M} C \gamma_{S}}{k C_{M}+1} \frac{\sinh u / 2}{1+A \cosh u / 2}
$$

Eq -29

with

$$
A=\frac{2 k_{M S}\left(k_{R} C_{M}+2 k_{S}+k_{S}^{m-a q}\right)}{\left(k_{D}+k_{M S}^{m-a q}\right)\left(k_{R} C_{M}+2 k_{S}+k_{S}^{m-a q}\right)-k_{R} C_{M k_{D}}}
$$

Eq -30 
29

Evaluating Eq-29 in the 1 imit of small voltages $(u \rightarrow 0)$ and substituting for 1 in Eq-28 yields:

$$
G_{0}=\frac{F^{2} d k_{M S}}{2 R T} \frac{k C_{M} C_{0} \gamma_{S}}{\left(k C_{M}+1\right)(\cdot 1+A)}
$$

Eq-31

From equations 6 and 7

$$
\begin{aligned}
& \mathrm{N}_{S}=\frac{d}{2} \frac{\gamma_{S} C_{0}}{1+C_{M} k} \\
& c_{0}=c_{S}+c_{M S}
\end{aligned}
$$

Eq -32

where

Since $k \ll 1 M^{-1}$ for the carrier -ion complex, then it follows that $\mathrm{C}_{\mathrm{M}^{k}} \ll 1$, which in turn implies that the concentration of valinemucin in the membrane, $N_{S}$, is independent of the ionic species concentration, ie.:

$$
\mathrm{N}_{S} \approx \frac{d}{2} \gamma_{S} C_{0}, \text { for } k \ll 1 M^{-1}
$$

Eq -33

Substituting from equations 26 and 33 into equation 31 gives:

$$
G_{0}=\frac{F^{2}}{R T} N_{S} K_{M S} \frac{C_{M} k_{R} / K_{D}}{1+A}
$$

Eq -34

Furthermore, for $\mathrm{C}_{\mathrm{M}^{\mathrm{k}}} \ll 1$ and Eq-33, Eq-34 reduces to:

$$
G_{0} \approx \frac{F^{2} d}{2 R T} \quad C_{0} \gamma_{S}{ }^{k} M S \quad \frac{C_{M} k_{R} / k_{D}}{(1+A)}
$$

Eq -35 
If one can neglect the ionic transport due to the exchange reaction (equation 10 ), which is reasonable for valinomycin (see above discussion of Ionic Charge Transport), then Eq-30 may be evaluated as if $k^{m-a q} \ll k_{R} C_{M}+2 k_{S}$ and $k^{m-a q} \ll k_{D}$; in which case A reduces to:

$$
A=\frac{k_{R} k_{M S}}{k_{D} k_{S}} C_{M}+\frac{2 k_{M S}}{k_{D}}
$$

Finally, combining equations 27,29 and 31 leads to an expression for $G / G_{0}$ which depends only on $A$ and $u$.

$$
G / G_{0}=\frac{2}{u}(1+A) \frac{\sinh u / 2}{1+A \cosh u / 2}
$$

$G$ and $G_{0}$ can be measured experimentally as a function of $u$ and the corresponding A's calculated using Eq-37. By doing these studies at different ionic concentrations, $C_{M}$, a graph of A vs $C_{M}$ (equation 36) can be prepared and the ratios $2 k_{M S} / k_{D}$ (y intercept) and $k_{R} k_{M S} / k_{D} k_{S}$ (slope) extracted (see Figure 11). In addition, Eq-35 yields $\gamma_{S} k_{M S} / k_{D}$ so that three independent equations combining the five variables $\left(\gamma_{S}, k_{M S}, k_{S}, k_{R}\right.$ and $\left.k_{D}\right)$ can be deduced from steady-state conductance measurements.

Further information obtained from membrane relaxation data can now be used to complete the solution. In voltage jump experiments a short voltage step is applied and the resulting current discharge is measured as a function of time. This current can be represented by the summation of two decay curves [47]: 


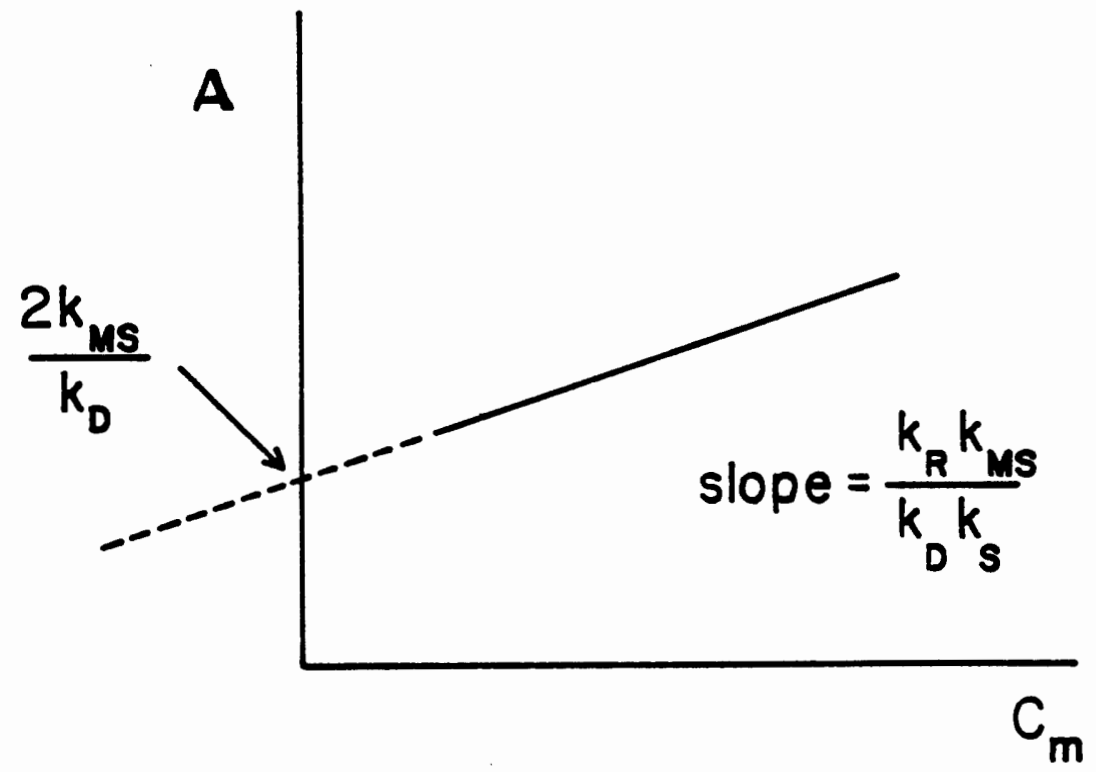

Fig. II Parameter Determination through Variations of $A$ vs $C_{m}$ 


$$
I(t)=I_{N}\left(1+\alpha_{1} e^{-t / \tau_{1}}+\alpha_{2} e^{-t / \tau_{2}}\right) \quad \text { Eq-38 }
$$

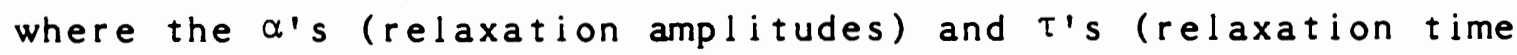
constants) are related to the rate constants $k_{M S}, k_{S}, k_{R}$ and $k_{D}$ by the following equations [47]:

$$
\begin{aligned}
& \alpha_{1}=\frac{1}{2}+\frac{P\left(C_{M} k_{R}+2 k_{S}\right)+C_{M} k_{R} k_{D}}{2\left(C_{M} k_{R}+2 k_{S}\right) \sqrt{S}}, \quad \alpha_{2}=1-\alpha_{1} \\
& \tau_{1}=1 / Q-\sqrt{5}, \quad \tau_{2}=1 / Q+\sqrt{5} \quad \text { Eq-40 } \\
& P \equiv \frac{1}{2}\left(C_{M} k_{R}-k_{D}+2 k_{S}-2 k_{M S}\right) \quad E q-41 \\
& Q \equiv \frac{1}{2}\left(C_{M} k_{R}+k_{D}+2 k_{S}+2 k_{M S}\right) \quad E q-42 \\
& S \equiv P^{2}+C_{M^{k} R^{k} D}^{E q-43}
\end{aligned}
$$

Experimental determination of these $\alpha^{\prime} s$ and $\tau$ 's from graphs of I vs $t$ on log-log scale along with the steady-state information are therefore sufficient to allow an exact numerical solution for each of the rate constants. The most significant problem with this experimental approach is that the time resolution is limited by the charging time of the membrane $\left(\tau_{C}\right)$. Usually membrane resistance is much greater than the external resistance $R_{e}$ $\left(R_{e}=R_{S}+R_{i}, R_{S} \equiv\right.$ resistance of solution and electrodes, $R_{i} \equiv$ input resistance of the amplifier) so that $\tau_{C} \approx R_{e} C=\left(R_{S}+R_{i}\right) C$ 
where $C$ is the combined electrical capacitance of the membrane $\left(C_{M}\right)$ and septum $\left(C_{S}\right)$. If $R_{i}$ can be kept on the order of $R_{S}$ then ${ }^{\tau} C$ as low as $0.2 \mu s e c$ can theoretically be achieved [28]. The actual $\tau_{C}$ is usually approximately ten times this value ( $\approx 2 \mu s e c$ ) since the charging current needs to decline to a small fraction of the initial value before the low amplitude relaxation currents can be measured. In addition, noise in the electronic measuring circuit may overlap and obscure the relaxation currents.

\section{Charge-Pulse Theory}

One method which circumvents the RC time limitation of the voltage-jump experiments is the charge-pulse technique. At time $t=0$. the membrane capacitance is charged, virtually instantaneously, to a voltage $v_{M}^{0}$. Then the external circuit is switched to a virtually infinite resistance and the subsequent voltage decay monitored.

The rate of change of the concentrations of $S$ and $M S^{+}$at the $r i g h t$ and left interfacial regions, after the charge pulse, is given by [7]:

$$
\begin{array}{ll}
\frac{d N_{S}^{\prime}}{d t}=-k_{R} C_{M} N_{S}^{\prime}+k_{D} N_{M S}^{\prime}-k_{S}\left(N_{S}^{\prime}-N_{S}^{\prime \prime}\right) & \text { Eq-44 } \\
\frac{d N_{S}^{\prime \prime}}{d t}=-k_{R} C_{M} N_{S}^{\prime \prime}+k_{D} N_{M S}^{\prime \prime}-k_{S}\left(N_{S}^{\prime \prime}-N_{S}^{\prime}\right) & E q-45 \\
\frac{d N_{M S}^{\prime}}{d t}=k_{R} C_{M} N_{S}^{\prime}-k_{D} N_{M S}^{\prime}-k_{M S}^{\prime} N_{M S}^{\prime}+k_{M S}^{\prime \prime} N_{M S}^{\prime \prime} & E q-46 \\
\frac{d N_{M S}^{\prime \prime}}{d t}=k_{R} C_{M} N_{S}^{\prime \prime}-k_{D} N_{M S}^{\prime \prime}-k_{M S}^{\prime \prime} N_{M S}^{\prime \prime}+k_{M S}^{\prime} N_{M S}^{\prime} & \text { Eq-47 }
\end{array}
$$


The decay rate of the voltage $V_{M}$ is a function of both the specific membrane capacitance $C_{M}$ and the current density, $J$, in the membrane:

$$
\frac{d v_{M}}{d t}=-\frac{J}{C_{M}}=-\frac{F}{C_{M}}\left(k_{M S}^{\prime} N_{M S}^{\prime \prime}-k_{M S}^{\prime \prime} N_{M S}^{\prime \prime}\right)
$$

$k_{M S}^{\prime}$ and $k_{M S}^{\prime \prime}$ are both voltage dependent and functions of time (see Eq-15 and Eq-16). If the analysis is further restricted to small voltages $\left(|\mathrm{u}| \ll 1\right.$ or $\left.\left|V_{M}\right| \ll 25 \mathrm{mV}\right)$ then the following approximations can be used:

$$
\begin{aligned}
& k_{M S}^{\prime} \approx k_{M S}\left[1+\frac{u}{2}\right] \\
& k_{M S}^{\prime \prime} \approx k_{M S}\left[1-\frac{u}{2}\right]
\end{aligned}
$$

Equations 44-48 constitute a system of five linear differential equations from which, in the case of small voltages, $V_{M}(t)$ may be obtained (see [7, appendix A] for details), in the following form:

$$
\begin{gathered}
v_{M}(t)=v_{M}\left[\alpha_{1} e^{-\lambda_{1}}+\alpha_{2} e^{-\lambda_{2}}+\alpha_{3} e^{-\lambda_{3}}\right] \\
\alpha_{1}+\alpha_{2}+\alpha_{3}=1
\end{gathered}
$$

$\alpha_{i}$ and $\tau_{i}=1 / \lambda_{i}(i=1,2,3)$ are the relaxation amplitudes and relaxation times respectively. These $\alpha$ 's and $\tau$ 's may be 
expressed in terms of the rate constants but the resulting equations are quite cumbersome. A more convenient formalism involves the following quantities:

$$
\begin{array}{ll}
\mathrm{P}_{1}=\lambda_{1}+\lambda_{2}+\lambda_{3} & \text { Eq-53 } \\
\mathrm{P}_{2}=\lambda_{1} \lambda_{2}+\lambda_{1} \lambda_{3} \lambda_{2} \lambda_{3} & \text { Eq-54 } \\
\mathrm{P}_{3}=\lambda_{1} \lambda_{2} \lambda_{3} & \text { Eq-55 } \\
\mathrm{P}_{4}=\alpha_{1} \lambda_{1}+\alpha_{2} \lambda_{2}+\alpha_{3} \lambda_{3} & \text { Eq-56 } \\
\mathrm{P}_{5}=\alpha_{1} \lambda_{1}^{2}+\alpha_{2} \lambda_{2}^{2}+\alpha_{3} \lambda_{3}^{2} & \text { Eq-57 }
\end{array}
$$

From these five variables, which may be experimentally determined from the $\alpha^{\prime} s$ and $\tau$ 's, the four rate constants $k_{R}, k_{D}, k_{S}$ and $k_{M S}$ as well as the carrier concentration $N_{0}\left(N_{O}=N_{S}^{\prime}+N_{S}^{\prime \prime}+N_{M S}^{\prime}+N_{M S}^{\prime \prime}\right)$ may be calculated (see [7, Appendix A]):

$$
\begin{aligned}
& k_{M S}=\frac{1}{2}\left(\frac{P_{5}}{P_{4}}-P_{4}\right) \\
& k_{D}=\frac{1}{2 k_{M S}}\left[\frac{P_{1} P_{5}}{P_{4}}-P_{2}+\frac{P_{3}}{P_{4}}-\left(\frac{P_{5}}{P_{4}}\right)^{2}\right] \\
& k_{S}=\frac{1}{2 k_{D}} \frac{P_{3}}{P_{4}} \\
& k_{R}=\frac{1}{C_{M}}\left(P_{1}-P_{4}-2 k_{S}-2 k_{M S}-k_{D}\right) \\
& N_{0}=\frac{2 R T ~}{F_{M}^{2}} \frac{P_{4}}{k_{M S}}\left(1+\frac{k_{D}}{C_{M} k_{R}}\right)
\end{aligned}
$$


This method has an additional advantage in that very small applied voltages may be employed. However, both the experimental procedure and subsequent calculations are more complicated plus; any voltage dependence of the rate constants cannot be determined in this manner.

\section{A.C. Theory}

In both the voltage-jump and charge-pulse experimental methods a step change was applied to the membrane system. Information about the transport kinetics of carrier-mediated ion transport, in principle, can also be extracted from the application of periodic perturbations to the system. Such a harmonically oscillating voltage may be represented by:

$$
v_{M}(t)=v_{M}^{0} \cos \omega t
$$

The response of the membrane may then be measured for various frequencies $\omega$. In the steady state the current is also given by a harmonic function, with the same frequency $\omega$ :

$$
I(t)=I_{0} \cos (\omega t-\phi) \quad \text { Eq-64 }
$$

where $I_{0}$ is the current amplitude and $\phi$, the phase shift, may be expressed by the (small-signal) admittance $Y(\omega)$.

$$
\begin{aligned}
& I_{0}=V_{M}^{0}|Y(\omega)|=V_{M}^{0} \sqrt{\operatorname{Re}^{2}[Y(\omega)]+I^{2}[Y(\omega)]} \quad E q-65 \\
& \tan \phi=-\operatorname{Im}[Y(\omega)] / \operatorname{Re}[Y(\omega)] \quad \operatorname{Eq}-66
\end{aligned}
$$

where Re means "the real part of" and Im "the imaginary part of." 
At any given instant the current $I$ in the membrane is the sum of the charging current $C_{M} \frac{d V_{M}}{d t}$ and the current due to charge movements within the membrane.

As in the charge-pulse method, equations 44-47 represent the interfacial concentration variations of $S$ and $\mathrm{MS}^{+}$, with time. Now, however, $k_{M S}^{\prime}$ and $k_{M S}^{\prime \prime}$ must be represented by periodic functions of time, so equations 49 and 50 are replaced by:

$$
\begin{aligned}
& k_{M S}^{\prime} \approx k_{M S}\left[1+\frac{u_{0}}{2} \cos (\omega t)\right] \\
& k_{M S}^{\prime \prime} \approx k_{M S}\left[1-\frac{u_{0}}{2} \cos (\omega t)\right]
\end{aligned}
$$

The solution of equations 44-47 may now be obtained by standard differential methods $[17,25]$. The results are ( $e_{0}=$ elementary electronic charge, $A_{M}=$ membrane area, $k=$ the Boltzmann constant, and $C_{M}=$ membrane capacitance):

$$
\begin{aligned}
& G_{M}(\omega) \equiv \operatorname{Re}[Y(\omega)]=\frac{e_{0}^{2}}{k T} A_{M} N_{M S}{ }^{k} M S\left[1-\left(\frac{\alpha_{1}}{1+\omega^{2} \tau_{1}^{2}}-\frac{\alpha_{2}}{1+\omega^{2} \tau_{2}^{2}}\right)\right]_{E q-69} \\
& C_{M}(\omega) \equiv \operatorname{Im}[Y(\omega)]=\omega C_{M}+\frac{e_{0}^{2}}{k T} A_{M} N_{M S} k_{M S}\left(\frac{\alpha_{1} \omega \tau_{1}}{1+\omega^{2} \tau_{1}^{2}}+\frac{\alpha_{2} \omega \tau_{2}}{1+\omega^{2} \tau_{2}^{2}}\right)
\end{aligned}
$$


with

$$
\alpha_{1}=\frac{k_{M S}}{\sqrt{a}} \cdot \frac{\sqrt{a}-P}{\sqrt{a}+Q} \quad, \quad \alpha_{2}=\frac{k_{M S}}{\sqrt{a}} \cdot \frac{P+\sqrt{a}}{Q-\sqrt{a}}
$$

and

$$
\tau_{I}=\frac{1}{Q+\sqrt{a}}, \quad \tau_{2}=\frac{1}{Q-\sqrt{a}}
$$

where

$$
\begin{aligned}
& P=\frac{1}{2}\left(C_{M} k_{R}-k_{D}+2 k_{S}-2 k_{M S}\right) \\
& Q=\frac{1}{2}\left(C_{M} k_{R}+k_{D}+2 k_{S}+2 k_{M S}\right) \\
& a=P^{2}+C_{M} k_{R} k_{D}
\end{aligned}
$$

The real part of the admittance (Eq-69) corresponds to the membrane conductance, while the time constants $\tau_{1}$ and $\tau_{2}$ (Eq-72) are identical to the relaxation times for the voltage-jump experiments.

Kolb and Läuger used a similar analysis in their current noise experiments [25]. They employed the Nyquist theorem (an equation relating the voltage fluctuations in linear electrical systems with the electrical resistance $[12,34]$ to describe the spectral intensity, $S_{I}$; at equilibrium, $V=0$, as:

$$
S_{I}(\omega)=4 \mathrm{kT} \cdot \operatorname{Re}[Y(\omega)]
$$


The spectral intensity represents the power within a frequency range $d \omega$, for a particular $w$, which is being dissipated as noise. Substituting Eq-69 into Eq-76 gives a current noise spectral intensity of :

$$
S_{1}(\omega)=4 e_{0}^{2} A_{M} N_{M S} k_{M S}\left[1-\frac{\alpha_{1}}{1+\omega^{2} \tau_{1}^{2}}-\frac{\alpha_{2}}{1+\omega^{2} \tau_{2}^{2}}\right]
$$

It can be seen from Eq-46 that the spectral intensity becomes frequency independent at both high and low frequencies. Furthermore, $S_{I}(0)$ is related to the membrane steady-state conductance, while $S_{I}(\infty)$ is related to the initial membrane conductance which is observed immediately after the application of a voltage jump. By simultaneous solution of equations $71-75$ and 77 , the following expressions are obtained for the rate constants $\left(\lambda_{1}=1 / \tau_{1}\right.$, $\left.\lambda_{2}=1 / \tau_{2}\right):$

$$
\begin{aligned}
& k_{M S}=\frac{1}{2}\left(\alpha_{2} \lambda_{2}+\alpha_{1} \lambda_{1}\right) \\
& k_{S}=\frac{\lambda_{1} \lambda_{2}\left\{4 k_{M S}^{2}\left(1-\alpha_{1}-\alpha_{2}\right)\right\}}{4 k_{M S}\left(\alpha_{1} \lambda_{1}^{2}+\alpha_{1} \lambda_{2}^{2}-4 k_{M S}^{2}\right)} \\
& k_{R}=\frac{\alpha_{1} \alpha_{2} \lambda_{1} \lambda_{2}\left(\lambda_{1}-\lambda_{2}\right)^{2}}{2 C_{M} k_{M S}\left(\lambda_{1} \lambda_{1}^{2}+\lambda_{1} \lambda_{2}^{2}-4 k_{M S}^{2}\right)} \\
& k_{D}=\frac{\alpha_{2} \lambda_{2}^{2}+\alpha_{1} \lambda_{1}^{2}-4 k_{M S}^{2}}{2 k_{M S}} \\
& N_{M S}=S_{I}(\infty) / 4 e_{0}^{2} k_{M S}
\end{aligned}
$$


These equations ${ }^{1}$ are then used to determine the rate constants from the experimentally measured $a^{\prime} s$ and $\tau^{\prime} s$.

1 It should be noted that equations 78-82 do not correspond exactly to equations B1-B5 in [25]. Several transcriptional and/or printing errors appeared in the original publication. Equations 78-82 do correctly invert to equations 69-75. 


\section{EXPERIMENTAL METHODS AND MATERIALS}

\section{Introduction}

The basic experimental setup consists of a membrane formed across a hole in a septated teflon cell separating two identical aqueous ionic solutions and an accompanying electrical circuit to measure and apply the current and voltage across the membrane. These basic components are diagrammed in Figure 8. The materials, membrane forming technique, and electrical circuits will be discussed in detail. 
Materials

Bilayer lipid membranes were formed from a solution of glycerylmonooleate (CMO) in $n$-decane. The GMO was purchased from Nu-Check-Prep, Inc. ( $>99 \%$ purity). The GMO was stored as a $5 \%$ weight by volume stock solution $(1,000 \mathrm{mg}$ solute in $1.0 \mathrm{ml}$ solvent is equivalent to a $100 \%$ solution) in chloroform at $-15^{\circ} \mathrm{C}$. Membrane forming solutions were mixed daily by removing, at room temperature the chloroform from a known volume of stock solution (measured by a Rainin micropipet) in a rotary evaporator for fifteen minutes at -30 in $\mathrm{Hg}$ vacuum and adding $n$-decane to achieve the desired concentration (usually $2.5 \%$, weight by volume).

Aqueous solutions containing the metal ions were formed from $\mathrm{KCl}$ or $\mathrm{RbCl}$ (>99\% pure, from Matheson, Coleman and Bell) with water deionized through a Q2 Millipore system (resistivity>10M $-\mathrm{cm})$. Ionic strength was maintained at $1.0 \mathrm{M}$ through the addition of appropriate amounts of $\mathrm{LiCl}_{\mathrm{C}}$ to any of the aqueous solutions where the concentration of metal ion was less than one molar. This was necessary to insure a constant membrane surface potential so that any observed variations in the rate constants with different ionic concentrations could not be ascribed to variations in the aqueous charge distribution. In addition, the $1 \mathrm{M}$ concentration keeps cell resistance low and improves the accuracy. Lithium has a negligible effect on membrane conductivity in the presence of valinomycin [4,32]. The lithium presumably acts as an inert electrolyte which cannot coordinate with the valinomycin because of its very large sphere of hydration. 
The addition of LiCl is also of importance in the d.c. measurements. Here the additional ions lower the resistance of the solution $\left(R_{E}=\right.$ electrical resistance, $R_{S}=$ resistance of the aqueous solution, $R_{M}=$ membrane resistance) and insure that $R_{S}$ does not overwhelm $R_{E}$ and $R_{M}$ as the concentration of the transport ion decreases to $0.001 \mathrm{M}$. The aqueous solution $\mathrm{pH}$ was consistently between 6 and 7 .

Valinomycin (A grade, from Calbiochem) was stored as a stock solution with ethanol and kept refrigerated, in a dark bottle wrapped with foil. This stock solution is added to the aqueous ion solution prior to the formation of membranes. The ethanol concentration in the aqueous solution was approximately $0.08 \%$ and should not have affected the structural or electrical properties of the bilayers [45]. It is also possible to add the valinomycin directly to the membrane forming solution $\left(10^{-7} \mathrm{M}\right.$ aqueous is equivalent to $10^{-3} \mathrm{M}$ membrane [45]). This technique was tried but problems were encountered with membrane structural stability. The membranes would last only from three to ten minutes. This should not have been due to ethanolic disruption as the ethanol was removed, along with the chloroform, in the rotary evaporator at -30 in $\mathrm{Hg}$ vacuum for 45 minutes. This method was not pursued further, although it has the inherent advantage of a shorter conductance stabilization period. 


\section{Cell Preparation}

Both the a.c. and d.c. teflon cells were initially baked for six days at a temperature between $90^{\circ}$ and $130^{\circ} \mathrm{C}$, then soaked in chromic acid and finally boiled in NaOH/EtOH to remove any possible nonactin contamination from prior experiments, as reported by Smejtek and Paulis-I1langasekare [44]. In between uses the cells were stored in $95 \%$ EtOH. Prior to use the cell was rinsed with fresh ethanol and force dried by a Sanyei E-2105 hair dryer operating at 1200 watts for 10 to 15 minutes. Whenever new ionic concentrations or ions were to be investigated a more thorough cleaning procedure was followed by boiling in a $95 \% \mathrm{EtOH} / \mathrm{NaOH}$ solution for ten minutes followed by ten minutes of boiling in disti 1 led water.

After any boiling procedure the cell was "painted" prior to forming any membranes. After drying the cell the painting was performed by placing the aperture in a nitrogen gas stream and applying a brush of lipid around the hole. The lipid was spread evenly, moving away from the center in a spiral fashion. This was performed with three brush fulls of lipid until a uniformly smooth, glistening layer was present. It was found that the formation ease and membrane stability was enhanced by this painting procedure. Then the cell was placed in an acrylic container, the aqueous ion solution added, and membranes formed as follows. 


\section{Membrane Formation}

Membranes were formed by drawing a sable brush dipped in lipid across a circular aperture in the wall of a teflon cell. Immediately after formation the membrane is thousands of angstroms thick, but within seconds the central portion begins to thin and continues until a thickness of approximately $70 \AA$ is reached. This thinning process begins at the bottom of the membrane and progresses upward. The excess lipid gathers on the cell surface and in an annular $r$ ing within the hole's $r$ im, surrounding the optically black, thin membrane. This ring is referred to as the torus (see Figure 12). Only the black portion contains the bilayer configuration which corresponds to biological membranes, so it is important to insure that sufficient time is allowed for its completion. In order to minimize the torus size and lipid build-up, as little membrane solution as possible was used. This also reduces any exchange of valinomycin that might occur between the black membrane and surrounding 1 ipid.

\section{Electrical Measurements}

The basic alternating current and direct current circuits and their respective operational procedures will now be discussed in detail.

\section{Alternating Current System}

The alternating current measuring system includes the following components (see Figure 13): 


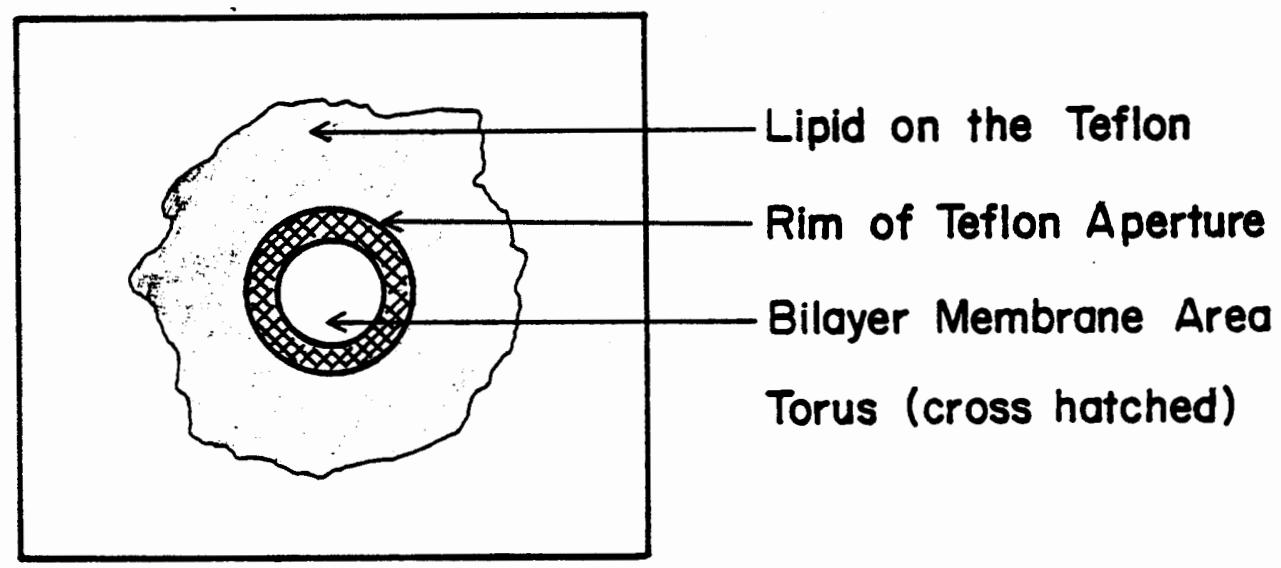

Fig. 12 Membrane Formation on the Tefion Cup 


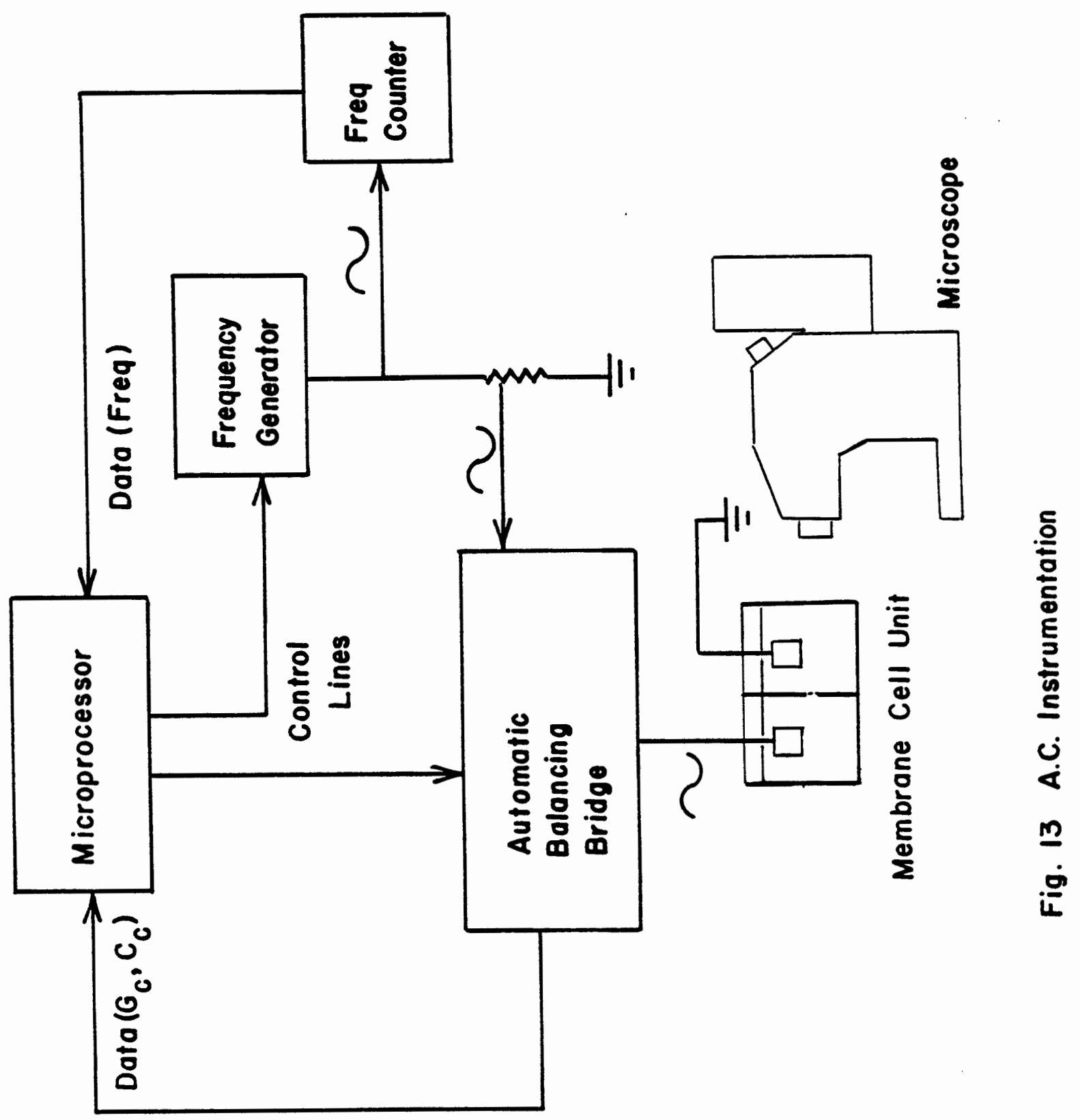


(1) A Hewlett-Packard 4270A automatic capacitance bridge, which is used to measure the conductance and capacitance of the cell-membrane system. The standard instrument has been modified by A.D. Pickar to allow operation with an external oscillator, thereby providing measurements over a continuous frequency range and at low test voltages.

(2) A Hewlett-Packard 5245L Electronic Counter to record the frequency being applied to the membrane.

(3) Two oscillators: one contained within the microcomputer which automatically generates the experimental frequencies; the other, a Hewlett-Packard HP-651B test oscillator, is used as an external source to perform manual comparisons with the automatic oscillator.

(4) A relay box containing various resistances and capacitances, which is used to modify the membrane circuit (see A.C. Operations).

(5) An amplification unit to boost the signal and filter noise from the frequencies produced by the signal generating components within the microcomputer.

(6) A Motorola MEK6800D2 microprocessor chip interfaced with various memory, control and frequency chips performs an automatic sequential run of twenty-five frequency steps $(0.1$ to $900 \mathrm{KHz})$ and stores the measured conductance, capacitance and frequency values for each step. 
Microcomputer

The signal generating board consists of two frequency chips; one with a range of 0.123 to $400.0 \mathrm{KHz}$, the other with two distinct ranges (lower range from 200 to $400 \mathrm{KHz}$, and a higher range of 500 to $1,000 \mathrm{KHz})$. Since the frequency range of the two chips overlaps between 200 and $400 \mathrm{KHz}$, it was necessary to decide which frequency chip would be used for that range.

To accomplish this a dumy circuit was designed to simulate the conductance and capacitance of a GMO membrane in the presence of valinomycin $\left(C_{M}=10 \mathrm{nF}, G_{0}=100 \mu S\right)$. The microcomputer then performed an automated run on this dummy membrane circuit. The test oscillator was then used to generate identical frequencies, and the corresponding conductance and capacitance values were then compared with those obtained by the microprocessor. The greatest. discrepancy occurred at higher frequencies ( $>300 \mathrm{KHz}$ ), but even then the capacitance and conductance values for the automatic and manual runs agreed within one percent. An oscilloscope was also used to monitor the wave forms produced by the microprocessor. The low frequency range chip generated well-formed sinusoidal waves except for slight distortion of the peaks (between 0.1 and $0.5 \mathrm{KHz}$ ) and gross assymetries of frequencies greater than $300 \mathrm{KHz}$. The high frequency range chip wave forms were good except for definite peak flattening of the $200 \mathrm{KHz}$ wave generated by the low range of this chip. From these considerations the following assignments were made: low frequency chip generated 0.1 - $200 \mathrm{KHz}$ frequencies, while the high frequency chip produced 
those frequencies between 300 and $1,000 \mathrm{KHz}(300$ and $400 \mathrm{KHz}$ by the low range of the high frequency chip; 500,700 and $900 \mathrm{KHz}$ by the high range of the high frequency chip). Programing instructions were loaded into the microprocessor, from a magnetic tape, using a Sankyo SAV-1060 recorder. Data stored in the microprocessor was output to a teletype and a paper punch tape created.

\section{A.C. Operations}

A membrane was formed (see Membrane Formation section below for full details) across a $1.652 \mathrm{~mm}$ diameter aperture, in the presence of a $1 \mathrm{KHz}$ test signal. Conductance and capacitance were then monitored by the Hewlett-Packard bridge until fluctuations in both values had stopped (approximately five to ten minutes after formation). Then an area measurement was made of the bilayer portion of the membrane as follows: an American Optical fibre optics system with two independently flexible heads was used to illuminate the membrane, causing the line separating the thicker torus from the bilayer portion to glisten (see Figure 12). A measurement of the diameter was made with a traveling microscope. The bilayer region was assumed to be round and the area calculated from a measured diameter. The microcomputer then was instructed to generate twenty-five successive frequencies $(0.1$ to $900 \mathrm{KHz})$ and store the capacitance, conductance and frequency values for each frequency step.

Cell temperatures were not rigidly controlled but experiments were performed at ambient room temperature, which varied from 
$19.6^{\circ}$ to $21.8^{\circ} \mathrm{C}$. This temperature range was far from the $10^{\circ} \mathrm{C}$ where substantial rate constant variations have been observed [7].

\section{Bridge Settings}

The Hewlett-Packard bridge was originally designed to operate at four separate frequencies $\left(1,10,100\right.$ and $\left.1,000^{\circ H z}\right)$ with a separate internal signal generating circuit for each frequency. After modifying the bridge to accept an external frequency source, it is necessary to select the appropriate bridge frequency range position for the various input signals. Table 1 lists the frequency range which the microcomputer directed the bridge to use for the various external frequencies. These and the other settings 1 isted were chosen so as to give the fewest possible overranges and the best agreement of capacitance and conductance values for the dummy circuit (as described in the Microcomputer section). The $1 \mathrm{MHz}$ position could not be used, even for the highest frequencies $(700,900 \mathrm{KHz})$, because of erroneously low conductance measurements at this setting. The bridge can still balance for these higher frequencies in the $100 \mathrm{KHz}$ position, and there is good agreement of the conductance values. However, the capacitance measurements for these frequencies is poorer at the $100 \mathrm{KHz}$ versus the $1 \mathrm{MHz}$ setting. The importance of this trade-off will be further explored in the Data Analysis section.

The test voltage position is critical in these experiments as it determines the magnitude of the voltage applied to the membrane. This switch must be set in either Low or Remote, as the Normal 
position results in a five times greater applied voltage which causes membrane instability and structural breakdown. For the Low setting the applied voltages, to the membrane, were about $30 \mathrm{mV} \mathrm{rms}$ for the entire run (though slightly higher for lower frequencies) with a d.c. component of approximately $4 \mathrm{mV}$ due to electrode polarization (platinized platinum strip electrodes were used).

\section{Table 1 - Hewlett-Packard Bridge Settings}

$\begin{array}{lll}\text { Freq - Remote } & \text { Meas Rate - Med } & \text { Meas CKT - Float } \\ \text { Range Mode - Hold } & \text { Loss Meas - G } & \begin{array}{l}\text { Range Step - nF } \\ \text { (three decimal places) }\end{array} \\ \text { Test Voltage - Low } & \text { Bias Range - Off } & \text { Bias Vernier - Remote }\end{array}$

External Frequency (f)

$\begin{array}{rr}0<f< & 1 \\ 1 \leq f< & 50 \\ 50<f<1,000\end{array}$

\section{Bridge Frequency Range Position}

$1 \mathrm{KHz}$

$10 \mathrm{KHz}$

$100 \mathrm{KHz}$

After the first twenty steps (ending with $300 \mathrm{KHz}$ ) are completed, a $51.1 \Omega$ resistor is added in series with the cell resistance and data obtained for 200, 300, 500, 700 and $900 \mathrm{KHz}$. This procedure is also under microprocessor control so that the change may be affected without any break in the experiment. Such a modification is necessary because the membrane conductance becomes so large at the higher frequencies that the bridge overranges. The additional series resistance lowers the net equivalent parallel 
conductance $(G=1 / R)$ of the membrane circuit, thereby eliminating the overranges. This factor is taken into account during the reduction of data.

The entire automated run was approximately forty-five seconds in duration. This permitted multiple data runs on each membrane as well as the investigation of unstable membranes with short life spans.

\section{D.C. Circuit Components}

The d.c. circuit consisted of the following:

(1) Keithley Picoameter to measure membrane current;

(2) Keithley 160 B digital voltmeter;

(3) a potentiometer circuit to apply the voltage;

(4) a Hewlett-Packard Moseley 7035A X-Y recorder.

\section{D.C. Operations}

The membrane was formed across a $2.064 \mathrm{~mm}$ diameter opening, in the presence of a $10 \mathrm{mV}$ applied test voltage. After formation the $X-Y$ recorder was monitored until the membrane current was seen to have reached a steady-state value $(\approx 5-15 \mathrm{~min})$. Then an area determination was made, as in the a.c. section. Finally, membrane current values were obtained for applied voltages of $25,50,75$ and $100 \mathrm{mV}$. The membrane usually broke if it was subjected to voltages much greater than $100 \mathrm{mV}$.

The calomel fiber tip electrodes were stored in concentrated $\mathrm{KCl}$ and $\mathrm{rinsed}$ with deionized water before and after use. They 
were checked periodically for polarization by monitoring the conductance of a membrane without any applied voltage. No significant polarization curents were ever observed $\left(I \approx 10^{-2}\right.$ amps) so no correction was applied to the data. All measurements were made at ambient room temperature levels $\left(19.6^{\circ}-21.8^{\circ} \mathrm{C}\right)$. 
Data Reduction - Introduction

Table 2 contains a summary of the computer programs employed in the data analysis. Each will receive detailed discussion below. Sample print-outs for certain programs are contained in Appendix A.

Table 2 - Computer Program Sumary
(see text for details)

\begin{tabular}{|c|c|c|}
\hline Name & Input & Output \\
\hline REDU 1 & $G_{C}(\omega), C_{C}(\omega)$ & $R_{S}, G_{M}(\omega), C_{M}(\omega)$ \\
\hline REDU 2 & $G_{C}(\omega), C_{C}(\omega)$ & Normalized $G_{M}(\omega), G_{M}(w)$ \\
\hline TOTAL & Normalized $G_{M}(\omega)$ & $\alpha_{1}, \alpha_{2}, \tau_{1, \tau_{2}}$ \\
\hline TOECAP & Normalized $C_{M}(\omega)$ & $\alpha_{1,} \alpha_{2}, \tau_{1, \tau_{2}}$ \\
\hline PDA 1 & $\alpha_{1,} \alpha_{2}, \tau_{1, \tau_{2}}$ & $k_{R}, k_{D}, k_{S}, k_{M S}, r_{S}$ \\
\hline & $\begin{array}{l}\text { measured } A_{M} \\
\text { low frequency } G_{M}, C_{M} \\
\text { high frequency } C_{M}\end{array}$ & $\begin{array}{l}A_{M} \text { corrected for bulging } \\
G_{M}^{M}(\omega)\end{array}$ \\
\hline ADP 1 & $k_{R}, k_{D}, k_{S}, k_{M S}, \gamma_{S}$ & $\alpha_{1}, \alpha_{2}, \tau_{1,} \tau_{2}$ \\
\hline & $A_{M}$, membrane thickness & $G_{M}(\omega), G_{M}(\omega)$ \\
\hline ADP 2 & ${ }_{E}^{k_{R}},{ }^{k_{I}},{ }^{k_{S}}, k_{M S}, r_{S}$ & $G_{M}(\omega), G_{M}(\omega)$ \\
\hline
\end{tabular}




\section{$\underline{\text { REDU } 1}$}

In order to determine the various rate constants, using Equations 78-81, values for $\alpha_{1}, \alpha_{2}, \tau_{1}$ and $\tau_{2}$ must be obtained from the experimental data. This can be accomplished from a knowledge of the membrane capacitance $\left(C_{M}{ }^{\omega}\right)$ and conductance $\left(G_{M}{ }^{\omega}\right)$ for various applied frequencies, as will be detailed in the following pages. However, the Hewlett-Packard bridge measures $G_{C}(\omega)$ and $C_{C}(\omega)$

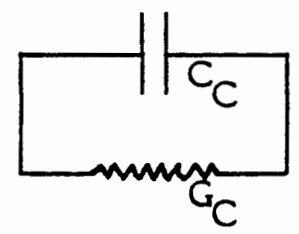

which transforms to the following equivalent membrane series cicuit,

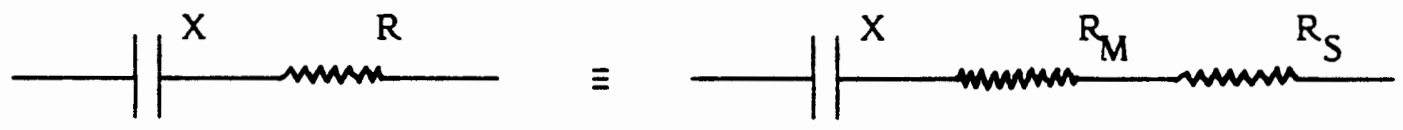

where

$x=\frac{\omega C_{C}}{\left(\omega C_{C}\right)^{2}+G_{C}^{2}}$

$R=\frac{G_{C}}{\left(C_{C}\right)^{2}+G_{C}^{2}}$

$R=R_{S}+R_{M}$ 
The REDU 1 program evaluates $R$ and $R_{S}$ (the cell resistance) from which $R_{M}$ may be calculated, as above. Then the membrane conductance and capacitance are obtained from

$$
G_{M}=\frac{R_{M}}{R_{M}^{2}+x^{2}} \quad, \quad C_{M}=\frac{x / \omega}{R_{M}^{2}+x^{2}}
$$
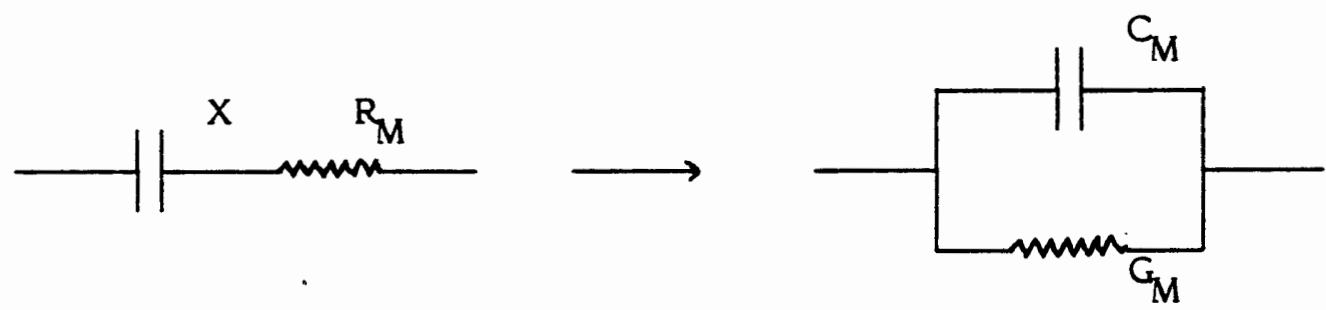

Appendix A contains an example of the REDU 1 experimental data printout, which shows the bridge readings $G_{C}(\omega), C_{C}(\omega)$ followed by cell resistance computations and finally, the calculated $G_{M}(\omega)$ and $G_{M}(\omega)$ values. The conductances clearly indicate the increasing influence of $R_{S}$ with the higher applied frequencies. A detailed discussion of the actual $R_{S}$ determination follows. 
Determination of Cell Resistance, $R_{S}$

The cell resistance can be graphically determined for each membrane data run by plotting $C_{C} v s G_{C}$, for successive applied high frequencies, and then extrapolating the curve as a semicircle to obtain the cell impedance at infinite frequency (see Figure 14 and Table 3 ). This method takes advantage of the fact that at high frequencies the membrane/cell system behaves as a practically pure capacitance in series with the cell resistance. For such a circuit the admittance of the system falls on a semicircle when plotted in the complex plane [16]. The intercept of this semi-circle with the zero-susceptance axis corresponds to the conductance due to the application of an infinite frequency. The inverse of this conductance is then taken to be the cell resistance. This graphical procedure is carried out analytically in REDU 1 for several sets of frequences as follows:

(1) $w C_{C}$ and $G_{C}$ for two successive frequencies (e.g. frequency steps 25 and 24 in Table 3) are assumed to be points on the semi-circle;

(2) a perpendicular bisector is constructed between the two points and its intersection with the $x$-axis is used to identify the center of the circle which, in turn, allows a determination of the radius ( $r)$;

(3) the $r$ determined in step (2) is then used to construct a semi-circle which includes the points from step (1); 


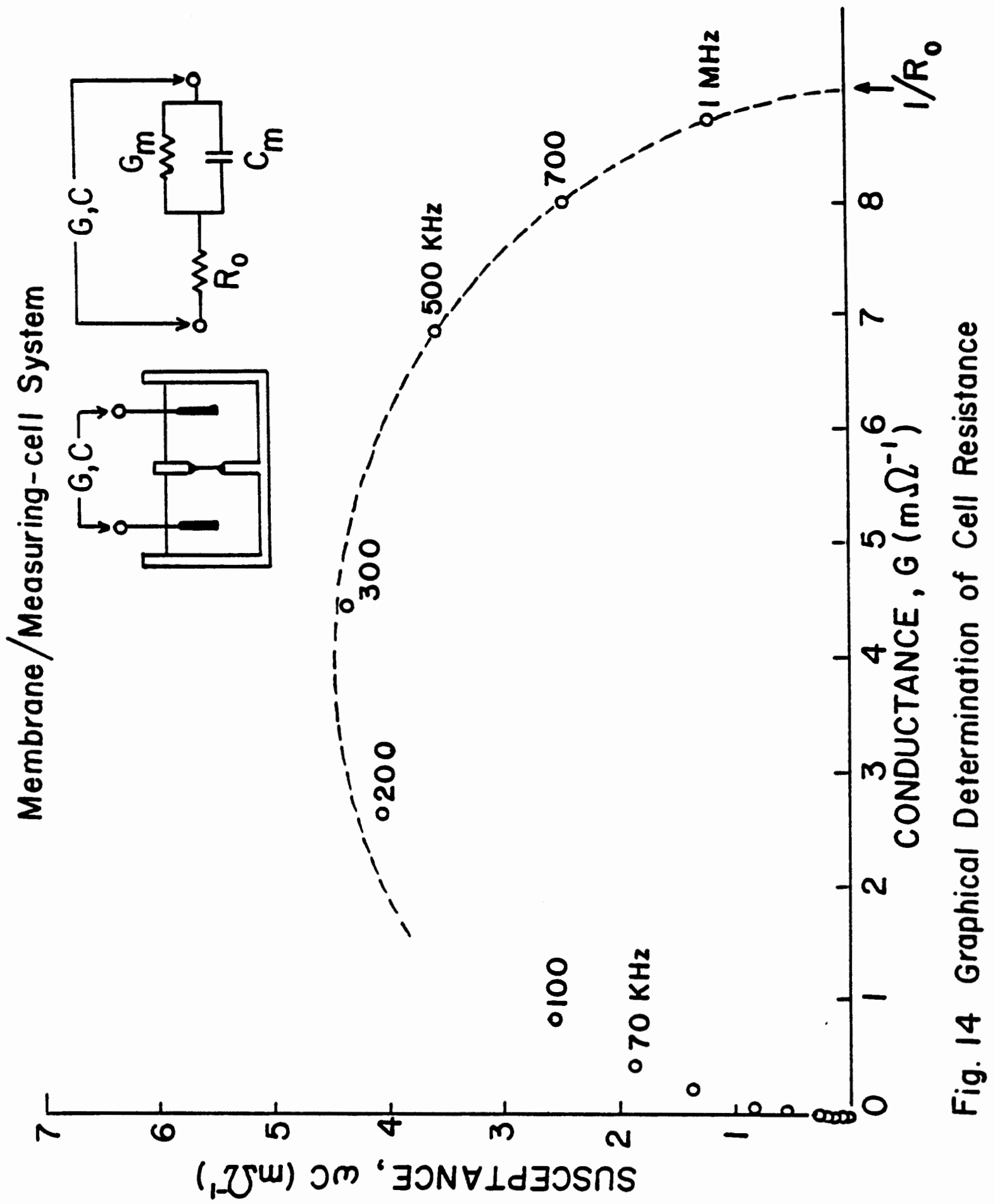


(4) the high frequency intersection of this semi-circle with the zero-susceptance axis is taken to be the conductance due to the cell resistance (in the limit of high frequency $\mathrm{R}_{\mathrm{S}}$ should be the dominant circuit component, as described above) and $R_{S}^{\prime}$ is calculated from the inverse of this conductance;

(5) steps (1) to (4) above are then repeated for the next couplet of frequencies (e.g. frequency steps 24 and 23 in Table 3 );

(6) the two $R_{S}^{\prime}$ values obtained in steps (1) to (5) are then averaged to yield $\mathrm{R}_{\mathrm{Savg}}$;

(7) since $R_{\text {Savg }}$ includes the $51.1 \Omega$ resistance added in series with the cell resistance to prevent bridge overranges (see A.C. Operations) the actual cell resistance is calcluated from $\mathrm{R}_{\text {Savg }}$ by, $\mathrm{R}_{\mathrm{S}}=\mathrm{R}_{\text {Savg }}-51.1$;

(8) steps (1) to (7) are repeated for two more triplets of frequencies (frequency steps $24,23,22$ and $23,22,21$ in Table 3 ). Steps (1) to (8) above result in three values for $R_{S}$ which are not identical. Due to slight distortions present in the microprocessor generated wave forms at frequency steps 21 and 25 (200 and $900 \mathrm{KHz})$ the value calculated from the frequency triplet $24,23,22$ was generally used in subsequent calculations as the assumed cell res is tance. 
Table 3 - Typical Cell Resistance Calculation

(see text for details)

\begin{tabular}{|c|c|c|c|c|c|c|c|c|}
\hline $\begin{array}{l}\text { Freq } \\
\text { S tep }\end{array}$ & $\begin{array}{l}\text { Freq } \\
(\mathrm{KHZ})\end{array}$ & $\begin{array}{l}\mathrm{C}_{\mathrm{C}} \\
(\mathrm{pF})\end{array}$ & $\begin{array}{c}\mathrm{G}_{\mathrm{C}} \\
(\mu \mathrm{S})\end{array}$ & & $\begin{array}{l}\mathbf{R}_{S^{\prime}} \\
(\Omega)\end{array}$ & & $\begin{array}{c}\mathrm{R}_{\text {Savg }} \\
(\Omega)\end{array}$ & ${ }_{(\Omega)}^{\mathrm{R}_{\mathrm{S}}\left(\mathrm{R}_{\mathrm{Savg}}\right.}{ }^{-51 \cdot 1)}$ \\
\hline 25 & 884 & 750 & 5,880 & & & & & \\
\hline 24 & 693 & 932 & 5,850 & $>$ & $\begin{array}{l}168.8 \\
168.1\end{array}$ & $>$ & 168.4 & 117.3 \\
\hline 23 & 496 & 1,270 & 5,710 & & & & & \\
\hline 24 & 693 & 932 & 5,850 & $>$ & 167.0 & & & \\
\hline $\begin{array}{l}23 \\
22\end{array}$ & $\begin{array}{l}496 \\
295\end{array}$ & $\begin{array}{l}1,270 \\
1,924\end{array}$ & $\begin{array}{l}5,710 \\
5,134\end{array}$ & $>$ & & $>$ & 166.8 & 115.7 \\
\hline 23 & 496 & 1,270 & 5,710 & & 165.6 & & & \\
\hline 22 & 295 & $\begin{array}{l}1,924 \\
2,375\end{array}$ & $\begin{array}{l}5,134 \\
4,603\end{array}$ & $>$ & 166.5 & $>$ & 166.1 & 115.0 \\
\hline
\end{tabular}

Data obtained for a GMO membrane separating an aqueous solution (0.1 M RbCL, 1.0 M LICl, 10-7 M valinomycin) (RVGM 6). 
REDU 2, TOTAL, TOECAP

The calculated $G_{M}(\omega)$ and $G_{M}(\omega)$ data values can now be normalized and the curve fit to extract the desired parameters ( $\alpha$ 's and $\tau$ 's). REDU 2 performs the normalization while TOECAP and TOTAL curve $f$ it the normalized capacitance and conductance data respectively. $A^{\prime}$ discussion of the normalization process follows. First, consider Eq-69:

$$
G_{M}(\omega) \equiv \operatorname{Re}[Y(\omega)]=\frac{e_{0}^{2}}{k T} A_{M} N_{M S}{ }^{k} M S\left[1-\frac{\alpha_{1}}{1+\omega^{2} \tau_{1}^{2}}-\frac{\alpha_{2}}{1+\omega^{2} \tau_{2}^{2}}\right]
$$

In the limit of high frequencies

$$
G_{M}(\infty)=\frac{e_{0}^{2}}{k T} A_{M} N_{M S} k_{M S}
$$

Substituting Eq-83 into Eq-69 and Eq-70 yields:

$$
\begin{aligned}
& G_{M}(\omega)=G_{M}(\infty) \quad\left[1-\frac{\alpha_{1}}{1+\omega^{2} \tau_{1}^{2}}-\frac{\alpha_{2}}{1+\omega^{2} \tau_{2}^{2}}\right] \\
& C_{M}(\omega)=C_{M}+G(\infty) \quad\left[\frac{\alpha_{1} \tau_{1}}{1+\omega^{2} \tau_{1}^{2}}+\frac{\alpha_{2} \tau_{2}}{1+\omega^{2} \tau_{2}^{2}}\right]
\end{aligned}
$$

Let $\omega \rightarrow \infty$ in Eq-82, this results in:

$$
C_{M}(\infty)=C_{M}
$$

where $C_{M}$ is defined as the capacitance of an undoped membrane at infinite frequency.

Similarly, let $\omega=0$ in Eq-84 and Eq-85 while substituting Eq-86 for $C_{M}$. This gives equations for steady-state conductance and capacitance without an applied external voltage. 


$$
\begin{aligned}
& G_{M}(0)=G_{M}(\infty)+G_{M}(\infty)\left(\alpha_{1} \tau_{1}+\alpha_{2} \tau_{2}\right) \\
& G_{M}(0)=G_{M}(\infty)\left(1-\alpha_{1}-\alpha_{2}\right)
\end{aligned}
$$

Dividing Eq-84 by Eq-88 results in a normalized conductance of :

$$
G_{M}(\omega) / G_{M}(0)=\frac{1}{1-\alpha_{1}-\alpha_{2}} \quad\left[1-\frac{\alpha_{1}}{1+\omega^{2} \tau_{1}^{2}}-\frac{\alpha_{2}}{1+\omega^{2} \tau_{2}^{2}}\right]
$$

Such a normalization is helpful since the absolute magnitude of $G_{M}(\omega)$ (and $C_{M}(\omega)$ ) varies considerably from membrane to membrane; normalization also allows for easier comparisons between different membranes.

The capacitance is normalized as follows:

Let

$$
\frac{C_{k}(\omega)}{C_{k}(0)}=\frac{C_{M}(\omega)-C_{M}^{(\infty)}}{C_{M}(0)-C_{M}^{(\infty)}}
$$

Substituting for $C_{M}(\omega)-C_{M}(\infty)$ from Equations $85-86$ and for $C_{M}(0)-C_{M}(\infty)$ from Eq-87 yields:

$$
\frac{C_{k}(\omega)}{C_{k}(0)}=\frac{\frac{\alpha_{1} \tau_{1}}{1+\omega^{2} \tau_{1}^{2}}+\frac{\alpha_{2} \tau_{2}}{1+\omega^{2} \tau_{2}^{2}}}{\alpha_{1} \tau_{1}+\alpha_{2} \tau_{2}}
$$


In order to utilize Equations 89 and $91, G_{M}(0)$ and $C_{K}(0)$ must be determined for each membrane data run. The normalization was performed by the REDU 2 computer program with the normalized data output placed on a paper punch tape formatted for acceptance by the Digital $11 / 20$ computer containing the curve-fitting programs. The sample printout of REDU 1 in Appendix A illustrates the relative independence of $G_{M}(w)$ and $C_{K}(w)$ at low frequencies. Therefore, the conductance was normalized according to $G_{M}(\omega) / G_{M}(0)$ with $G_{M}(0)$ determined by an average of the three lowest frequency independent values of $\mathrm{G}_{M}(\omega)$. Capacitance was normalized according to Eq-90, with $G_{M}(0)$ also obtained from an average of the three lowest frequency values of $C_{M}(\omega)$ while $C_{M}(\omega)$ was assumed to be equivalent to the capacitance of an undoped (no valinomycin present) membrane. This undoped membrane capacitance was determined for control membranes and used in conjunction with the measured membrane area to determine $C_{M}(\infty)$ for each data run.

The normalized $G_{M}(\omega)$ and $G_{M}(\omega)$ values can now be used in curve fitting to either Eq-89 or Eq-91. Utilizing Eq-89 produces $\alpha_{1}, \alpha_{2}, \tau_{1}$ and $\tau_{2}$ which in turn are used in Equations $78-82$ to generate the rate constants. Eq- 89 has a slight disadvantage in that since $\alpha_{1}+\alpha_{2} \approx 1$ in our data the factor $1 /\left(1-\alpha_{1}-\alpha_{2}\right)$ is very sensitive to small variations in the $\alpha$ s. Eq-91, however, does not contain this sensitive term. In addition, whereas Eq-89 requires four curve-fitting parameters, Eq-91 can be $f$ it using only three parameters $\left(\alpha_{1} / \alpha_{2}, \tau_{1}\right.$ and $\left.\tau_{2}\right)$ as follows: 


$$
\begin{aligned}
& \frac{\mathrm{c}_{\mathrm{k}}(\omega)}{\mathrm{C}_{\mathrm{k}}(0)}=\frac{1 / \alpha_{1} \alpha_{2}}{1 / \alpha_{1} \alpha_{2}}\left[\frac{\frac{\alpha_{1} \tau_{1}}{1+\omega^{2} \tau_{1}^{2}}+\frac{\alpha_{2} \tau_{2}}{1+\omega^{2} \tau_{2}^{2}}}{\alpha_{1} \tau_{1}+\alpha_{2} \tau_{2}}\right] \\
& \frac{\mathrm{C}_{\mathrm{k}}(\omega)}{\mathrm{C}_{\mathrm{k}}(0)}=\frac{\alpha_{1}}{\alpha_{1}}\left[\frac{\frac{1}{\alpha_{2}}\left(\frac{\tau_{1}}{1+\omega^{2} \tau_{1}^{2}}\right)+\frac{1}{\alpha_{1}}\left(\frac{\tau_{2}}{1+\omega^{2} \tau_{2}^{2}}\right)}{\frac{\tau_{1}}{\alpha_{2}}+\frac{\tau_{2}}{\alpha_{1}}}\right] \\
& \frac{\mathrm{c}_{\mathrm{k}}(\omega)}{\mathrm{C}_{\mathrm{k}}(0)}=\frac{\frac{\alpha_{1}}{\alpha_{2}}}{\left(\frac{\tau_{1}}{1+\omega^{2} \tau_{1}^{2}}\right)+\frac{\tau_{2}}{1+\omega^{2} \tau_{2}^{2}}}
\end{aligned}
$$

Both approaches have been utilized in this research with the TOTAL program fitting to conductance data (Eq-89) and the TOECAP program fitting to capacitance data (Eq-91), see Figure 15. Both programs incorporated a method of steepest descent to roughly fit the region of interest, then a Taylor expansion where one term is the gradient and the best possible fit is obtained [10]. Since the capacitance method doesn't yield discrete $\alpha$ 's, only data obtained from curvefitting to conductance values is presented here. 


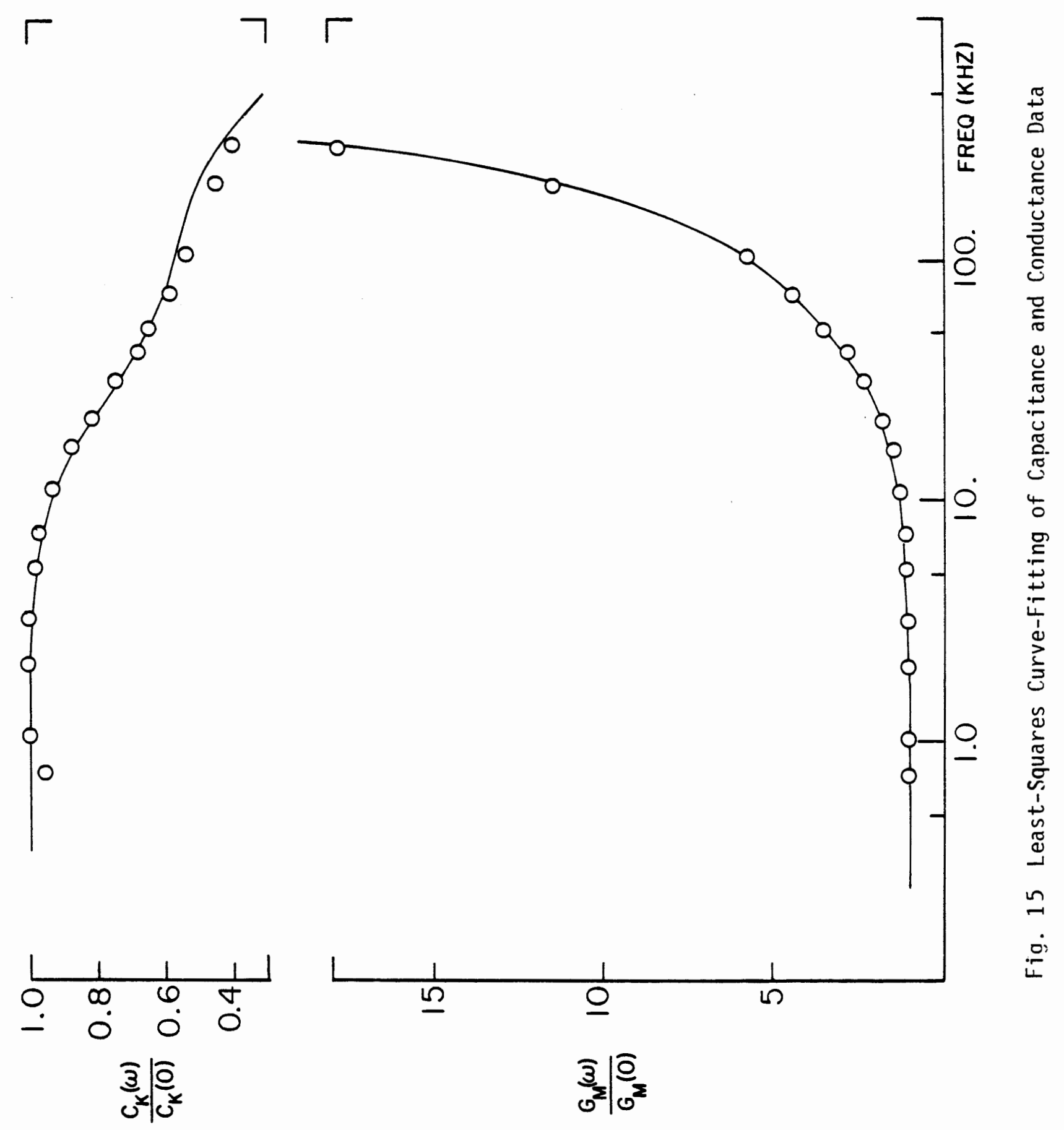


$\underline{\text { PDA } 1}$

The basic function of this program is to take the $\alpha^{\prime} s$ and $T^{\prime} s$ obtained from the curve-fitting procedure (TOTAL) and generate a set of kinetic parameters from inverting forms of Equations $71-75$. In addition, the program also generated the $G_{M}(\omega)$ and $G_{M}(\omega)$ values corresponding to the input $\alpha^{\prime} s$ and $\tau^{\prime} s$. These values were then normalized and compared with the original data values (from the REDU 1 computer program). This comparison provided an opportunity to check the performance of the curve-fitting program (TOTAL). The good agreement between both the original and regenerated conductance and capacitance values (see Figure 16, Table 4) indicates that TOTAL is producing $\alpha^{\prime}$ s and $\tau^{\prime}$ s which faithfully reflect the experimental data.

The regenerated conductance and capacitance values where also checked for their sensitivity to variations in the $\alpha^{\prime} s$ or $\tau^{\prime} s$ in order to study whether various kinetic parameters might be insensitive to one of the $\alpha^{\prime} s$ or $\tau^{\prime} s$. 


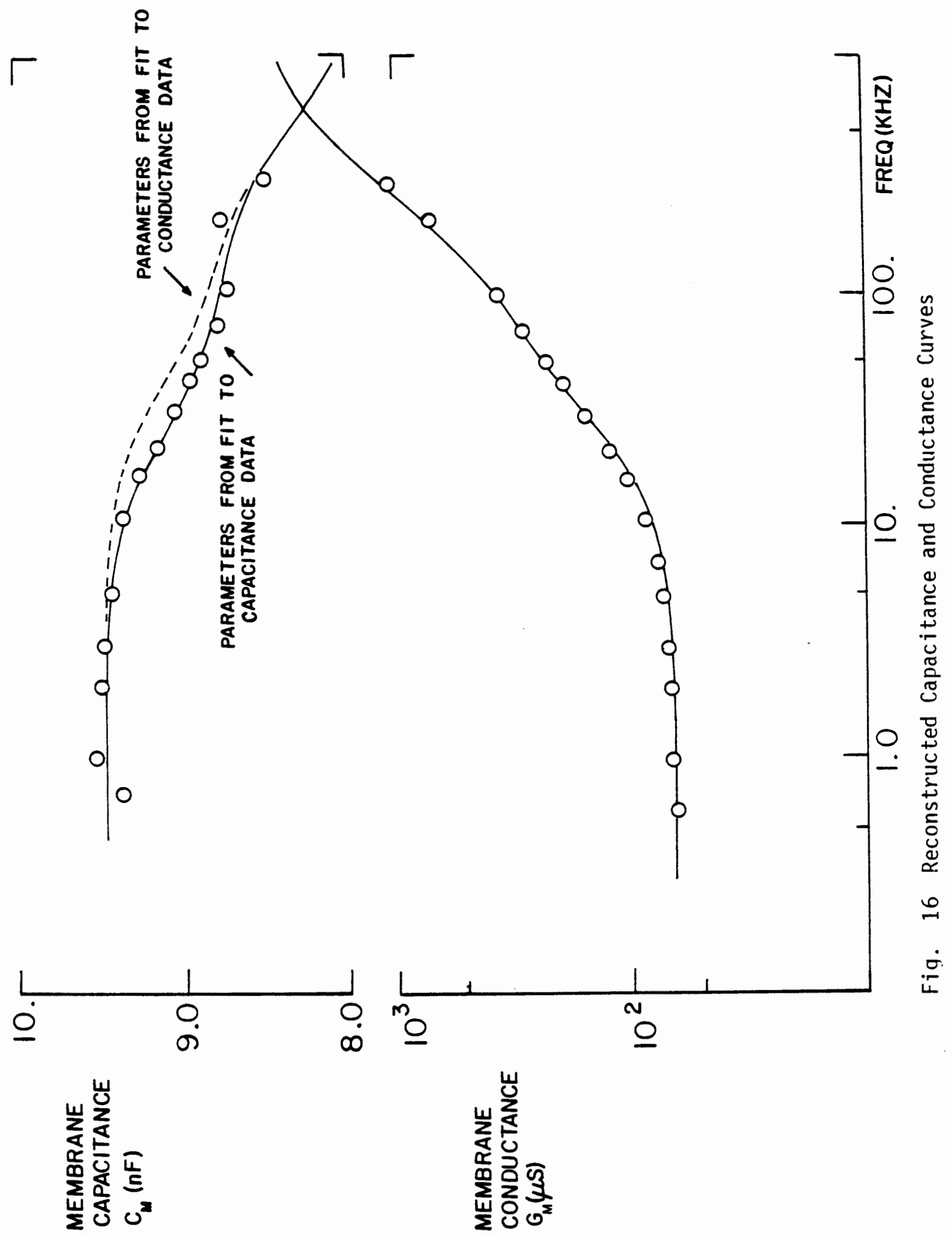


Table 4 - Comparison of Experimental and Regenerated Values of Conductance and Capacitance

(see test for details)

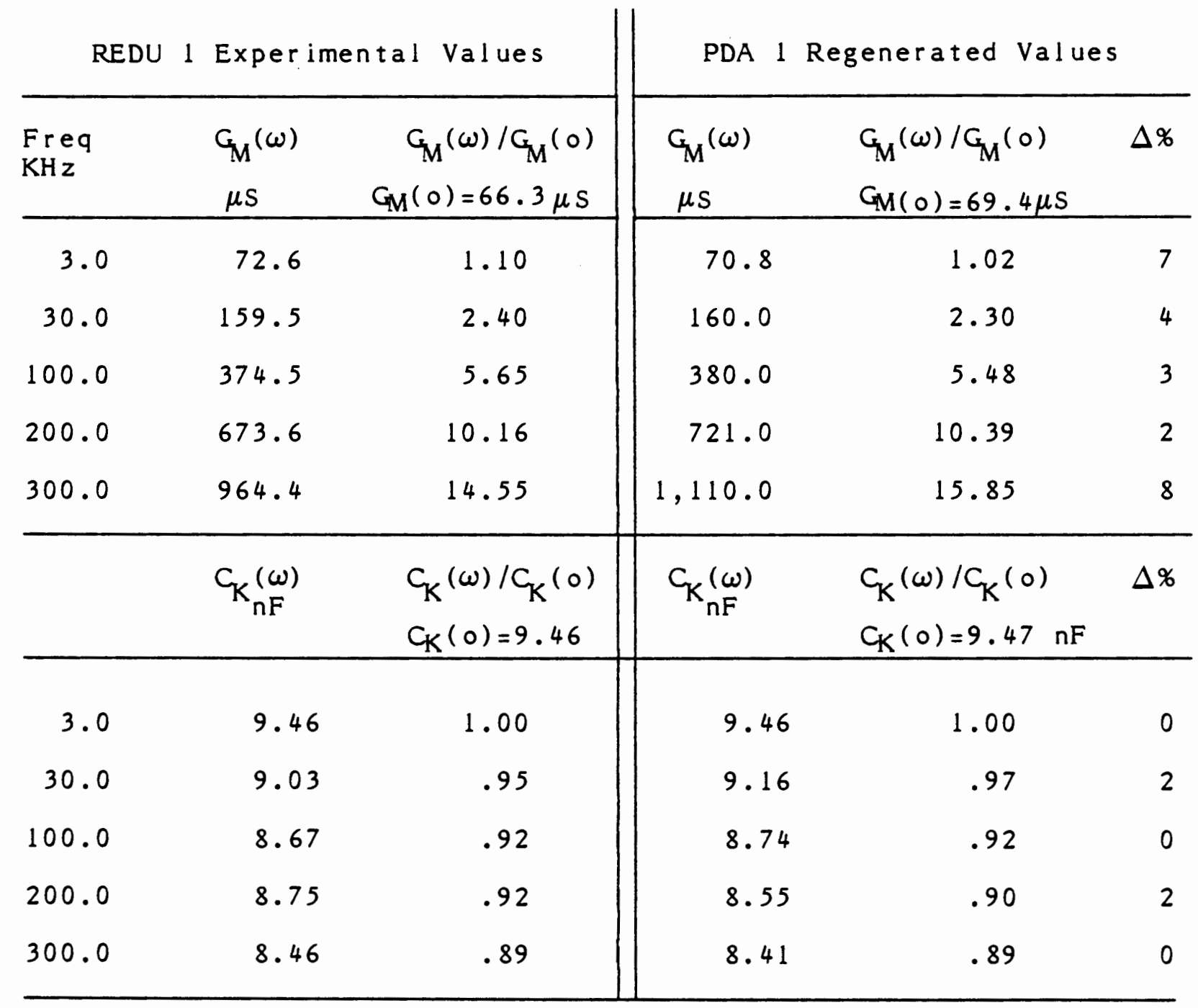

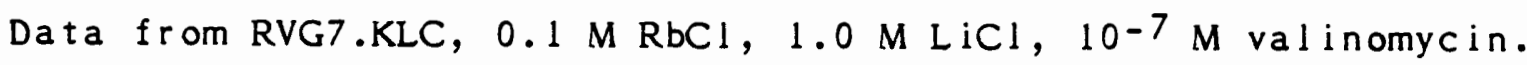


Table 5 lists for a typical case the calculated kinetic parameters determined after $10 \%$ increases or reductions in either $\alpha_{1}$, $\alpha_{2}, \tau_{1}$, or $\tau_{2}$ individually. The kinetic rate constants are sensitive to changes in all of these parameters so that none of them may be disregarded. Although these individual perturbations account for some of the differences between ac and relaxation derived rate constants, $10 \%$ variations are insufficient to fully reconcile the two sets of value (complete comparisons are presented in the Results and Discussion section).

Table 5 - An Example of the Effect on Rate Constants Due to Variations in $\alpha$ or $\tau$

\begin{tabular}{l|r|r|r|r|r|r}
\hline \multirow{2}{*}{$\begin{array}{c}\text { Rate } \\
\text { Constants }\end{array}$} & \multicolumn{5}{|c|}{ A.C. Experimental Values } & $\begin{array}{c}\text { Relaxation } \\
\text { Values }\end{array}$ \\
\cline { 2 - 6 } & \multicolumn{1}{|c|}{ I } & II & III & IV & V & VI \\
\hline $\mathrm{k}_{\mathrm{R}}\left(10^{4} \mathrm{M}^{-1}-\mathrm{S}^{-1}\right)$ & 20.4 & 9.7 & 18.0 & 20.4 & 18.6 & 37.0 \\
$\mathrm{k}_{\mathrm{D}}\left(10^{4} \mathrm{~S}^{-1}\right)$ & 11.2 & 25.9 & 11.5 & 10.0 & 11.5 & 24.0 \\
$\mathrm{k}_{\mathrm{MS}}\left(10^{4} \mathrm{~S}-1\right)$ & 83.6 & 76.3 & 83.6 & 76.1 & 83.6 & 27.0 \\
$\mathrm{k}_{\mathrm{S}}\left(10^{4} \mathrm{~S}^{-1}\right)$ & 0.7 & 6.1 & 1.9 & 0.7 & 0.6 & 3.5 \\
$\mathrm{~V}_{\mathrm{S}} 10^{3}$ & 5.0 & 1.3 & 2.1 & 4.9 & 5.6 & 5.3 \\
\hline
\end{tabular}

Column Explanations:

I initial calculated $\alpha$ 's and $\tau$ 's for $1.0 \mathrm{M} \mathrm{RbCl}, 10-7 \mathrm{M}$ valinomycin; $\alpha_{1}=0.9210, \alpha_{2}=0.0747, \tau_{1}=0.5556$, and $\tau_{2}=4.907$

I I decreased $\alpha_{1}$ by $10 \%$, to 0.8389

II decreased $\alpha_{2}$ by $10 \%$, to 0.0673

IV increased $\tau_{1}$ by $10 \%$, to 0.6112

$V$ increased $\tau_{2}$ by $10 \%$, to 5.398

VI rate constants obtained from [7, Table 2] 
$\underline{A D P \quad 1}$

Rate parameters $k_{R}, k_{D}, k_{S}, k_{M S}$ and $\gamma_{S}$ were obtained from charge-pulse experimental results [7] and used in Equations 71-75 to produce the corresponding $\alpha^{\prime} s, \tau \tau^{\prime} s, G_{M}(\omega)$ and $G_{M}(\omega)$. These $\alpha^{\prime} s$ and $\tau$ 's can be compared directly with the $\alpha^{\prime} s$ and $\tau^{\prime} s$ produced by the conductance curve-fitting procedure. The $G_{M}(\omega)$ and $C_{M}(\omega)$ values were used to construct the relaxation loss tangent curves which are presented in the RESULTS section.

$\underline{A D P \quad 2}$

This computer program performs the same functions as ADP 1 but differs in that the membrane model consists of three dielectric regions instead of only one. Although there is not a closed mathematical form available to represent this model, numerical evaluation methods are possible and used by ADP 2 to produce the $G_{M}(\omega)$ and $G_{M}(\omega)$ values for comparison (see RESULTS Three Capacitor Model and Appendix B for further details). 


\section{RESULTS \& DISCUSSION}

\section{Control Membrane Data}

Two types of conductance control experiments were performed. Type I used pure GMO/decane membranes with ion containing aqueous solutions but no added carrier, while Type Il experiments also included the carrier valinomycin.

\section{Type I Conductance Controls}

These membranes were used to verify whether background conductivity was indeed negligible. Both $1.0 \mathrm{M} \mathrm{KCl}$ and $1.0 \mathrm{M} \mathrm{RbCl}$ aqueous ionic solutions were investigated. $G_{M}(\omega)$ values were calculated for several low frequencies and averaged to yield $G_{M}(0)$ (as described in the previous section). The results are listed in Table 6 .

Table 6 - Low Frequency Conductance in the Absence of Valinomycin

$n$ number of membranes

\begin{tabular}{|c|c|c|}
\hline Ionic Solution & $G_{M}(0)\left(10^{-5} S-\mathrm{cm}^{-2}\right)$ & $n$ \\
\hline $\mathrm{KCl} 1.0 \mathrm{M}$ & $0.85 \pm .36$ & 6 \\
$\mathrm{RbCl} 1.0 \mathrm{M}$ & $1.37 \pm .42$ & 3 \\
\hline
\end{tabular}

Note: All listed numerical errors are for one standard deviation. All graph error bars signify \pm one standard deviations unless otherwise indicated. 
As these conductances are two to three orders of magnitude less than the corresponding carrier-mediated transport, this background conductance was ignored in all subsequent calculations.

\section{Type II Conductance Controls}

These membranes were used for periodic checks of valinomycin quality and for comparison with conductance values reported in the literature. $G_{M}(0)$ values for both dc and low-frequency ac membranes for various concentrations of metal ions were obtained (see Table 7). The dc measurements were repeated periodically to insure that variations in the measured conductance and calculated rate constants were not due to valinomycin degradation during storage. Although not exact, Table 7 does illustrate reasonable agreement of the conductance values and no valinomycin degradation was observed.

\section{Capacitance Controls}

Type I conductance control membranes were also used for comparisons of $C_{M}$ values. Control ac membrane $C_{M}$ values were obtained and are listed in Table 8. 
Table 7 - Comparison of Conductance Values for $\mathrm{OD} / \mathrm{n}$-decane BLM with $10^{-7} \mathrm{M}$ Valinamycin in Aqueous Solution

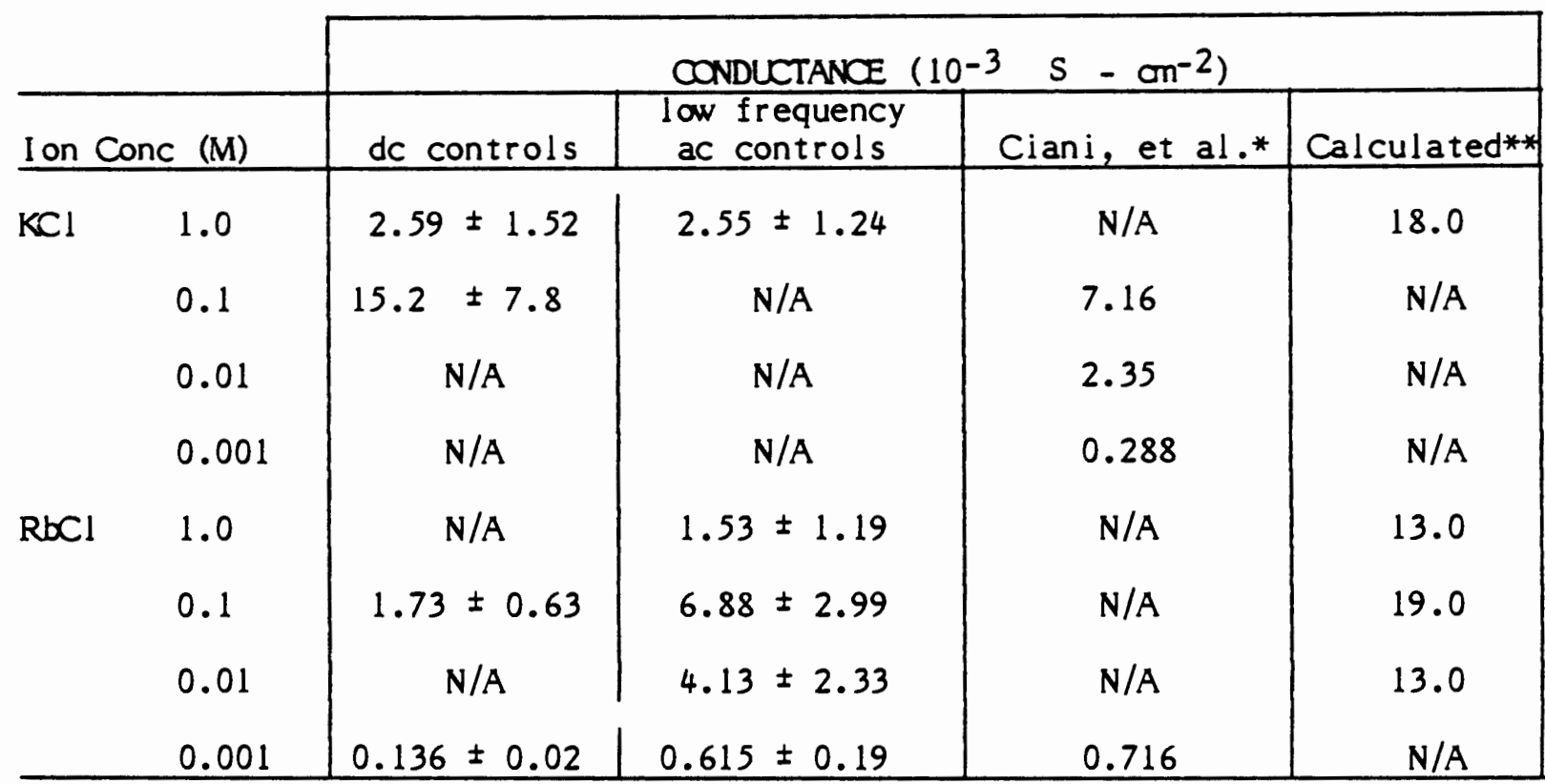

*Data from [14, Figures 2 and 4]

* Calculated values us ing Eq-69 and rate constants from [7, Table 2]

Table 8 - Comparison of Capacitance Values for $\mathrm{MD} / \mathrm{n}$-decane BLM's wi th Various Aqueous Ionic Solutions

\begin{tabular}{|r|l|l|}
\hline Conc Ion & $\mathrm{C}_{\mathrm{M}}{ }^{\mathrm{nF}} / \mathrm{C}_{\mathrm{M}}^{2}$ & Reference \\
\hline $1.0 \mathrm{M} \mathrm{KCl}$ & $433 \pm 33$ & \\
$\mathrm{RbCl}$ & $453 \pm 51$ & \\
$\mathrm{NaCl}$ & $380 \pm 11$ & {$[11]$} \\
$0.1 \mathrm{M} \mathrm{KCl}$ & $390 \pm 18$ & {$[5]$} \\
$\mathrm{RbCl}$ & $383 \pm 8$ & {$[19]$} \\
$\mathrm{NaCl}$ & $364 \pm 8$ & {$[11]$} \\
\hline
\end{tabular}

Note: All solutions of $0.1 \mathrm{M}$ were corrected to a total ionic strength of $1.0 \mathrm{M}$. 
A question which inevitably arises is whether $C_{M}$ varies with different ions or ionic concentrations. Benz and Janko [6] have determined that there is no significant difference in the $\mathrm{G}_{M}$ for similar (same lipid/solvent) membranes, using either $0.01,0.1$ or 1.0 $\mathrm{M} \mathrm{NaCl}$, hence concentration variations of $\mathrm{C}_{\mathrm{M}}$ are negligible. Table 8 indicates that $\mathcal{G}_{M}$ varies 1 ittle, if at all, with the ion used.

Although our values appear to be higher than those reported in the literature, the difference can be accounted for by the fact that our membrane areas were not corrected for bulging due to hydrostatic pressure differences across the membrane. This pressure gradient is created when the brush is placed in one side of the aqueous container during membrane formation. The membrane is easily distensible and will bulge into the solution with the lower liquid level. Subsequent investigations by Bill Brown of our group, using a modified ac apparatus, have noted a less than $6 \%$ decrease in $C_{M}$ when the membrane is flattened by adding extra fluid to the aqueous solution on the bulging side of the membrane and monitoring $G_{M}$ until a minimum value is obtained. A similar degree of bulging in this experiment could account for a majority of the difference in the $G_{M}$ values, while the remainder may be attributable to area measurement errors. The area measurement itself contains intrinsic observational errors which are greater than normal in comparison with usual instrumentation errors. The error is larger since the entire torus is not usually visible, which leads to errors in diameter determination. In an effort to minimize this error, 
the membrane diameter was measured several times and an average value used for area calculations. The bulging was assumed to be constant throughout the experiments (similar membrane formation technique, same volume of aqueous solution, etc.) and a bulging correction factor of $433 / 390=1.11$ was applied to all membrane areas employed in data reduction for comparison with literature values. It should be noted that the only final parameter determinations affected by the values of membrane area are $\gamma_{S}$ and $\mathrm{N}_{\text {MS }}$ (see Equations 28, 77, 82) although some of the variation of conductance controls 1 isted in Table 7 may also be explained by membrane area errors.

\section{Kinetic Parameters}

Table 9 lists the ac relaxation times and amplitudes as calculated by the curve fitting procedure discussed in the Data Analysis section. The error ranges reflect membrane population variation rather than systematic errors. Data analysis was performed only on the second or subsequent runs on any given membrane. The first run was disregarded to better insure that the membrane was stable and any membrane which did not survive more than one automated run was discarded from the data pool. Also listed for comparison are corresponding $\alpha_{1}^{\prime}$ s and $\tau^{\prime}$ s derived from relaxation experimental data (charge-pulse rate constants given by Benz and Lauger [7] were used in Equations $71-75$ ).

Table 10 gives the rate constants and the partition coefficient which corresponds to the kinetic parameters in Table 9 
(Equations $78-81$ are used to generate the rate constants from the relaxation times and amplitudes). The error range for the chargepulse rate constants [7, Table 2] have also been included. 
Table 9 - A.C. Relaxation Times and Amplitudes

$$
\begin{array}{llll}
\tau_{1}(\mu \mathrm{sec}) & \tau_{2}(\mu \mathrm{sec}) & \alpha_{1}
\end{array}
$$

n

$\underline{1.0 \mathrm{M} \mathrm{KCl}}$

$\begin{array}{lccccc}\text { from A.C. } & 1.50 \pm 0.27 & 7.55 \pm 1.33 & 0.768 \pm 0.072 & 0.172 \pm 0.005 & 4 \\ \begin{array}{l}\text { experiment } \\ \text { derived from }\end{array} & 1.18 & 4.89 & 0.370 & 0.512 & 9 \\ \begin{array}{l}\text { Relaxation } \\ \text { experiment* }\end{array} & & & & & \end{array}$

$1.0 \mathrm{M} \mathrm{RbCl}$

A.C. $\quad 0.63 \pm 0.10 \quad 4.86 \pm 0.27 \quad 0.882 \pm 0.049 \quad 0.111 \pm 0.045 \quad 4$

Relaxation

1.05

3.75

0.424

0.510

7

$\underline{0.1 \mathrm{M} \mathrm{RbCl}}$

$\begin{array}{lllllll}\text { A.C. } & 0.40 \pm 0.15 & 3.72 \pm 0.74 & 0.884 \pm 0.055 & 0.084 \pm 0.040 & 8\end{array}$

Relaxation

0.86

5.05

0.551

0.300

8

$\underline{0.01 \mathrm{M} \mathrm{RbCl}}$
A.C.
$0.29 \pm 0.19$
$2.59 \pm 1.36$
$0.925 \pm 0.51$
$0.056 \pm 0.041$
8
Relaxation
1.09
5.23
0.608
0.117
7

*calculated from ([25], Equations 5-9), using kinetic parameters given in [7].

$\mathrm{n} \equiv$ number of membranes investigated. 
Table 10 - Kinetic Parameters Corresponding to Table 9

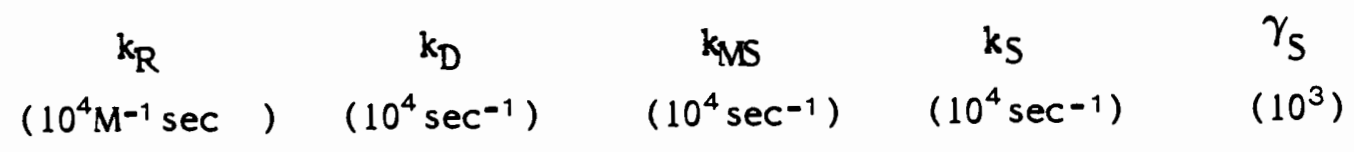

$1.0 \mathrm{M} \mathrm{KCl}$

A.C. $\quad 10.9 \pm 2.4 \quad 10.4 \pm 2.1 \quad 28.2 \pm 7.5 \quad 2.6 \pm 0.5 \quad 2.1 \pm 0.8$

$\begin{array}{lllllll}\text { Relaxation } & 29 \pm 4 & 27 \pm 6 & 21 \pm 4 & 3.8 \pm 0.8 & 7.5\end{array}$

$1.0 \mathrm{M} \mathrm{RbCl}$

A.C. $\quad 21.2 \pm 1.0 \quad 13.6 \pm 2.7 \quad 73.8 \pm 13.7 \quad 0.8 \pm 0.1 \quad 3.7 \pm 1.8$

Relaxation

$37 \pm 12$

$24 \pm 6$

$27 \pm 3$

$3.5 \pm 0.4$

5.3

$0.1 \mathrm{M} \mathrm{RbCl}$

$\begin{array}{lrrrrr}\text { A.C. } & 224 \pm 85 & 24.6 \pm 5.7 & 134 \pm 60 & 4.3 \pm 1.0 & 2.6 \pm 1.2 \\ \text { Relaxation } & 190 \pm 40^{*} & 38 \pm 15 & 35 \pm 13 & 4.5 \pm 1.0 * & 8.1\end{array}$

$0.01 \mathrm{M} \mathrm{RbCl}$

A.C. $\quad 4550 \pm 3910 \quad 19.4 \pm 7.2 \quad 207 \pm 84 \quad 6.8 \pm 2.3 \quad 1.3 \pm 1.1$

$\begin{array}{llllll}\text { Relaxation } & 630 \pm 300 & 31 \pm 3 & 29 \pm 5 & 7.8 \pm 0.5 & 8.6\end{array}$

*All pairs of ac and relaxation means differ significantly $(\zeta>.05)$ except for $0.1 \mathrm{M} \mathrm{RbCl}\left(\mathrm{k}_{\mathrm{R}}\right.$ and $\left.\mathrm{k}_{\mathrm{S}}\right)$ as indicated. 
Although the ac data error bars reflect scatter among the membranes, there is also the possibility of systematic errors in the determination of the solution resistance $\left(R_{S}\right)$. As outlined under Data Analysis, the standard procedure actually produces three values for $R_{S}$ from which only one value was selected to be used in the subsequent data reduction. The three values of $R_{S}$ usually varied from the mean by $1-3 \%( \pm 0.5-1.5 \Omega)$ for a particular membrane data run. However, for a given ionic concentration the overall agreement of $R_{S}$ between different membranes is quite good. Table 11 lists the overall variation of the chosen $R_{S}$ values for all membranes in a particular aqueous solution. Table 11 also shows (at least for $1.0 \mathrm{M} \mathrm{RbCl}$ or $\mathrm{KCl}$ ) that $\mathrm{R}_{\mathrm{S}}$ does not clearly correlate with the concentration of valinomycin.

In order to determine the additional rate parameter error due to this uncertainty in $R_{S}$ a membrane data run was reanalyzed. The original $R_{S}$ value was varied by the pessimistic uncertainty of $\pm 1.5 \Omega$ and used to produce new sets of conductance values from which the rate constants are determined as before. Table 12 lists the results, while Table 13 shows the additional uncertainties $(\Delta \%)$ in the a.c. experimental kinetic parameters and rate constants. Although the parameters are all sensitive to variations in $R_{S}$ the differences are usually insufficient to fully reconcile these values with those derived from the relaxation experiments. 
Table 11 - Variation of Solution Resistance with Ionic Concentration

$n^{\prime} \equiv$ total number of membrane data runs

\begin{tabular}{|c|c|c|c|c|c|c|}
\hline \multirow{3}{*}{$\mathrm{KCl}$} & \multirow{3}{*}{$1.0 \mathrm{M}$} & & & & $\mathrm{R}_{\mathrm{S}}(\Omega)$ & \multirow{2}{*}{$\begin{array}{l}n^{\prime} \\
12\end{array}$} \\
\hline & & & & & $85.4 \pm 3.0$ & \\
\hline & & $\bar{c}$ & $10-7$ & val in & $82.6 \pm 1.6$ & 16 \\
\hline \multirow[t]{4}{*}{$\mathrm{RbCl}$} & $1.0 \mathrm{M}$ & & & & $84.9 \pm 0.7$ & 5 \\
\hline & & $\overline{\mathrm{C}}$ & $10-7$ & valin & $89.4 \pm 2.9$ & 14 \\
\hline & $0.1 \mathrm{M}$ & $\bar{C}$ & $10-7$ & val in & $115.6 \pm 1.2$ & 15 \\
\hline & $0.01 \mathrm{M}$ & $\bar{c}$ & $10-7$ & valin & $141.4 \pm 9.6$ & 23 \\
\hline
\end{tabular}

Table 12 - Variation in Rate Parameters due to Uncertainty in $R_{S}$ Data from $0.1 \mathrm{M} \mathrm{Rb}^{+} \overline{\mathrm{C}} 10^{-7} \mathrm{M}$ valinomycin membrane *From Tables 9 and 10

\begin{tabular}{|c|c|c|c|c|}
\hline \multirow{2}{*}{$\begin{array}{l}\text { Kinetic } \\
\text { Parameter }\end{array}$} & \multicolumn{3}{|c|}{ Solution Resistance $\left(R_{S}\right)$} & \multirow{2}{*}{$\begin{array}{c}\text { Relaxation } \\
\text { Values* } \\
\end{array}$} \\
\hline & $116.5 \Omega$ & $115 \Omega$ & $113.5 \Omega$ & \\
\hline$\alpha_{1}$ & .6364 & .8625 & .9225 & .551 \\
\hline$\alpha_{2}$ & .2718 & .1029 & .0577 & .300 \\
\hline$\tau_{1}(\mu \mathrm{s})$ & .4729 & .3237 & .2845 & .8613 \\
\hline$\tau_{2}(\mu s)$ & 3.533 & 3.531 & 3.581 & 5.047 \\
\hline$k_{R}\left(M^{-1}-s^{-1}\right.$ & $.289 \times 10^{7}$ & $.231 \times 10^{7}$ & $.214 \times 10^{7}$ & $.190 \times 10^{7}$ \\
\hline$k_{D} \quad\left(s^{-1}\right)$ & $.593 \times 10^{6}$ & $.465 \times 10^{6}$ & $.240 \times 10^{6}$ & $.380 \times 10^{6}$ \\
\hline$k_{M S}\left(s^{-1}\right)$ & $.711 \times 10^{6}$ & $.135 \times 10^{7}$ & $.163 \times 10^{7}$ & $.350 \times 10^{6}$ \\
\hline$k_{s}\left(s^{-1}\right)$ & $.463 \times 10^{5}$ & $.414 \times 10^{5}$ & $.404 \times 10^{5}$ & $.450 \times 10^{5}$ \\
\hline
\end{tabular}


Table 13 - Percent Variation in Rate Parameters due to Uncertainty in $R_{S}$ (determined from data in Table 12)

\begin{tabular}{|c|c|c|r|}
\hline Parameter & $\Delta \%$ & Rate Constant & $\Delta \%$ \\
\hline$\alpha_{1}$ & $+5 /-25$ & $k_{R}$ & $+25 /-5$ \\
$\alpha_{2}$ & $+150 /-50$ & $k_{D}$ & $+25 /-50$ \\
$\tau_{1}$ & $+50 /-10$ & $k_{\text {MS }}$ & $+20 /-50$ \\
$\tau_{2}$ & $+0 /-1$ & $k_{S}$ & $+10 /-2$ \\
\hline
\end{tabular}




\section{Loss Tangent Results and Discussion}

Due to the ambiguities in determining the membrane area, discussed above, an alternative data analysis was also carried out [36]. This involves comparing experimental curves of loss tangent vs. frequency to curves obtained on the basis of parameters from relaxation experiments. The loss tangent, LT, is defined by:

$$
L T \equiv G_{M} / \omega C_{M}
$$

With such a ratio of capacitance and conductance, the area factor in each value cancels and that source of error is removed. Figures 17 through 20 give the loss tangents as calculated from the normalized ac and relaxation data.

The $1.0 \mathrm{M} \mathrm{K}^{+}$and $\mathrm{Rb}^{+}$curves (Figures 17 and 18) from ac data faithfully reproduce the general shape of the relaxation curves, but there has been a general shift downward, indicating a relatively constant difference in the loss tangent magnitude throughout the entire frequency range.

The 0.1 and $0.01 \mathrm{M} \mathrm{Rb}^{+}$curves (Figures 19 and 20 ) exhibit the same curve shape duplication with a shift in magnitude at the lower frequencies. However, at higher frequencies there is a definite discrepancy. While the relaxation data curves continue to tail off downward, the ac curves plateau and begin to $r$ ise by $300 \mathrm{KHz}$. It should be noted that the $200 \mathrm{KHz}$ point of the ac data lies consistently above its anticipated position in both the $1.0 \mathrm{M} \mathrm{K}^{+}$and $1.0 \mathrm{M} \mathrm{Rb}^{+}$curves. This peculiarity is believed to be an artifact due to an electronic problem with the microprocessor un it. 


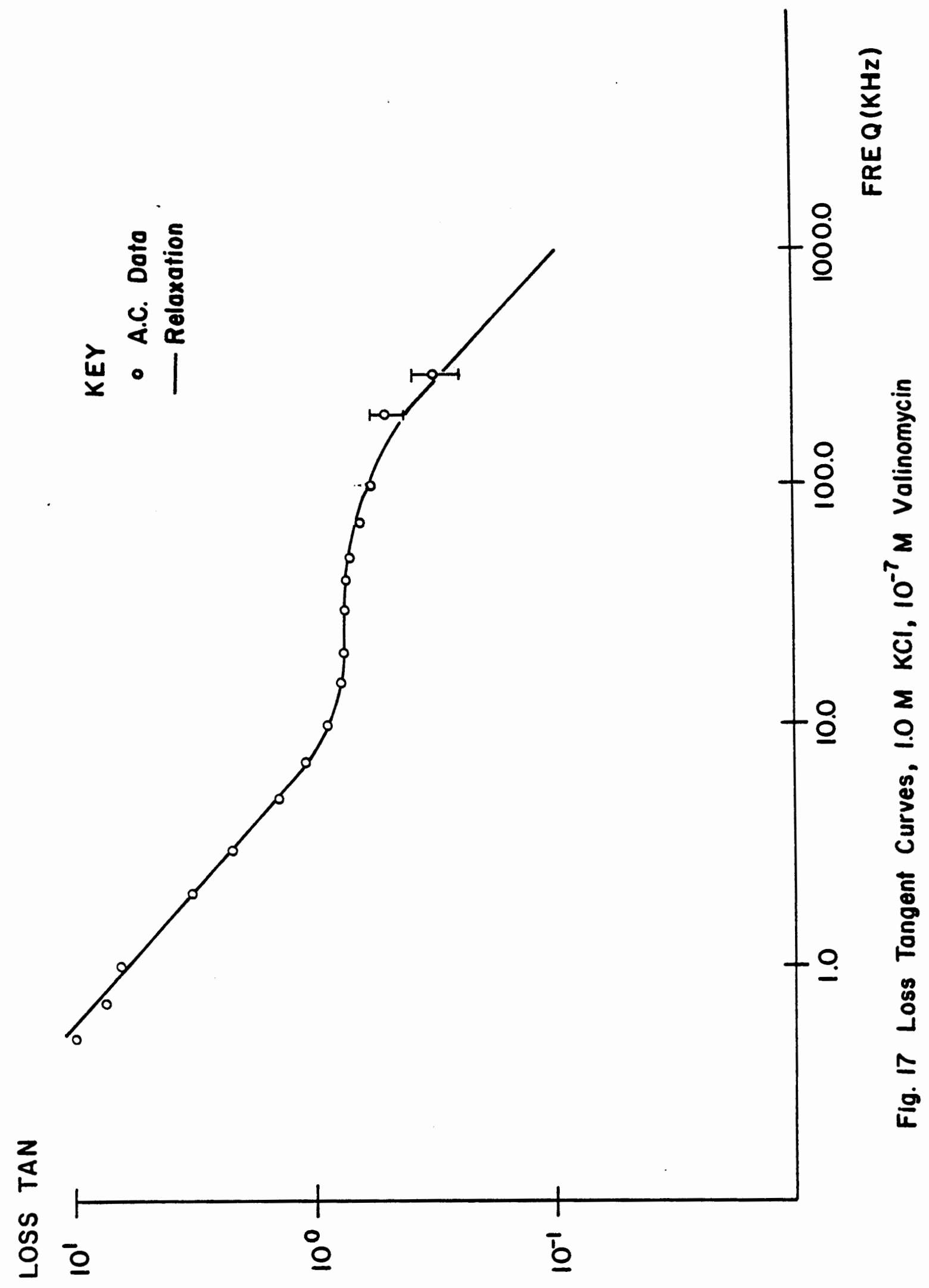




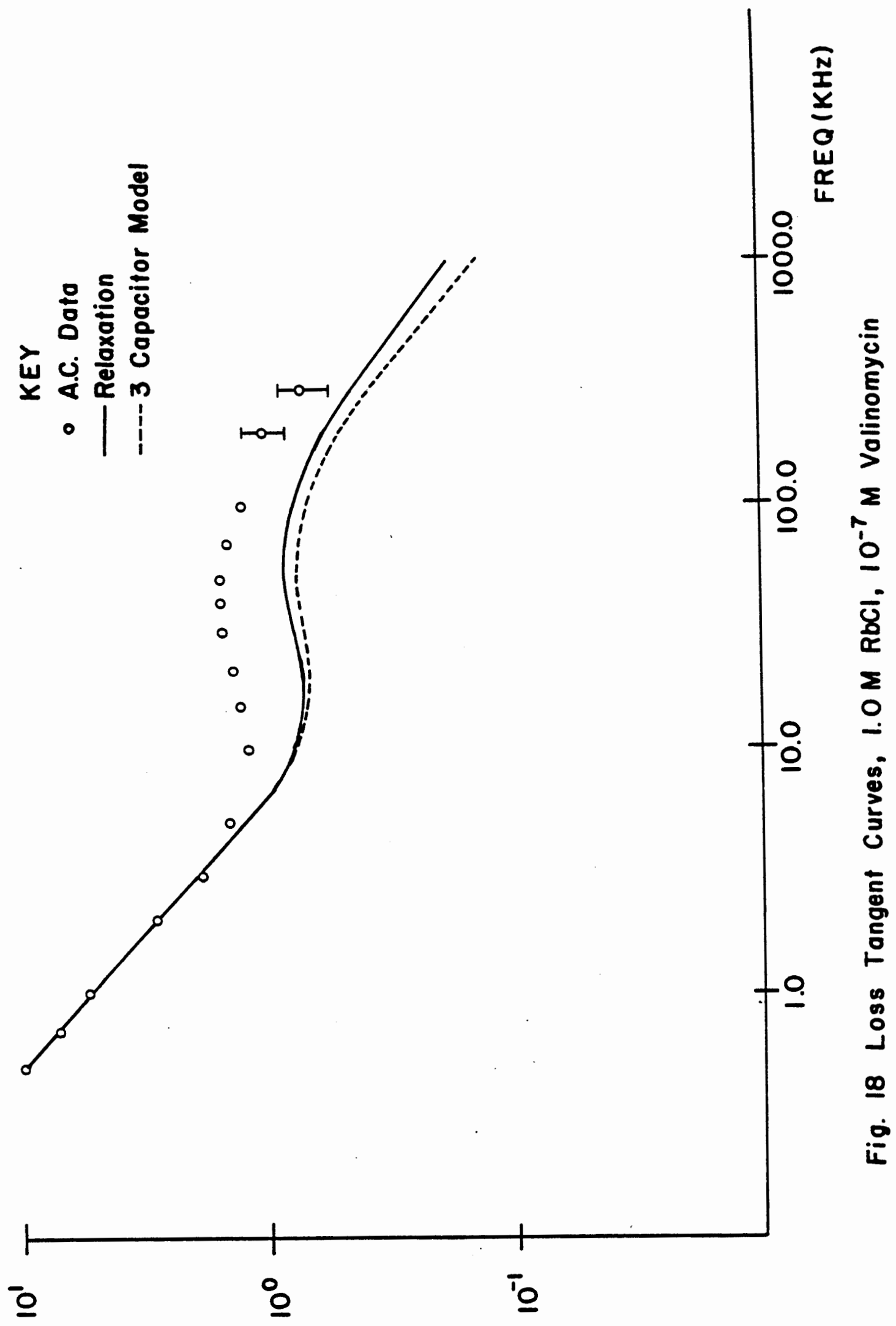




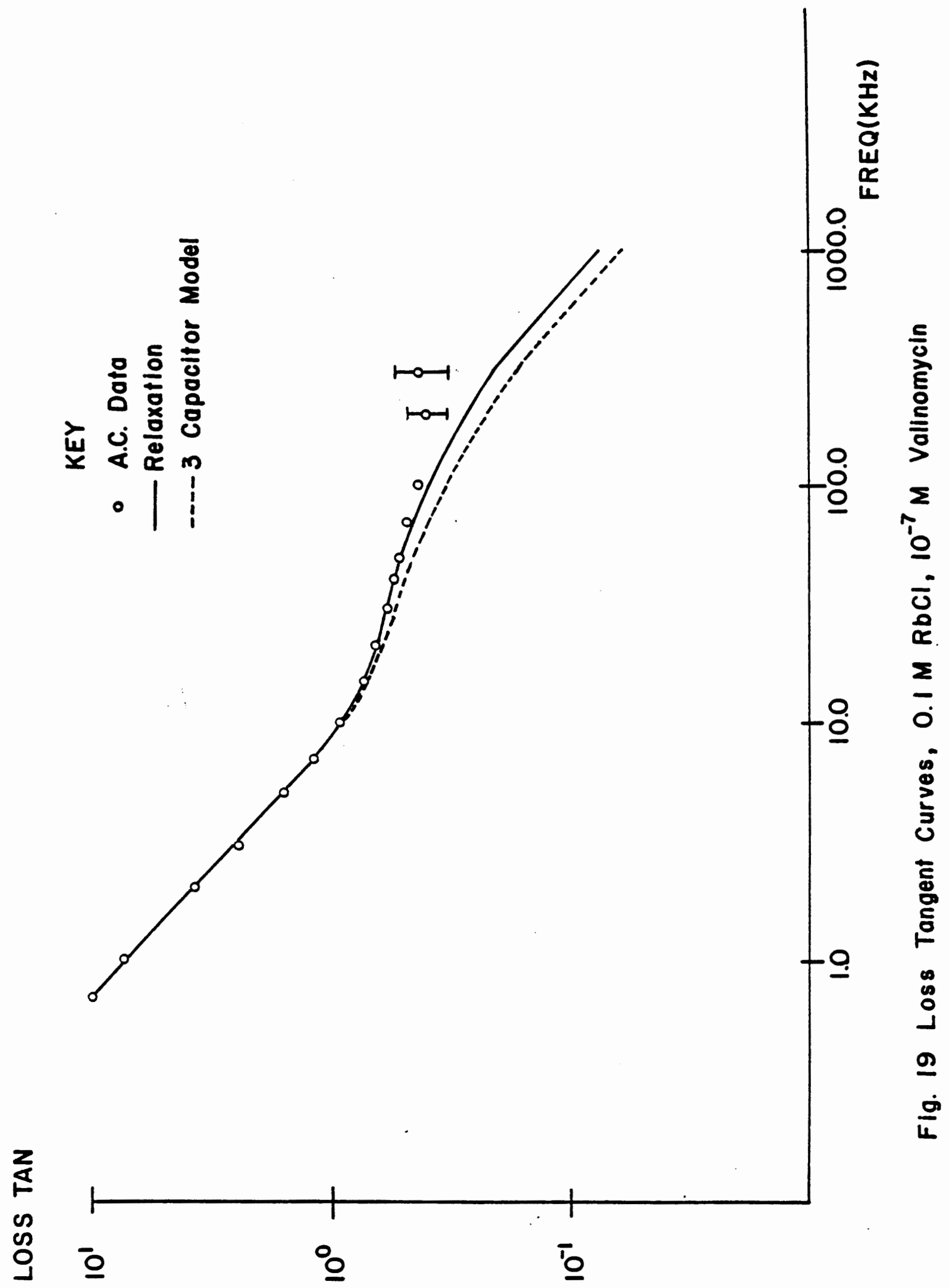




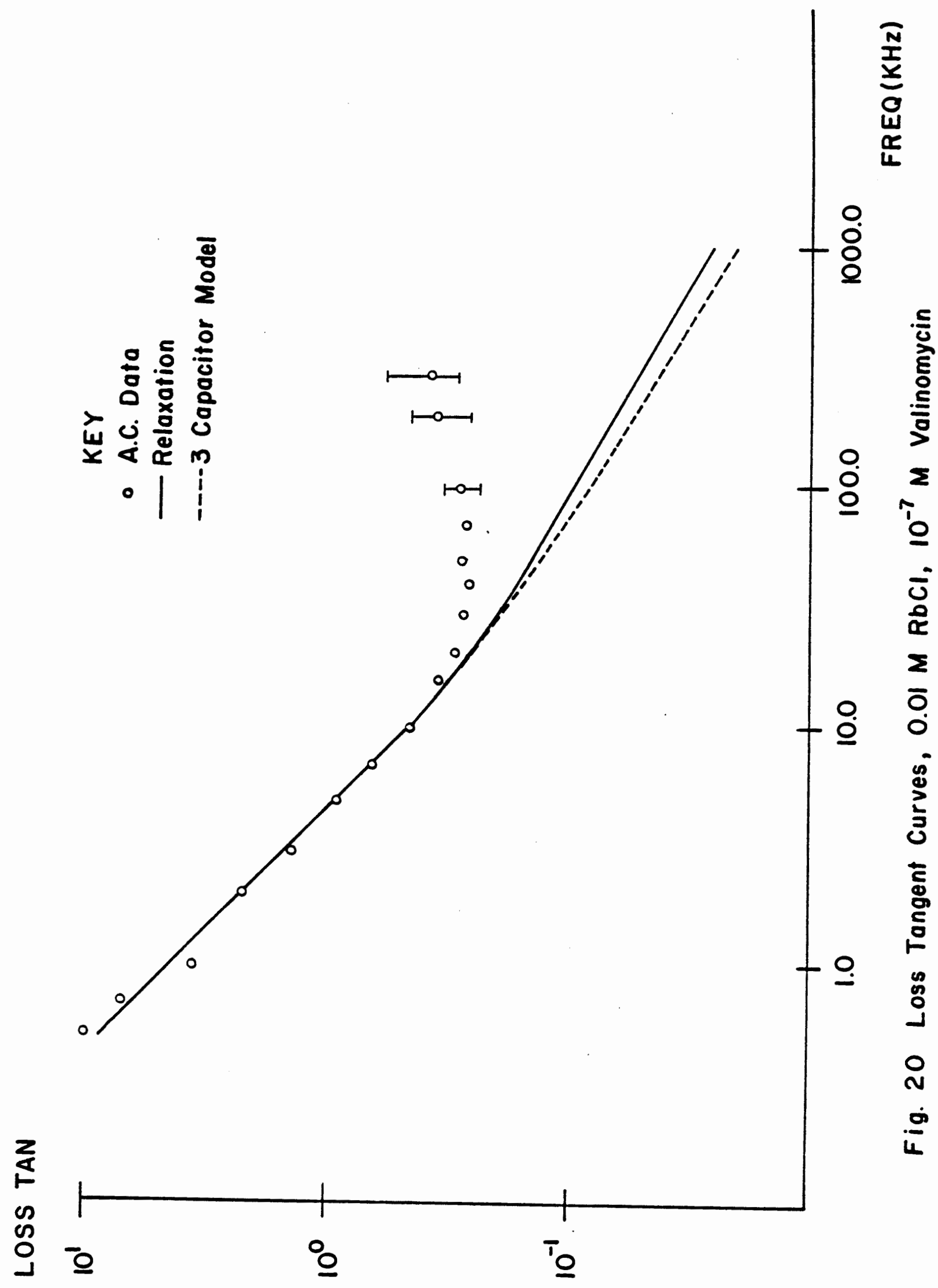


In an effort to understand the cause of the high frequency discrepancy between the loss tangent curves for 0.1 and $0.01 \mathrm{M} \mathrm{Rb}^{+}$ the relaxation curves were recalculated. Figures 21 through 24 give the results after individually varying each rate parameter to the extremes of its error range (as reported in [7]). Curves were also obtained for each parameter being a factor of ten greater than reported in [7]. Although these values are outside of the reported error ranges, it does place each rate constant closer to the ac values and would hopefully give an indication as to which constants would be most likely to account for the LT curve differences.

From the graphs in Figures 21 to 24 , the following observations can be made: the low frequency range of the loss tangent curve is sensitive to variations in $k_{D}, k_{S}$ and to a lesser degree $k_{R}$ while the high frequency range is predominantly affected by changes in $k_{R}$ and $k_{M S}$. Therefore, the discrepancy in the high frequency portion of the loss tangent curve is probably due to differences between $k_{R}$ and/or $k_{M S}$ between the two experiments.

\section{Three Capacitor Model}

The membrane model assumed by Läuger and which forms the basis for the analysis previously discussed in this thesis considers the membrane as if it were a single dielectric slab. However, a three slab-capacitor has been proposed as a more realistic model. This consists of two identical external regions 


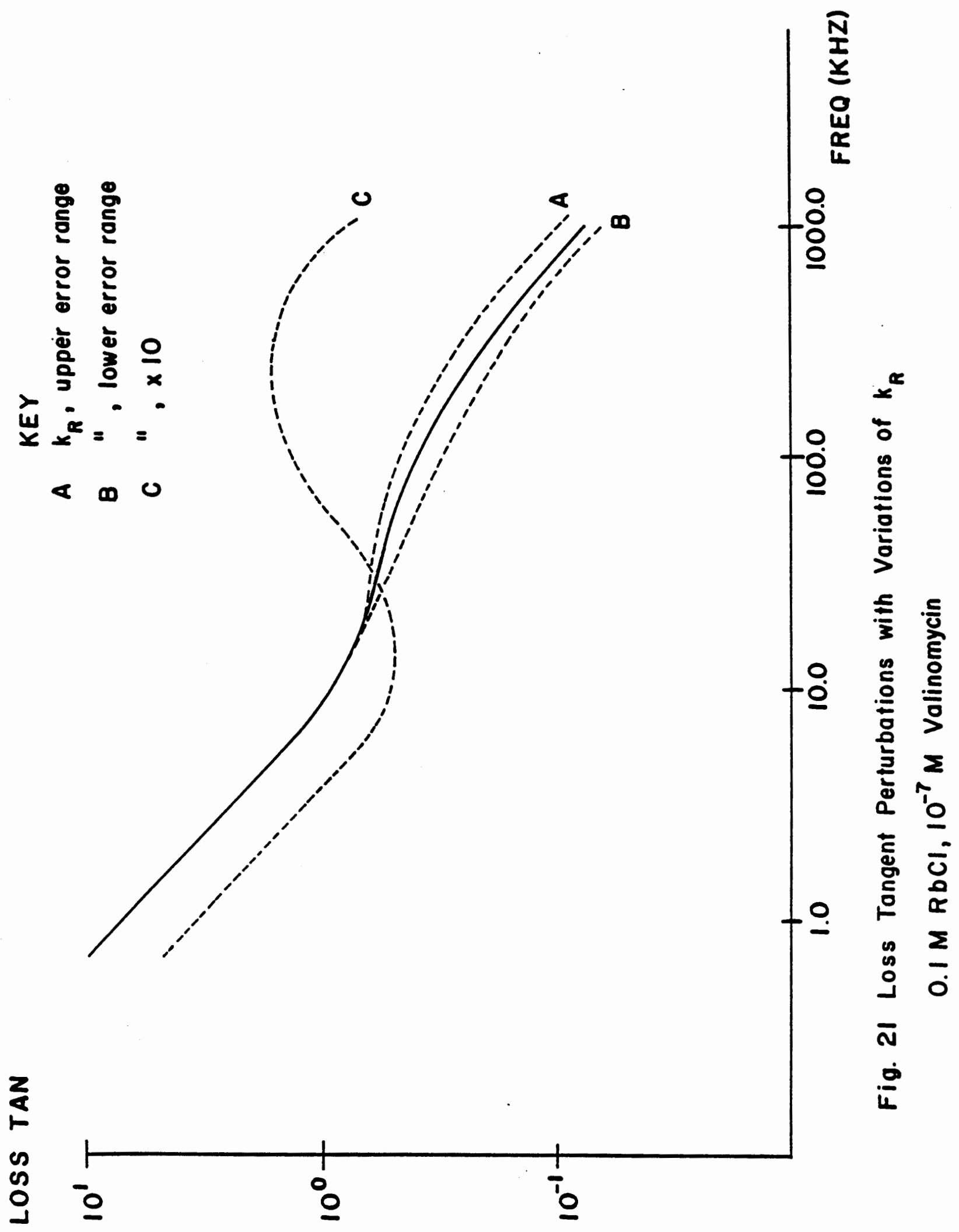




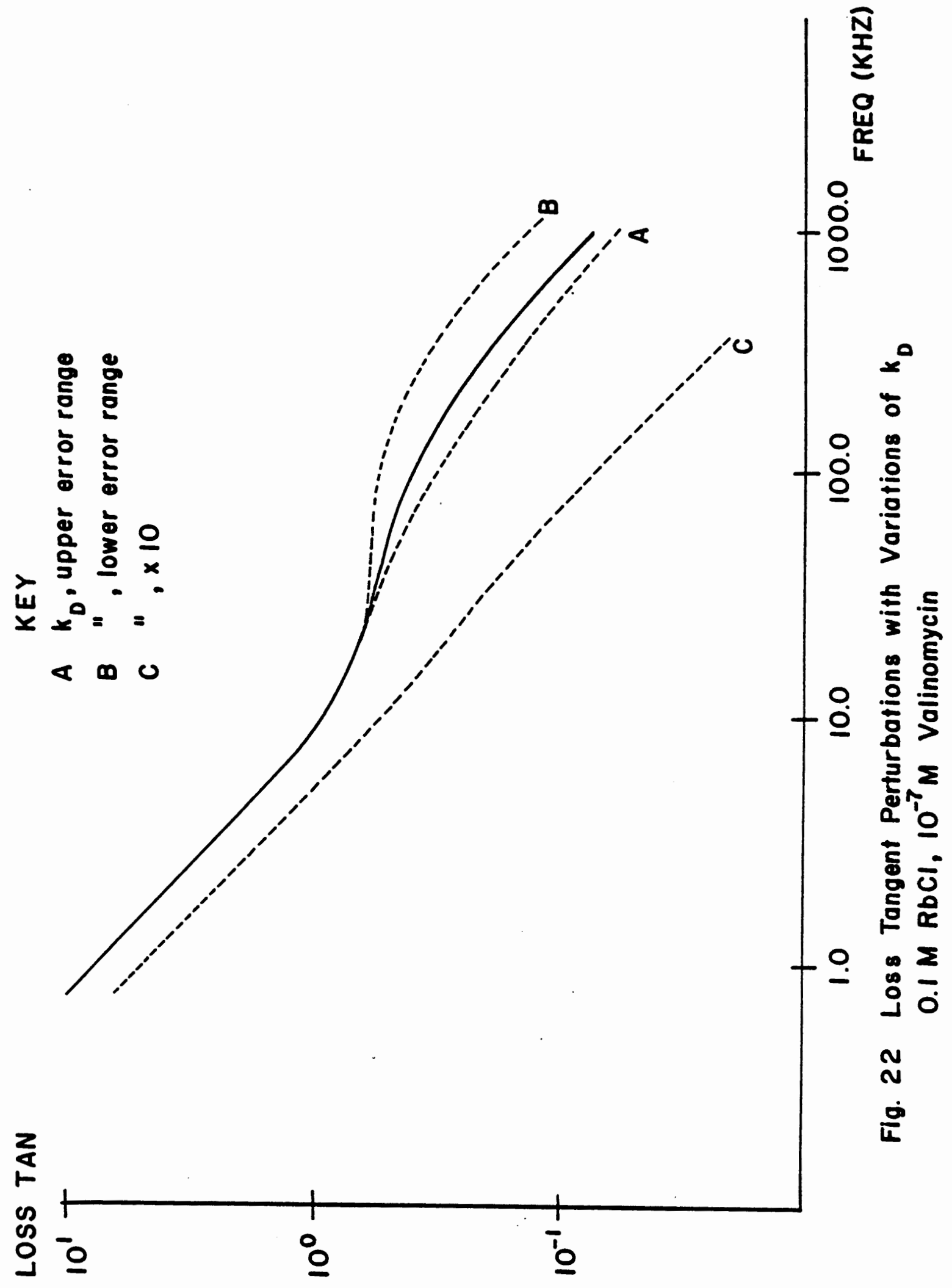




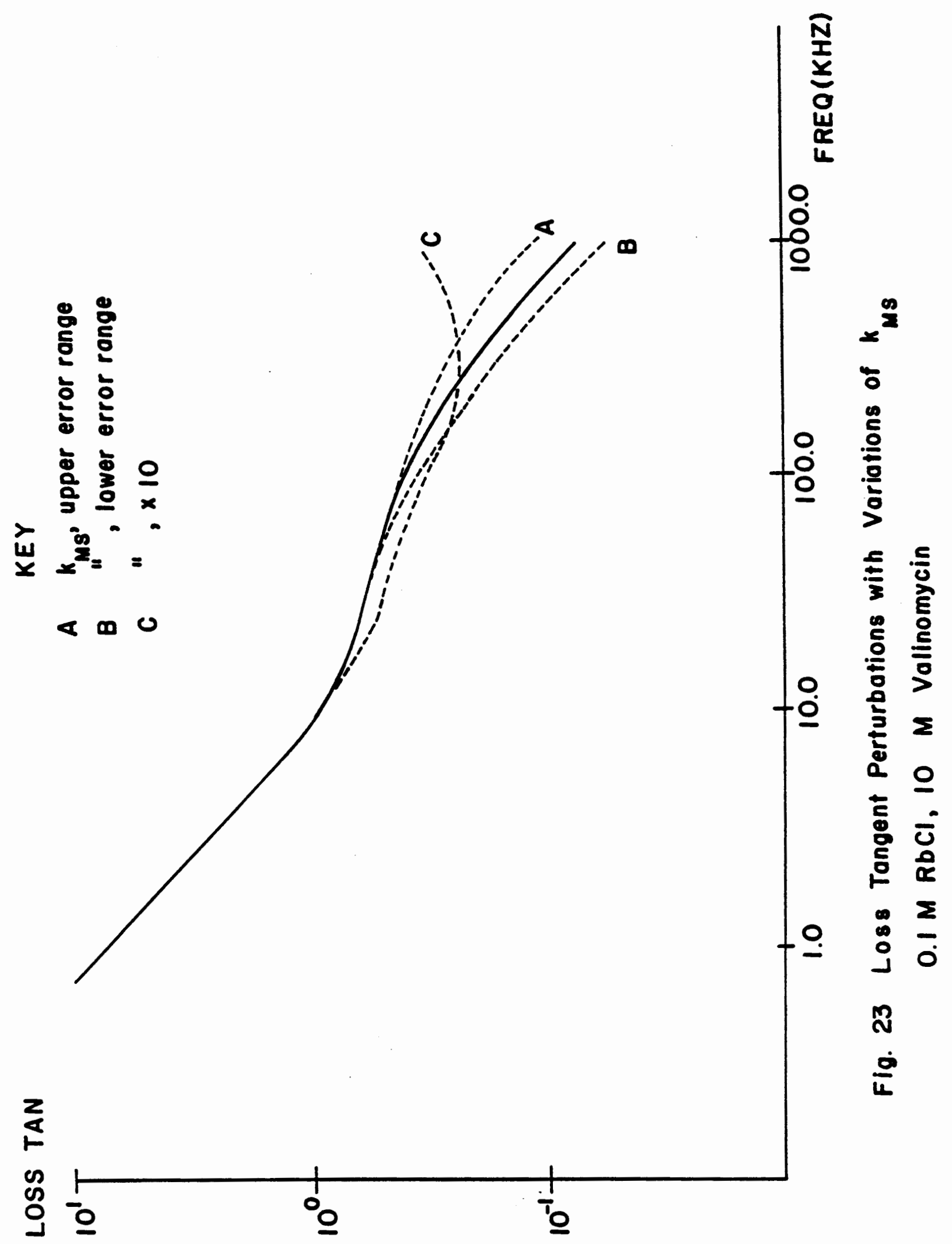




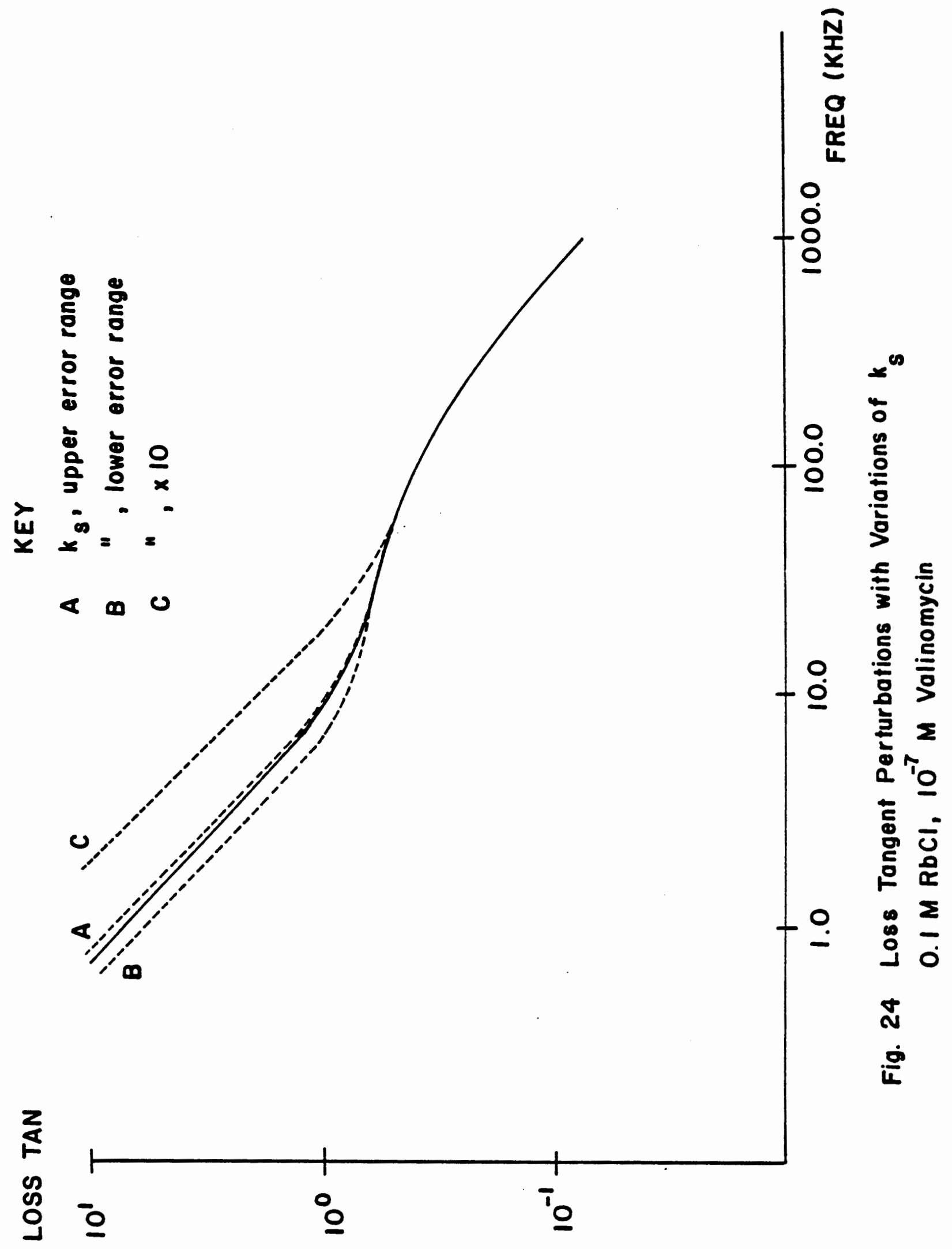


(consisting of the polar heads with part of the adjacent hydrocarbon and aqueous regions characterized by capacitance $C_{E}$ ) sandwiched about a single internal capacitance (capacitance $\mathrm{C}_{I}$, corresponding to the hydrophobic, non-polar lipid tail region as envisioned in Figure 25.

In this model the applied ac voltage would be capacitively divided across the three regions so that both the surface reactions and charge translocations are voltage driven. In a typical case, where approximately $8 \%$ of the applied ac voltage is assumed to drive the interfacial reactions, the data analysis yields relaxation parameters which differ from those obtained when the voltage is assumed to act only on the translocation process by the following percentages:

$$
\begin{aligned}
& \tau_{1}:-2 \% \quad \alpha_{1}:-6 \% \\
& \tau_{2}:+0.5 \% \quad \alpha_{2}:+40 \%
\end{aligned}
$$

The rate constants from [7] and values of $C_{E}$ and $C_{I}$ are similar to estimates made by Coster, et al. [15] and Pickar and Amos [49] in such a model (see Appendix B for details) to produce loss tangent curves. Figures 17-20 illustrate the relative insensitivity of the LT curves to the choice of a three capacitor model.

This model also predicts a slight $r$ ise in the capacitance values for applied frequencies less than $1 \mathrm{KHz}$, an effect which has been observed in our data and is not predicted by relaxation theory. 


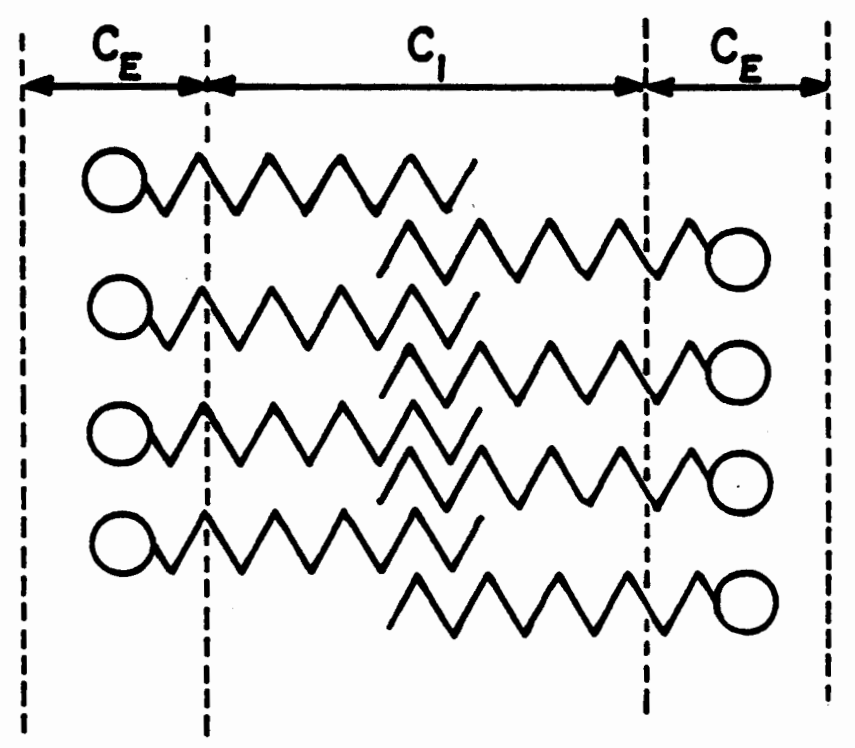

Fig. 25 Three Capacitor Model

$$
\begin{aligned}
& C_{E}=\text { External Capacitance } \\
& C_{1}=\text { Internal Capacitance }
\end{aligned}
$$


These preliminary investigations would seem to indicate that the parameters derived from the three capacitor model might not vary as markedly from the relaxation values as our values do. However, further experiments are necessary to confirm these findings . 


\section{CONCLUS IONS}

In this experiment we have measured the frequency dependence of the membrane admittance for a series of glycerylmonoolein / $n$-decane bilayers in various aqueous ionic solutions wich also contained the ion carrier valinomycin. The admittance data was then normalized and curve-fitted to produce relaxation times and amplitudes which in turn allowed the calculation of the kinetic rate parameters as deduced from a single slab dielectric membrane model. These ac experimental rate constants were then compared with those obtained from charge-pulse relaxation methods.

It is clear that in most cases these two sets of values do not agree. However, with the exception of the $0.01 \mathrm{M} \mathrm{Rb}^{+}$case, the discrepancies are not extreme. The largest range of variations appears in the relaxation amplitudes and times (Table 9) but seemingly these differences partially compensate to allow more even agreement of the kinetic parameters (Table 10). Although the absolute values vary, it should be noted that a similar trend is present in the values for both types of experiments, e.g. $k_{R}$ increases with decreasing ionic concentration.

A careful consideration of both random and systematic errors does bring the two sets of values closer together but cannot fully reconcile the differences. The discrepancies may also reflect the need for changes in the basic model, which was a major reason for performing the ac experiments in parallel with relaxation studies. 
In order to assess this possibility one must decide if the experimental ac data fits the original model. One way to check this possibility is by using the experimental parameters, which are obtained from a fit to conductance data, to reconstruct the capacitance. Table 4 illustrates the good agreement between the reconstructed and experimental capacitance values.

The model used to interpret the data contains a number of simplifications. For instance the association and dissociation reactions are assumed to be single step rather than multistep. Also, the translocation processes are not strictly monomolecular transitions over a single narrow barrier but rather are diffusive movements across relatively broad barriers. The membrane was considered to be of uniform thickness throughout the course of the experiment while in reality thermal fluctuations probably cause inhomogenous variations of the thickness with time. This, in turn, would lead to a spectrum of $k_{S}$, $k_{M S}$ and time constants rather than discrete values. Another simplification previously discussed is the single dielectric slab employed in this model versus the possible three capacitor model. It is possible that these simplifications to the model have a different influence on the calculated rate constants in the relaxation and ac techniques. However, this does not explain the larger discrepancies at $0.01 \mathrm{M} \mathrm{RB}^{+}$when compared to the variations at the other ionic concentrations. 
Definitive answers to these questions cannot be obtained from this research. A possible solution would be to perform both relaxation and ac studies on each individual membrane. Another improvement would be to extend the frequency range of the experiment. The waveforms at 100,200 and $300 \mathrm{KHz}$ are not as pure as those at lower frequencies. In addition future analysis will include careful correction of the data for control membrane conductance, which decreases the discrepancy between the ac and relaxation results. This correction has been applied to some of the data for $0.1 \mathrm{M} \mathrm{Rb}^{+}$since completion of this work, and the resultant agreement is highly encouraging [38]. Refinements to the experimental method (improved lighting, membrane area determination, membrane flattening, etc.) are also desirable. Indeed, some of these improvements have already been incorporated into the experimental procedures of other researchers in the membrane biophysics group. 


\section{REFERENCES}

1. Abrahamsson, S. and Pascher, Irmin [Eds.], 1976: Structure of Biological Membranes. Plenum Press, New York.

2. Ait'yan, S.K., Markin, V.S. and Chizmadzhev, Y.S., 1973: Theory of the passage of alternating current across artificial membranes in the carrier scheme. Biofizika 18:75.

3. Bamberg, E., Läuger, P. and Walz, D., 1969: Nonlinear electrical effects in lipid bilayer membranes; I. Ion injection. Biophys. J. 9:1150.

4. Benz, R., 1972: Kinetik des carrier transportes durch bimolekulare phospholipid membramen. Thesis, University of Konstanz, Konstanz, West Germany

5. Benz, R., Fröhlich, O., Läuger, P. and Montal, M., 1975: Electrical capacity of lipid bilayers made from monolayers. Biochim. Biophys. Acta. 394:323.

6. Benz, R., Janko, K., 1976: Voltage-induced capacitance relaxation of lipid bilayer membranes, effects of membrane composition. Biochim. Biophys. Acta. 455:721-738.

7. Benz, R. and Läuger, P., 1976: Kinetic analysis of carriermediated ion transport by the charge-pulse technique. J. Membrane Biol. 27:171-191.

8. Benz, R. and Stark, G., 1975: Kinetics of macrotetrolideinduced ion transport across lipid bilayer membranes. Biochim. Biophys. Acta. 382:27-40

9. Benz, R., Stark, G., Janko, K. and Läuger, P., 1973: Valinomycin-mediated ion transport through neutral lipid membranes: Influence of hydrocarbon chain length and temperature. J. Membrane Biol. 14:339-364.

10. Bevington, P.R., 1969: Data Reduction and Error Analys is for the Physical Sciences. McGraw-Hill, New York.

11. Brown, W.C. and Pickar, A.D., 1983: Capacitance of bilayers in the presence of lipophilic ions. Biophys. J. 41:354a.

12. Callen, H.B. and Green, R.F., 1952: On a theorem of irreversible thermodynamics. Phys. Rev. 86:702.

13. Chapman, D. [Ed.], 1968: Biological Membranes - Physical Fact and Function. Academic Press, London.

14. Ciani, S., Gambale, F., Gliozzi, A. and Rolandi, R., 1975: Effects of unstirred layers on the steady-state and zerocurrent conductance of bilayer membranes mediated by neutral carriers of ions. J. Membrane Biol. 24:1-34. 
15. Coster, H.G.L. and Smith, J.R., 1974: The molecular organisation of bimolecular 1 ipid membranes. A study of low frequency Maxwe 1 -Wagner impedance dispersion. Biochim. Biophys. Acta. 373:151-164.

16. Daniel, V.V., 1967: Dielectric Relaxation, Chapters 1,5,7. Academic Press, London.

17. Eigen, M. and DeMayer, L., 1963: Relaxation Methods, in Technique of Organic Chemistry, Vol VIII, part II, pp. $895-$ 1054. (A. Weissberger, ed.) Interscience, New York.

18. Eisenman, G. [Ed.], 1973: Membranes, (three volumes). M. Dekker, New York.

19. Fettiplace, R., Andrews, D.M. and Haydon, D.A., 1971: The thickness, composition and structure of some lipid bilayers and natural membranes. J. Membrane Biol. 5:277-296.

20. Frye, L. and Edidin, M., 1970: The rapid intermixing of cell surface antigens after formation of mouse-human heterokaryons. J. Cel1 Sci. 7:319.

21. Greenfield, S., Brostoff, S., Eylar, E.H. and More11, P., 1973: Protein composition of myelin of the peripheral nervous system. J. Neurochem. 20:1207.

22. Hinkle, P.C. and McCarty, R.E., 1978: How cells make ATP. Scientific American 238:104.

23. Hladky, S.B., 1975: Steady-state ion transport by nonactin and trinactin. Biochim. Biophys. Acta. 375:350.

24. Knoll, W. and Stark, G., 1977: Temperature-jump experiments on thin lipid membranes in the presence of valinomycin.

J. Membrane Biol. 37:13-28

25. Kolb, H.A. and Läuger, P., 1978: Spectral analysis of current noise generated by carrier-mediated ion transport. J. Membrane Biol. 41:167-187.

26. Laris, P.C., Bahr, D.P. and Chaffee, R.R.J., 1975: Membrane potentials in mitochondrial preparations. Biochim. Biophys. Acta. 376:415.

27. Läuger, P. and Stark, R., 1970: Kinetics of carrier-mediated ion transport across lipid bilayer membranes. Biochim. Biophys. Acta. 211:458.

28. Läuger, P., Benz, R., Stark, G., Bamberg, E., Jordan, P.C., Fahr, A. and Brock, W., 1981: Relaxation studies of ion transport systems in lipid bilayer membranes. Quarterly Rev. Biophys. 14, 4:513-598. 
29. Lehninger, A.L., 1975: Biochemistry, Chapter 11. Worth Publishers, New York.

30. McConne11, H.M., 1976: Spin Labeling, Chapter 13. (L.J. Berliner, Ed.) Academic, New York.

31. McKusick, V.A., Neufeld, E.F. and Kelly, T.E., 1982: The mucopolysaccharide storage diseases. In The Metabolic Basis of Inherited Disease. (Stanbrury, J.B., Wyngaarden, J.B., Fredrickson, D.S., Goldstein, J.L. and Brown, M.S., Eds.) McGraw-Hill, New York.

32. McLaughlin, S.G.A., Szabo, G., Eisenman, G. and Ciani, S., 1970: Surface charge and the conductance of phospholipid membranes. Proceedings of the National Academy of Science, U.S.A. $67: 1268$.

33. Mitche11, P. and Moyle, J., 1969: Estimation of membrane potential and $\mathrm{pH}$ difference across the cristae membrane of rat liver mi tochondria. European J. Biochem. 7:471-484.

34. Nyquist, H., 1928: Thermal agitation of electric charge in conductors. Phys. Rev. 32:110.

35. Nystrom, R.A., 1973: Properties of lipid films. In Membrane Physiology. Prentice-Hall.

36. Pickar, A.D. and Amos, W.D., 1976: Alternating current studies of charge carrier transport in lipid bilayers. Biochim. Biophys. Acta. 455:36-55

37. Pickar, A.D. and Hobbs, J., 1982: The influence of sterols on pentachlorophenol-induced charge transfer across lipid bilayers studied by alternating current methods. Biochim. Biophys. Acta. 693:221-236.

38. Pickar, A.D. and Cox, K.L., 1983: Alternating current studies of valinomycin-mediated ion transport across lipid bilayers. Biophys. J. 41:183a.

39. Pressman, B.C., 1968: Ionophorous antibiotics as models for biological transport. Fed. Proc. 27:1283.

40. Rothfield, L.I. [Ed.], 1971: Structure and Function of Biological Membranes. Academic, New York.

41. Rouser, G., Nelson, G.J., Fleischer, S. and Simon, G., 1968: In Biological Membranes, Chapter 2 (D. Chapman, Ed.) Academic, New York.

42. Shemyakin, M.M., Ovchimnikov, Yu. A., I vanov, V.T., Antonov, V.K., Vinogradova, E.I., Shkrob, A.M., Malenkov, G.G., Evstratov, A.V., Laine, I.A., Melnik, E.I. and Ryabova, I.D., 1969: Cyclodepsipeptides as chemical tools for studying ionic transport through membranes. J. Membrane Biol. 1:402. 
43. Singer, S.J. and Nicholson, G., 1972: The fluid mosaic model of the structure of cell membranes. Science 175:720.

44. Smejtek, P. and Paulis-Illangasekare, M., 1979: Modification of ion transport in 1 ipid bilayer membranes in the presence of 2,4-dichlorophenoxyacetic acid; I. Enhancement of cationic conductance and changes of the kinetics of nonactin-mediated transport of potassium. Biophys. J. 26:441-466.

45. Stark, G. and Benz, R., 1971: The transport of potassium through lipid bilayer membranes by the neutral carriers valinomycin and monactin. J. Membrane Biol. 5:133-153.

46. Stark, G., Benz, R., Pohl, G. and Janko, K., 1972: Valinomycin as a probe for the study of structural changes of black lipid membranes. Biochim. Biophys. Acta. 266:603

47. Stark, G., Ketterer, B., Benz, R. and Läuger, P., 1971: The rate constants of valinomycin-mediated ion transport through thin lipid membranes. Biophys. J. 11:981-994.

48. Szabo, G., Eisenman, G. and Ciani, S., 1969: The effects of macrotetralide actin antibiotics on the electrical properties of phospholipid.bilayer membranes. J. Membrane Biol. 1:346

49. Szabo, G., Eisenman, G., Laprade, R., Ciani, S. and Krasne, S., 1973: Experimentally observed effects of carriers on the electrical properties of bilayer membranes - Equilibrium Domain. In Membranes-A Series of Advances, Vol. II, PP. 179-328. (G. Eisenman, Ed.) M. Dekker, New York.

50. Szabo, G., Eisenman, G., Mclaughlin, S.G.A. and Krasne, S., 1972: Ionic probes of membrane structures. In Membrane Structure and its Biological Applications, Vol. 195, PP. 273-290. (D. Green, Ed.) New York ACademy of Sciences.

51. Weast, R.C., 1970: Handbook of Chemistry and Physics, E-67, F-152. CRC, Cleve Iand. 
Appendix A - Computer Printout Samples

REDU1

DATE 07/18/80 MEM\# 03 RUN\# 06

BRIDGE READINGS

$F(\mathrm{KHZ}) \quad \mathrm{C}(\mathrm{NF}) \quad G(\mathrm{UMHOS})$

$\begin{array}{rrrr}1 & 0.131 & \text { OVERRANGE } & \\ 2 & 0.208 & \begin{array}{l}\text { OVERRANGE } \\ \text { OVERRANGE }\end{array} \\ 3 & 0.311 & \text { OVERRANGE } & \\ 4 & 0.515 & 9.267 & 63.500 \\ 5 & 0.715 & 9.400 & 67.300 \\ 6 & 1.006 & 9.360 & 69.200 \\ 7 & 2.011 & 9.340 & 73.000 \\ 8 & 3.166 & 9.300 & 82.000 \\ 9 & 5.071 & 9.250 & 96.000 \\ 10 & 7.124 & 9.140 & 129.900 \\ 11 & 10.728 & 8.960 & 197.000 \\ 12 & 15.975 & 8.770 & 280.000 \\ 13 & 21.080 & 8.020 & 470.000 \\ 14 & 30.552 & 720.000 \\ 15 & 40.782 & 8.040 & 1010.000 \\ 16 & 51.071 & 7.660 & 1610.000 \\ 17 & 70.379 & 6.940 & 2630.000 \\ 18 & 101.297 & 5.830 & 5390.000 \\ 19 & 204.193 & 3.079 & 6530.000 \\ 20 & 295.308 & 1.869 & 4603.000 \\ 21 & 204.179 & 1.853 & 4130 \\ 22 & 295.234 & 1.038 & 5135.000 \\ 23 & 495.612 & 0.407 & 5710.000 \\ 24 & 693.528 & 0.214 & 5850.000 \\ 25 & 883.793 & 0.135 & 5880.000\end{array}$

CELI RESISTANCE COMPUTATIONS(OHMS)

FR.PTS. 25,24.23: $168.8 \quad 168.1$ AV.168.4 AV. $-51.1=117.3$ FR.PTS. 24.23,22: $167.0 \quad 166.5$ AV.166.8 AV. $-51.1=115.7$ FR.PTS. 23,22,21: $165.6 \quad 166.5$ AV.166.1 AV. $-51.1=115.0$

MEMBRANE PARAMETERS

CELI RESISTANCE $=115.7$ 
REDU1 - Continued

$\begin{array}{cccccl}\text { FREQ } & \text { COND } & \text { CAP } & \text { LT } & \text { D-IT } & \text { RS } \\ \text { KHZ } & \text { MIC-SIEN } & \text { NF } & & & \text { OHMS }\end{array}$

0.71

1.01

2.01

3.17

5.07

7.12

10.73

15.98

21.08

30.55

40.78

51.07

70.38

101.30

204.19

295.31

204.18

295.23

495.61

693.53

883.79
63.77

67.41

68.11

69.54

72.38

76.68

86.30

102.74

120.84

154.11

190.27

227.18

285.40

366.07

687.61

1034.03

5145.36

7820.96

13049.53

15729.77

16883.61

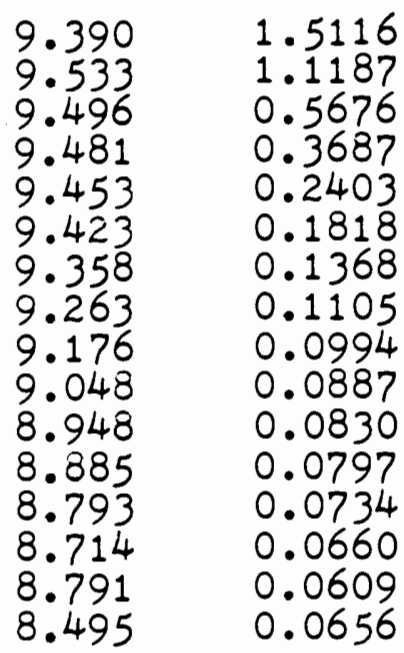

6.276

4.804

2.907

1.745

1.118
0.0008

0.0006

0.0004

0.0004

0.0004

0.0005

0.0007

0.0010

0.0013

0.0018

0.0023

0.0029

0.0039

0.0056

0.0113

0.0158

0.0113

0.0158

0.0279

0.0401

0.0521
**\#***

8245.5

3578.1

1721.0

754.2

417.3

212.9

117.4

81.0

50.7

35.9

27.8

18.8

11.8

5.4

4.1

56.4

55.6

51.7

51.5

52.2

REDU2

DATE 07/18/80 MEM\# 03 RUN\# 06

CELI RESIST. COMPUT.(OHMS) HOBBS VERSION

FR.PTS. 25.24.23:

$168.9 \quad 167.0 \quad \mathrm{AV}=167.9 \quad \mathrm{AV} .-51.1=116.8$

FR.FTS. $24,23,22$ :

$167.0165 .5 \mathrm{AV}=166.2 \mathrm{AV} .-51.1=115.1$

FR.PTS. 23,22,21:

$165.5 \quad 170.6 \quad \mathrm{AV}=168.0 \quad \mathrm{AV} .-51.1=116.9$

CELI RESISTANCE $=115.1$

MEASURED MEMB AREA $=0.181 \mathrm{E}-01 \mathrm{~S} 2 \mathrm{CM}$

HF CAPAC(ASSUME GMO/DEC NIENBB) 0.7835E-08

LOW FREQ MEMB PARAMS (AV.): KHZ(MAX), SIEMENS, FARADS $2.01 \quad 0.6643 E-04$

$0.94724 \mathrm{E}-08$ 
REDU2 - Continued

DATA FOR CURVE FIT: 16 DATA PTS

FREQ

0.715
1.006
2.011
3.166
5.071
7.124

10.728

15.975

21.080

30.552

40.782

51.071

70.179

101.297

204.193

295.308
NORM COND

1.000

1.015

1.025

1.047

1.090

1.156

1.303

1.554

1.832

2.347

2.911

3.493

4.432

5.787

11.487

17.796
NORM CAP

0.949

1.000

1.000

1.000

0.988

0.969

0.929

0.872

0.818

0.740

0.678

0.640

0.583

0.534

0.579

0.396

\section{TOTAL}

INPUT FARAMETERS :

ALFHA $-1=0.7000$

AIPHA - $2=0.2000$

TAU-1 $=0.5000 \mathrm{E}-06 \mathrm{SEC}$

TAU-2 $=0.5000 E-05$ SEC

SUM OF SQUARES $=185.0$

OUTPUT FARAMETERS:

AIPHA $-1=0.9339$

AIPHA $-2=0.5016 \mathrm{E}-01$

TAU-1 $=0.2971 \mathrm{E}-06 \mathrm{SEC}$

TAU $-2=0.4045 \mathrm{E}-05$ SEC

SUM OF SQUARES $=0.1872 \mathrm{E}-01$ 
$\underline{P D A 1}$

INPUT DATA: RELAX, TIMES (MICROSEC. )RELAX. AMELITUDES

TAU1 $=0.2971 \quad$ ALPHA $1=0.9339$

TAU2 $=4.045 \quad$ ALPHA $2=0.0501$

IF $G(S I E M)=0.664 \mathrm{E}-04 \quad$ LF $C($ FARAD $)=0.947 \pm-08$

ASSUNIING DMO/DEC NENE.: HF C $(F A R A D)=0.784 \bar{E}-08$

MEASURED AREA $(S Q . C M)=0.1812-01$

VAIINOMYCIN (CONC. ) $=0.100 E-06$ MOIES/IITER

METAL ION(CONC. ) $=0.100$ MOLES/LITER

$\begin{array}{rccc}F(\text { KHZ }) & \text { ITE } & \text { CAP }(N F) & \text { COND (UMHOS) } \\ 0.300 & 0.372 E+01 & 0.947 \mathrm{E}+01 & 0.664 \mathrm{E}+02 \\ 3.000 & 0.380 \mathrm{E}+00 & 0.947 \mathrm{E}+01 & 0.678 \mathrm{E}+02 \\ 30.000 & 0.892 \mathrm{E}-01 & 0.922 \mathrm{E}+01 & 0.155 \mathrm{E}+03 \\ 100.000 & 0.679 \mathrm{E}-01 & 0.884 \mathrm{E}+01 & 0.377 \mathrm{E}+03 \\ 200.000 & 0.678 \mathrm{E}-01 & 0.869 \mathrm{E}+01 & 0.741 \mathrm{E}+03 \\ 300.000 & 0.741 \mathrm{E}-01 & 0.857 \mathrm{E}+01 & 0.120 \mathrm{E}+04\end{array}$

OUTFUT PARAMETERS

$\mathrm{NMS}=0.349 \mathrm{E}-13 \mathrm{MOLES} / \mathrm{SQ} . \mathrm{CM}$

$G S=0.151 E+04$

$\mathrm{KR}=0.192 \mathrm{E}+07$ IITER/MOLES -SEC

$\mathrm{KD}=0.198 \mathrm{E}+061 / \mathrm{SEC}$

$\mathrm{KMS}=0.158 \mathrm{E}+071 / \mathrm{SEC}$

$\mathrm{KS}=0.36 \mathrm{E}+051 / \mathrm{SEC}$

AREA CORRECTED FOR BULGING $(S Q . C M)=0.201 E-01$ FARAD 
ADP1

RELAXATION TIMES(MICROSEC.): GREQUENCY IIMITS(KHZ)

\begin{tabular}{|c|c|c|c|}
\hline$A U 1=0.861$ & TAU2 $=5.047$ & FRE1 $=$ & 61.871 \\
\hline$F(K H Z)$ & ITE & $\operatorname{CAP}(N F)$ & CON (UMHOS) \\
\hline $\begin{array}{r}0.100 \\
0.200 \\
0.300 \\
0.500 \\
0.700 \\
1.000 \\
2.000 \\
3.000 \\
5.000 \\
7.000 \\
10.000 \\
20.000 \\
30.000 \\
50.000 \\
70.000 \\
100.000 \\
200.000 \\
300.000 \\
500.000 \\
700.000 \\
1000.000\end{array}$ & $\begin{array}{l}0.468 \mathrm{E}+02 \\
0.234 \mathrm{E}+02 \\
0.156 \mathrm{E}+02 \\
0.936 \mathrm{E}+01 \\
0.669 \mathrm{E}+01 \\
0.469 \mathrm{E}+01 \\
0.236 \mathrm{E}+01 \\
0.159 \mathrm{E}+01 \\
0.992 \mathrm{E}+00 \\
0.746 \mathrm{E}+00 \\
0.575 \mathrm{E}+00 \\
0.416 \mathrm{E}+00 \\
0.375 \mathrm{E}+00 \\
0.324 \mathrm{E}+00 \\
0.284 \mathrm{E}+00 \\
0.244 \mathrm{E}+00 \\
0.177 \mathrm{E}+00 \\
0.140 \mathrm{E}+00 \\
0.949 \mathrm{E}+01 \\
0.707 \mathrm{E}-01 \\
0.507 \mathrm{E}-01\end{array}$ & $\begin{array}{l}0.64 \mathrm{E}+03 \\
0.64 \mathrm{E}+03 \\
0.64 \mathrm{E}+03 \\
0.64 \mathrm{E}+03 \\
0.64 \mathrm{E}+03 \\
0.64 \mathrm{E}+03 \\
0.64 \mathrm{E}+03 \\
0.64 \mathrm{E}+03 \\
0.64 \mathrm{E}+03 \\
0.63 \mathrm{E}+03 \\
0.63 \mathrm{E}+03 \\
0.59 \mathrm{E}+03 \\
0.55 \mathrm{E}+03 \\
0.50 \mathrm{E}+03 \\
0.48 \mathrm{E}+03 \\
0.45 \mathrm{E}+03 \\
0.42 \mathrm{E}+03 \\
0.41 \mathrm{E}+03 \\
0.40 \mathrm{E}+03 \\
0.39 \mathrm{E}+03 \\
0.39 \mathrm{E}+03\end{array}$ & $\begin{array}{l}0.19 \mathrm{E}+05 \\
0.19 \mathrm{E}+05 \\
0.19 \mathrm{E}+05 \\
0.19 \mathrm{E}+05 \\
0.19 \mathrm{E}+05 \\
0.19 \mathrm{E}+05 \\
0.19 \mathrm{E}+05 \\
0.19 \mathrm{E}+05 \\
0.20 \mathrm{E}+05 \\
0.21 \mathrm{E}+05 \\
0.23 \mathrm{E}+05 \\
0.31 \mathrm{E}+05 \\
0.39 \mathrm{E}+05 \\
0.51 \mathrm{E}+05 \\
0.59 \mathrm{E}+05 \\
0.70 \mathrm{E}+05 \\
0.94 \mathrm{E}+05 \\
0.11 \mathrm{E}+06 \\
0.12 \mathrm{E}+06 \\
0.12 \mathrm{E}+06 \\
0.12 \mathrm{E}+06\end{array}$ \\
\hline
\end{tabular}

KINETIC FARAMETERS:

$G S=0.810 \Sigma+04$

$K R=0.190 E+07$ IITER/MOLES -SEC

$K D=0.380 E+061 / S E C$

KMS $=0.350 E+061 / \mathrm{SEC}$

$\mathrm{KS}=0.450 \mathrm{E}+051 / \mathrm{SEC}$

THICKNESS $=47.60$ ANGSTROMS

$A R E A=0.181 E-01 \quad C M-S Q U A R E S$

VALINOMYCIN (CONC .) $=0.100 E-06$ MOLES/IITER

RBCL (CONC. ) $=0.100$ MOLES / IITER

$\mathrm{CI}=7.06 \mathrm{NF}$ 
THREE CAPACITOR MODEL

Alternating current properties of the three-capacitor model (Figure 25) can be calculated using a formalism similar in some respects to that used by Ait'yan et al. [2] in their general analysis of monomeric carrier schemes. This approach to numerical modelling of a.c. electrical behavior has also been applied to dimeric carrier transport systems by Pickar and Hobbs [37].

The voltage $\phi$ impressed across the membrane is assumed to divide across three membrane regions according to

$$
\phi=\phi_{1}+\phi_{2}+\phi_{3} \quad \text { Eq. - B } 1
$$

where $\phi_{1}$ is the component of the voltage across the surface layer bounded by the bulk aqueous solution and the adsorptionreaction plane on the left-hand side of the membrane (specific capacitance $C_{E}$ ), $\phi_{2}$ is the component across the region interior to the two adsorption-reaction planes (capacitance $c_{I}$ ), and $\phi_{3}$ is the component across the right-hand surface region (capacitance $C_{E}$ ). These component voltages are given by

$$
\begin{array}{lll}
\phi_{1}=\frac{1}{C^{\prime}}\left\{C_{I} \phi-F\left(1+\frac{C_{I}}{C_{E}}\right) \Delta N_{M S}^{\prime}-F \frac{C_{I}}{C_{E}} \Delta N_{M S}^{\prime \prime}\right\} & E q-B 2 \\
\phi_{2}=\frac{1}{C^{\top}}\left\{C_{E} \phi+F \Delta N_{M S}^{\prime}-F \Delta N_{M S}^{\prime \prime}\right\} & \text { Eq-B3 } \\
\phi_{3}=\frac{1}{C^{\prime}}\left\{C_{I} \phi+F \frac{C_{I}}{C_{E}} \Delta N_{M S}^{\prime}+F\left(1+\frac{C_{I}}{C_{E}}\right) \Delta N_{M S}^{\prime \prime}\right\} & E q-B 4
\end{array}
$$

where $F$ is the Faraday constant, the parameter $C^{\prime}=C_{E}+2 C_{I}$, and $\Delta N_{M S}^{\prime}$ and $\Delta N_{M S}^{\prime \prime}$ are the surface concentrations in excess of 
the equilibrium value of the loaded carrier in the leftand right-hand adsorption-reaction planes respectively.

The surface concentrations of free and loaded carriers vary in time according to the following differential equations (Eqs-B5,B6,B7,B8) in which the voltage dependence of the rate constants are given in explicit form:

$\frac{d N_{S}^{\prime}}{d t}=k_{S}\left(-N_{S}^{\prime}+N_{S}^{\prime \prime}\right)-k_{R} C_{M} N^{\prime}{ }_{S} \exp \left(\frac{F \phi_{1}}{2 R T}\right)+k_{D} N_{M S}^{\prime} \exp \left(-\frac{F \phi_{1}}{2 R T}\right)$

$\frac{d N_{S}^{\prime \prime}}{d t}=k_{S}\left(N_{S}^{\prime}-N_{S}^{\prime \prime}\right)-k_{R} C_{M} N_{S}^{\prime \prime} \exp \left(-\frac{F \phi_{3}}{2 R T}\right)+k_{D} N_{M S}^{\prime \prime} \exp \left(\frac{F \phi_{3}}{2 R T}\right)$

$\frac{d N_{M S}^{\prime}}{d t}=k_{R} C_{M} N_{S}^{\prime}\left(\frac{F \phi_{1}}{2 R T}\right)-k_{D} N_{M S}^{\prime} \exp \left(-\frac{F \phi_{1}}{2 R T}\right)$

$$
+k_{M S}\left[-N_{M S}^{\prime} \exp \left(\frac{F \phi_{2}}{2 R T}\right)+N_{M S}^{\prime \prime} \exp \left(-\frac{F \phi_{2}}{2 R T}\right)\right]
$$

$$
\begin{aligned}
\frac{d N_{M S}^{\prime \prime}}{d t}=k_{R} C_{M} N^{\prime \prime}{ }_{S} \exp \left(-\frac{F \phi_{3}}{2 R T}\right) & -k_{D} N_{M S}^{\prime \prime} \exp \left(\frac{F \phi_{3}}{2 R T}\right) \\
& +k_{M S}\left[N_{M S}^{\prime} \exp \left(\frac{F \phi_{2}}{2 R T}\right)-N_{M S}^{\prime \prime} \exp \left(-\frac{F \phi_{2}}{2 R T}\right)\right]
\end{aligned}
$$

In the above expressions the primes and double-primes refer to the left and right surfaces, respectively, and the surface concentrations of permeable species are the total concentrations, i.e., $N_{S}^{\prime}=N_{S}+\Delta N_{S}^{\prime}$ etc. The interchange between the bulk aqueous solution and the membrane surface of the neutral or loaded carrier (S or $\mathrm{MS}^{+}$) has been neglected. In the absence of an applied voltage these equations yield the equilibrium expression (previously Eq-21)

$$
-k_{R} C_{M} N_{S}+k_{D} N_{M S}=0 .
$$


If a small voltage which is harmonic in form

$$
\phi=\phi_{0} \exp (j \omega t) \quad E q-B 10
$$

is applied, the perturbations from equilibrium of the surface concentrations will, in the steady state, vary sinusoidally in time with an angular frequency w. We may then everywhere replace $\Delta N_{S}^{\prime}$ by $\Delta N_{S}^{\prime} \exp (j \omega t), \Delta N_{M S}^{\prime}$ by $\Delta N_{M S}^{\prime} \exp (j \omega t)$ etc., where the amplitudes $\Delta N_{S}^{\prime}, \Delta N_{M S}^{\prime}$, etc. are now regarded as time-independent complex quantities. We restrict our consideration of the problem to the case of small voltage amplitudes. We can then use the approximations

$$
\begin{aligned}
& \exp \left(\frac{ \pm F \phi_{1}}{2 R T}\right)=1 \pm \frac{F \phi_{1}}{2 R T} \\
& \exp \left(\frac{ \pm F \phi_{2}}{2 R T}\right)=1 \pm \frac{F \phi_{2}}{2 R T} \\
& \exp \left(\frac{ \pm F \phi_{3}}{2 R T}\right)=1 \pm \frac{F \phi_{3}}{2 R T}
\end{aligned}
$$

Furthermore, in the limit of very small voltages, after substituting Eqs-B2,B3,B4,B8, and B11 into Eqs-B5 through B8 we can neglect higher order terms such as those involving $\left(\Delta N_{S}^{\prime}\right)^{2},\left(\Delta N_{S}^{\prime}\right)\left(\Delta N_{M S}^{\prime}\right),\left(\Delta N_{S}^{\prime}\right) \phi_{0}$ etc. Time-independent terms are eliminated by virtue of the equilibrium expression Eq-B9.

The resulting set of four inhomogeneous linear equations in $\Delta N_{S}^{\prime}, \Delta N_{S}^{\prime \prime}, \Delta N_{M S}^{\prime}$, and $\Delta N_{M S}^{\prime \prime}$ can be solved to permit computation of the membrane admittance

$$
Y_{M} \equiv G_{M}+j \omega C_{M}=I / \phi
$$

where the membrane current $I$ is given by 


$$
I=F^{2} N_{M S} k_{M S}\left(\frac{\phi_{2}}{R T}\right)+F k_{M S}\left(\Delta N_{M S}^{\prime}-\Delta N_{M S}^{\prime \prime}\right) \exp (j \omega t)+j \omega C_{I} \phi_{2} E q-B 13
$$

We have made no attempt to write out the final expressions for membrane admittance in closed form; instead, we have used the above results to obtain numerical values of membrane conductance $G_{M}$ and capacitance $C_{M}$ as a function of frequency assuming various model parameters. 